\title{
UAB
}

Universitat Autònoma de Barcelona

\section{Mechanisms involved in the remyelinating effect of sildenafil}

\author{
Daniela Del Valle Diaz Lucena
}

ADVERTIMENT. L'accés als continguts d'aquesta tesi doctoral i la seva utilització ha de respectar els drets de la persona autora. Pot ser utilitzada per a consulta o estudi personal, així com en activitats o materials d'investigació i docència en els termes establerts a l'art. 32 del Text Refós de la Llei de Propietat Intel·lectual (RDL 1/1996). Per altres utilitzacions es requereix l'autorització prèvia i expressa de la persona autora. En qualsevol cas, en la utilització dels seus continguts caldrà indicar de forma clara el nom i cognoms de la persona autora i el títol de la tesi doctoral. No s'autoritza la seva reproducció o altres formes d'explotació efectuades amb finalitats de lucre ni la seva comunicació pública des d'un Iloc aliè al servei TDX. Tampoc s'autoritza la presentació del seu contingut en una finestra o marc aliè a TDX (framing). Aquesta reserva de drets afecta tant als continguts de la tesi com als seus resums i índexs.

ADVERTENCIA. El acceso a los contenidos de esta tesis doctoral y su utilización debe respetar los derechos de la persona autora. Puede ser utilizada para consulta o estudio personal, así como en actividades o materiales de investigación y docencia en los términos establecidos en el art. 32 del Texto Refundido de la Ley de Propiedad Intelectual (RDL 1/1996). Para otros usos se requiere la autorización previa y expresa de la persona autora. En cualquier caso, en la utilización de sus contenidos se deberá indicar de forma clara el nombre y apellidos de la persona autora y el título de la tesis doctoral. No se autoriza su reproducción u otras formas de explotación efectuadas con fines lucrativos ni su comunicación pública desde un sitio ajeno al servicio TDR. Tampoco se autoriza la presentación de su contenido en una ventana o marco ajeno a TDR (framing). Esta reserva de derechos afecta tanto al contenido de la tesis como a sus resúmenes e índices.

WARNING. The access to the contents of this doctoral thesis and its use must respect the rights of the author. It can be used for reference or private study, as well as research and learning activities or materials in the terms established by the 32nd article of the Spanish Consolidated Copyright Act (RDL 1/1996). Express and previous authorization of the author is required for any other uses. In any case, when using its content, full name of the author and title of the thesis must be clearly indicated. Reproduction or other forms of for profit use or public communication from outside TDX service is not allowed. Presentation of its content in a window or frame external to TDX (framing) is not authorized either. These rights affect both the content of the thesis and its abstracts and indexes. 


\section{UAB}

Universitat Autònoma

de Barcelona

\section{Mechanisms involved in the remyelinating effect of sildenafil.}

\section{Daniela Del Valle Diaz Lucena}

Doctoral program in Biochemistry, Molecular Biology and Biomedicine.

Department of Biochemistry and Molecular Biology of UAB .

Institute of Biotechnology and Biomedicine V. Villar Palasí. 



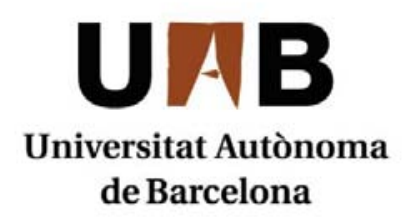

\title{
Mechanisms involved in the remyelinating effect of sildenafil.
}

\section{Daniela Del Valle Diaz Lucena}

\author{
Doctoral program in Biochemistry, Molecular Biology and Biomedicine. \\ Department of Biochemistry and Molecular Biology. \\ Institute of Biotechnology and Biomedicine V. Villar Palasí.
}

\section{Directors:}

Agustina García Sánchez, Ph.D.

Institute of Institute of Biotechnology and Biomedicine, Universitat Autònoma de Barcelona (UAB). Department of Biochemistry and Molecular Biology, UAB.

Paula Pifarré, Ph.D.

Center for Genomic Regulation (CRG), Parc de Recerca Biomédica de Barcelona.

Daniela Del Valle Diaz Lucena

Agustina García Sánchez, Ph.D.

Paula Pifarré, Ph.D. 

Dedicada mi familia

Mis padres, mi hermana y mi tia 

Aquesta tesi va ser desenvolupada amb el suport de la Secretaria d'Universitats i Recerca del Departament d'Economia i Coneixement de la Generalitat de Catalunya i del Fons Social Europeu

This thesis has been developed with the support of the Secretary of Universities and Research of the Ministry of Economy and Knowledge of the Generalitat of Catalonia and the European Social Fund

Esta tesis fue desarrollada con el apoyo de la Secretaría de Universidades e Investigación del Departamento de Economía y Conocimiento de la Generalidad de Cataluña y del Fondo Social Europeo 



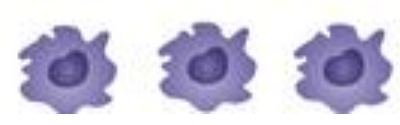

CONTENTS 
$\dddot{0}^{\circ}$ 


\section{CONTENTS}

ABSTRACT

ABREVIATIONS ___ _ _ _ _ _ _ 9

INTRODUCTION

1. Multiple Sclerosis __ 15

2. Experimental Autoimmune Encephalomyelitis___ 15

3. Neuroinflammation__ 17

3.1. Immunity in the Central Nervous System 17

4. Cyclic GMP 23

5. The NO-cGMP pathway_ 23

5.1. Nitric oxide synthases___ 24

5.2. Guanylyl cyclises___ 25

5.3. cGMP Targets___ 27

5.4. cGMP inactivation __ 29

5.5. cGMP and remyelination___ 30

AIMS 33

MATERIALS AND METHODS

RESULTS 55

DISCUSSION 79

CONCLUSIONS 99

REFERENCES 103 
4 
성 상 숭

ABSTRACT 


\section{ABSTRACT}

Multiple Sclerosis (MS) is a chronic autoimmune demyelinating disease of the central nervous system characterized by a coordinated inflammatory attack on the myelin sheaths with ensuing damage to the underlying axons. Using myelin oligodendrocyte glycoprotein (MOG)-induced chronic experimental autoimmune encephalomyelitis (EAE) as a MS model, it has been previously demonstrated that daily administration of the PDE-5 inhibitor sildenafil starting at peak disease rapidly ameliorates clinical symptoms whereas administration at the onset of symptoms prevents disease progression. These beneficial effects involved down-regulation of adaptive and innate immune responses and protection of axons and oligodendrocytes and promotion of remyelination. The aim of this work was confirm the remyelinating potential of sildenafil treatment and investigate mechanisms involved in this effect in CNS cells. Results show that sildenafil induces remyelination in EAE mice even when the administration of the drug starts during the chronic stage of the disease. Sildenafil also stimulates remyelination in cerebellar organotypic cultures demyelinated with lysophosphatidylcholine and this effect is prevented by inhibitors of nitric oxide-dependent guanylyl cyclase (NO-GC), NO synthase type 2 (NOS-2) and cGMPdependent protein kinase (PKG), indicating the involvement of the endogenous NO-cGMPPKG pathway. Maturation of oligodendrocytes as a potential mechanism implicated in the remyelinating effect of sildenafil was investigated by immunostaining for transcription factors involved in different stages of oligodendrocyte development. Results in the EAE model show that sildenafil treatment increases oligodendrocyte precursor cells (OPCS; $\mathrm{Nkx2.2+}$ cells) and promotes the final stage of oligodendrocyte maturation (olig2 $/ \mathrm{MBP}^{+}$ cells). These later result was confirmed in LPC-demyelinated cerebellar slices treated with cGMP increasing compounds. This work also shows that expression of the neurotrophic factor CNTF, that has been implicated in oligodendrocyte maturation, is increased in astroytes of sildenafil-treated EAE mice spinal cord, as well as in cerebellar slice cultures. Results also show that CGMP-increasing treatments alter expression of inflammatory phenotype markers (COX-2 and Arg-1) in microglia in demyelinated slice cultures. The potential of cGMP-increasing treatments for regulating the inflammatory phenotype of monocytes was confirmed in bone marrow derived macrophages (BMDM). In these cells sildenafil treatment induces arginase activity and potentiates the effect of IL-4 suggesting the promotion of an M2 phenotype. Analysis by flow cytometry of BMDM confirmed that cGMP augments the number of cells expressing an M2 phenotype marker (CD206). This work further demonstrates that sildenafil significantly increases the myelin phagocytic capacity of microglia/macrophages in EAE mice and in BMDM. Taken together these data suggest that promotion of oligodendrocyte maturation, growth factor expression, modulation of the inflammatory process and clearance of myelin debris may be relevant mechanisms involved in sildenafil enhancement of remyelination in demyelinated tissue. 
a do 상

ABREVIATIONS 


\section{ABREVIATIONS}

\begin{tabular}{|c|c|}
\hline Abreviation & Name \\
\hline 8BrcGMP & $\begin{array}{l}\text { 8-Bromoguanosine } 3^{\prime}, 5^{\prime}- \\
\text { cyclic monophosphate } \\
\text { sodium salt }\end{array}$ \\
\hline 8pCPTcGMP & $\begin{array}{l}\text { 8-(4-Chlorophenylthio)- } \\
\text { guanosine } \quad 3,5 \text {-cyclic } \\
\text { monophosphate } \\
\text { salt }\end{array}$ \\
\hline ANP & Atrial natriuretic peptide \\
\hline BAY41 & BAY 41-2272 \\
\hline BBB & Blood brain barrier \\
\hline BDNF & $\begin{array}{l}\text { Brain derived neurotrophic } \\
\text { factor }\end{array}$ \\
\hline bFGF & $\begin{array}{ll}\text { Basic fibroblast growth } \\
\text { factor }\end{array}$ \\
\hline BME & $\begin{array}{l}\text { Basal medium containing } \\
\text { Earle's salt }\end{array}$ \\
\hline BNP & Brain natriuretic peptide \\
\hline BSA & Neonatal Goat serum \\
\hline cGMP & $\begin{array}{ll}\text { Cyclic } & \text { Guanosine } \\
\text { Monophospate } & \\
\end{array}$ \\
\hline CNP & C-type natriuretic peptide \\
\hline CNPase & $\begin{array}{l}\text { Cyclic Nucleotide } \\
\text { Phosphodiesterase }\end{array}$ \\
\hline CNS & Central nervous system \\
\hline CNTF & Ciliary neurotrophic factor \\
\hline CPB & $\begin{array}{l}\text { Cytometry permeabilization } \\
\text { buffer }\end{array}$ \\
\hline dbcGMP & dibutyryl-cGMP \\
\hline Dil & $\begin{array}{l}\text { 1,1"-diotadecyl-3,3,3',3'- } \\
\text { tetramethyl- } \\
\text { lindocarbocyanide } \\
\text { perchlorate }\end{array}$ \\
\hline DMEM & $\begin{array}{l}\text { Dubelco's Modified Eagle } \\
\text { medium GlutaMax }\end{array}$ \\
\hline
\end{tabular}

\begin{tabular}{|c|c|}
\hline Abreviation & Name \\
\hline EAE & $\begin{array}{l}\text { Experimental Autoimmune } \\
\text { Encephalomyelitis }\end{array}$ \\
\hline EDTA & TRIS buffer solution \\
\hline FBS & Fetal Bovine Serum \\
\hline GC & Guanylyl cyclase enzymes \\
\hline GFAP & Glial fibrillary acidic protein \\
\hline Glucose & Glucose \\
\hline HBSS & Hank's buffered salt solution \\
\hline HS & $\begin{array}{l}\text { Heat Inactivated horse } \\
\text { serum }\end{array}$ \\
\hline Iba-1 & $\begin{array}{l}\text { ionized calcium-binding } \\
\text { adaptor protein-1 }\end{array}$ \\
\hline IFNp & \begin{tabular}{|ll} 
Recombinant & Mouse \\
Interferon $\gamma$ & \\
\end{tabular} \\
\hline IGF-1 & Insuline-like growth factor \\
\hline IL-4 & \begin{tabular}{|ll} 
Recombinant & Murine \\
Interleukin-4
\end{tabular} \\
\hline INFY & Interferon gamma \\
\hline IS & Immune system \\
\hline $\begin{array}{l}\text { L- } \\
\text { Glutamine }\end{array}$ & L-Glutamine $200 \mathrm{mM}$ \\
\hline L-NNA & L-NNA \\
\hline LPC & $\begin{array}{l}\text { L- } \alpha \text {-Lysophosphatidylcholine } \\
\text { from egg yolk }\end{array}$ \\
\hline LPS & Lipopolysaccharide \\
\hline LPS & $\begin{array}{ll}\text { Lipopolysaccharides } & \text { from } \\
\text { Salmonella enterica } & \end{array}$ \\
\hline
\end{tabular}




\begin{tabular}{|c|c|}
\hline Abreviation & Name \\
\hline MAG & \begin{tabular}{|ll} 
Myelin & Associated \\
Glycoprotein & \\
\end{tabular} \\
\hline MBP & Myelin Basic Protein \\
\hline M-CSF & $\begin{array}{l}\text { Recombinant Macrophage } \\
\text { Colony Stimulating Factor }\end{array}$ \\
\hline MHC & $\begin{array}{l}\text { Major histocompatibility } \\
\text { complex }\end{array}$ \\
\hline MOG & \begin{tabular}{|ll} 
Myelin & Oligodendrocyte \\
Glycoprotein & \\
\end{tabular} \\
\hline MS & Multiple Sclerosis \\
\hline NGF & Nerve growth factor \\
\hline NGS & Neonatal Goat serum \\
\hline NMDA & N-methyl-d-aspartate \\
\hline NMDA & N-methyl-D-Aspartate \\
\hline NO & Nitric oxide \\
\hline NO-GC & NO-sensitive guanylyl cyclase \\
\hline NOS & Nitric oxide synthases \\
\hline NOS-1 & Neuronal NOS \\
\hline NOS-2 & Inducible NOS \\
\hline NOS-3 & Endothelial NOS \\
\hline NP & Natriuretic peptide \\
\hline NPR & Natriuretic peptide receptor \\
\hline ODQ & ODQ \\
\hline Ols & Oligodendrocytes \\
\hline ON & overnight \\
\hline OPCs & $\begin{array}{l}\text { Oligodendroglial precursor } \\
\text { cells }\end{array}$ \\
\hline ORO & Oil Red-O \\
\hline PBS & Bovine serum albumim \\
\hline
\end{tabular}

\begin{tabular}{|c|c|}
\hline Abreviation & Name \\
\hline PDE5 & $\begin{array}{l}\text { Phosphodiesterase type } \\
5\end{array}$ \\
\hline PDEs & Phosphodiesterases \\
\hline PDGF $\alpha R$ & $\begin{array}{l}\text { Platlet Derived Growth } \\
\text { Factor } \alpha \text { Receptor }\end{array}$ \\
\hline Pen/Strep & Penicillin-Streptomycin \\
\hline PFA & Paraformaldehyde \\
\hline pGC & $\begin{array}{l}\text { Particulate guanylyl } \\
\text { cyclases }\end{array}$ \\
\hline PKG & $\begin{array}{l}\text { cGMP dependent protein } \\
\text { kinases }\end{array}$ \\
\hline PLP & Proteolipid Protein \\
\hline PP-MS & $\begin{array}{l}\text { Primary Progressive } \\
\text { Multiple Sclerosis }\end{array}$ \\
\hline $\mathbf{R I}$ & Remyelination index \\
\hline RIPA & RIPA Lysis Buffer \\
\hline ROCK & Rho-Associated-Kinase \\
\hline ROS & Reactive oxygen species \\
\hline $\begin{array}{l}\text { Rp-8pCPT- } \\
\text { cGMP }\end{array}$ & $\begin{array}{l}\text { 8-[(4-Chlorophenyl)thio]- } \\
\text { guanosine-cyclic } \quad 3^{\prime}, 5^{\prime} \\
\text { monophosphate }\end{array}$ \\
\hline RR-MS & $\begin{array}{l}\text { Relapsing-Remitting } \\
\text { Multiple Sclerosis }\end{array}$ \\
\hline S.c & sub-cutaneous \\
\hline SC & Spinal cord \\
\hline Sil & Sildenafil \\
\hline TGF- $\beta$ & $\begin{array}{l}\text { Transforming growth } \\
\text { factor beta }\end{array}$ \\
\hline TNF $\alpha$ & $\begin{array}{l}\text { Tumor necrosis factor } \\
\text { alpha }\end{array}$ \\
\hline Tris & Phosphate buffer saline \\
\hline U0126 & $\begin{array}{l}\text { 1,4-Diamino-2,3-dicyano- } \\
\text { 1,4-bis[2- } \\
\text { aminophenylthio]butadie } \\
\text { ne }\end{array}$ \\
\hline WB & Western Blot \\
\hline Ym-1 & Chitinase-like 3 \\
\hline
\end{tabular}




\section{这这 \\ INTRODUCTION}




\section{INTRODUCTION}

\section{Multiple Sclerosis}

Multiple Sclerosis (MS) is a chronic, inflammatory and demyelinating disease of the CNS (Herz et al. 2010). MS etiology and the initiation of autoimmunity that comes with it, are still unknown (Nave 2010). Symptoms of MS include limb weakness, numbness, blurred or double vision and ataxia. Some advanced cases present cognitive impairments and memory loss (Hauser and Oksenberg 2006). In MS the immune system reacts against central nervous system (CNS) myelin components, initiating a detrimental inflammatory cascade that leads to demyelination and axonal and neuronal degeneration which is the principal anatomical correlate of progressive clinical deterioration. Axon protection can be achieved directly by intervention on the mechanisms by which axons are injured or degenerate and can also be achieved by immune-modulatory therapies and by promotion of remyelination. MS research has mainly focused on the immunological aspects of the disease and has translated into the development of highly effective immunemodulatory therapies to control the initial relapsing-remitting phase of MS, however the secondary progressive phase, in which there is continual atrophy of demyelinated axons, remains largely untreatable. (Garg and Smith 2015, Nave 2010, Peterson and Fujinami 2007).

\section{Experimental Autoimmune Encephalomyelitis}

Experimental autoimmune encephalomyelitis (EAE) has been extensively used as an animal model of MS since it shares with the human autoimmune disease the presence of inflammatory infiltrates in the CNS parenchyma, demyelination and axonal loss, predominantly in the spinal cord, and paralysis (Friese et al. 2006). Like MS, EAE seems to be initiated by myelin antigen- 
specific CD4+ T-lymphocyte infiltration into the CNS. CD4+ cells together with infiltrated macrophages, dendritic cells, and resident microglia constitute the ultimate effector cells of neuroinflammation, progression of demyelination, and axonal damage (Bynoe et al. 2007, Friese et al. 2006). In contrast, accumulating evidence indicates that local astroglial activation is neuroprotective in EAE. Using transgenic mice with targeted ablation of proliferating scar-forming astrocytes it has been shown that severity of EAE is enhanced and that leukocyte and macrophage entry into the CNS parenchyma is significantly increased (Voskuhl et al. 2009). Recent evidence additionally indicates that demyelination and oligodendrocyte degeneration follows inflammation-induced astrocyte dysfunction (Sharma et al. 2010). High levels of inflammatory mediators are secreted by infiltrating immune cells and resident CNS cells, which is characteristic of the inflammatory environment during disease (Raivich and Banati 2004).

EAE can be classified as passive (when induced by introducing MBPreactive T-cells into the animal) or active (when induced by immunization with CNS tissue or myelin peptides). Active EAE can also be divided into two different types according to the mouse strain and peptide used to induce it. In the SJL/J mouse strain active induction with PLP develops a relapsing-remitting form, while in the C57BL/6 mouse, immunization with $\mathrm{MOG}_{35-55}$ in CFA induces a chronic-sustained form of EAE (Constantinescu et al. 2011, McCarthy et al. 2012). Symptoms are characterized by ascending hind limb paralysis that is associated with inflammation and demyelination of axonal tracks. 


\section{Neuroinflammation}

\subsection{Immunity in the Central Nervous System}

The CNS has been classically considered an immunologically "privileged" organ because it was thought to be isolated from the immune system (IS) and excluded from its surveillance. Nowadays, it is well accepted that the "immune privilege" of the CNS is an active process, the immune response is present but restricted and involves a closely regulated inter-communication between CNS resident cells and the IS which allows control of immune-mediated inflammation and related secretion of potentially damaging molecules that could have devastating consequences in this essential organ with limited capacity for regeneration (Nakamizo et al. 2003).

\section{The Blood Brain Barrier}

The most important feature in CNS immune privilege is the presence of the Blood-Brain Barrier (BBB), a structure formed by blood vessel endothelial cells joined by tight junctions, the basal lamina in which pericytes are embedded and the end-feet of astrocytes, in conjunction with intra- and extracellular enzymes that represent a metabolic barrier. The BBB exerts bidirectional control over the transcellular passage of substances such as regulatory proteins, nutrients and electrolytes, maintaining the optimal ionic composition for axonal transmission and synaptic signaling. The BBB also avoids the entry of potentially harmful or toxic substances and supervises the infiltration of IS cells by expression of adhesion molecules in endothelial cells. However, in neuropathological conditions activating signals are produced by resident (glial) cells that can facilitate inflammation or promote recovery, but uncontrolled neuroinflammation can induce secondary injury (Abbott et al. 2010). 
In addition to the BBB, other factors also contribute to restricting the immune response in the CNS, like the absence of a conventional lymphatic system and the failure of antigen presenting cells (APCs) to migrate to lymph nodes along perivascular lymphatic drainage pathways in the healthy brain, although they might do so in the inflamed CNS. In addition, the highly regulated entrance of immune cells by the presence of immune-inhibitory factors constitutively produced by neurons, and the very low expression of activating and co-stimulatory molecules, are also important factors that contribute to minimize inflammatory responses in the CNS (Griffiths et al. 2009, Weller et al. 2010). Nevertheless, immunological reactions do occur in the CNS in response to infections and in immune-mediated disorders such as multiple sclerosis (MS).

\section{Resident immune effector cells in the CNS}

The functions of immune surveillance and differentiation between "self" and "non-self" antigens in non-CNS tissue, provided by neutrophils, dendritic cells, macrophages and natural killer cells in the periphery, are in the CNS attributed to resident glial cells, astrocytes and microglia (Veerhuis et al. 2011). After a CNS injury, glial cells show phenotypic changes referred to as reactive gliosis, one of the most important features in neuroinflammation (Aloisi 2001, Dong and Benveniste 2001). Glial activation plays a crucial role in acute and chronic inflammatory responses and reactive glia has been found in brains after traumatic injury, ischemia, infections, neuropathic pain, seizures, autoimmune inflammatory diseases, glaucoma, leukodystrophies, edema, psychiatric disorders, brain tumors and also in neurodegenerative diseases (Ghafouri et al. 2006, Kim Y. S. and Joh 2006, Sofroniew and Vinters 2010, Streit et al. 2005, Wyss-Coray 2006) 


\section{Astrocytes}

Astrocytes are the glial cells responsible of the CNS structure support, regulate blood flow, form and maintain the $B B B$ and also mediate its permeability. Astrocytes regulate transport of ions, nutrients and toxins. These cells also regulate synapses and nerve impulse transmission (Ludwin et al. 2016). After a brain injury, astrocytes are recruited to the lesion site and help forming a glial scar that promotes healing after the lesion (Lee et al. 2015). Astrocytes express neurotrophic and growth factors such as brain derived neurotrophic factor (BDNF), ciliary neurotrofic factor (CNTF), transforming growth factor beta (TGF- $\beta$ ) and insulin-like growth factor (IGF-1). Astrocytes are also able to express pro and anti-inflammatory cytokines (Ludwin et al. 2016, Peterson and Fujinami 2007).

\section{Microglia}

Microglial cells are considered the resident macrophages of the CNS, descendants of the monocytic lineage invade the central nervous system early during ontogenesis (Fedoroff and Hao 1991, Hailer 2008). In resting conditions, microglial cells present a ramified morphology with an elaborate tertiary and quaternary branch structure. Their prolongations cover a space of 30-50 $\mu \mathrm{m}$ not overlapping each other, expanding throughout the CNS (Raivich et al. 1999). Although in their apparent resting state, microglial cells are greatly active, continually surveying their microenvironment with extremely motile processes and protrusions poised to rapidly respond to environmental changes (Nimmerjahn et al. 2005). CNS injury provokes immediate and focal activation of microglia, which is thought to occur before astrocyte activation, switching their behavior from resting to defending cells in the injured site, with a different response depending on the stimulation provided (Town et al. 2005). 
Reactive microglial cells proliferate, retract its ramifications and acquire amoeboid morphology, extend new pseudopodia that enable active migration and phagocytic capacity for removing dead cells and cell debris. These characteristics together with their antigen presenting capacity in MHC-II, make them the antigen-presenting cells of the CNS initiating the adaptive immune response (Fig.2) (Aloisi 2001, Hailer 2008, Kim S. U. and de Vellis 2005).

\section{Microglia/macrophage activation phenotype}

Activation of microglia in response to brain injury involves a continuum spectrum of phenotypes that share characteristics with their homologue IS cells, the macrophages. The reactive microglia/macrophage phenotype oscillates between two end-points depending on the stimulatory environment, one corresponds to the adaptive activation with release of pro-inflammatory cytokines that is associated with capacity for stimulation of Th1 and Th2 subpopulations (M1 or classically activated phenotype), and the other to innate activation with a phagocytic phenotype and anti-inflammatory cytokine secretion ( 12 o alternativelly activated). In vitro, the M1 phenotype is induced in the presence of pro-inflammatory cytokines and LPS and the M2 phenotype in the presence of anti-inflammatory cytokines such as IL-4. Recent studies have identified $\mathrm{M} 2$ phenotype subtypes that have been classified according to specific protein expression and possible functions. M2a has been associated with regeneration and repair, $\mathrm{M} 2 \mathrm{~b}$ is considered immunoregulatory and $\mathrm{M} 2 \mathrm{c}$ immunosuppressive (Chhor et al. 2013, Miron and Franklin 2014, Mosser and Edwards 2008, Ransohoff and Perry 2009). Microglia/macrophage phenotypes can be recognized by changes in the expression of specific molecules. NOS-2, TNF $\alpha$, COX-2, and IL-1 $\beta$ are characteristic molecules of a M1 phenotype while arginase-1, CD206, Ym-1 and FIZZ-1 are considered M2-phenotype markers 
(Chhor et al. 2013, Fernando et al. 2014, Gensel and Zhang 2015). However, recent studies in vitro and in vivo have revealed that reactive microglia/macrophages are able to co-express $\mathrm{M} 1$ and $\mathrm{M} 2$ markers. In vivo experiments have shown that treatent of mice with LPS increases proinflammatory cytokines including IL-1 $\beta$, but also IL-4R and further treatment with IL-4 induced the expression of Arg-1 as well as IL-1 $\beta$, and this unique phenotype was able to promote neurite growth and spinal cord injury recovery (Fenn et al. 2014). Furthermore, macrophages treated with IL-4 in vitro, were shown to produce IL-6 while co-expressing the $\mathrm{M} 2$ characteristic molecule CD206, and the co-expression of IL-6 did not affect immunosuppressive properties of the M2 phenotype macrophages (Casella et al. 2016). Other studies aimed at characterizing specific molecules to delineate and identify microglia /macrophage phenotypes have also shown co-expression of the antiand pro-inflammatory phenotype markers (Chhor et al. 2013, Gensel and Zhang 2015).

\section{Myelination/Remyelination}

Myelination is an ordered and rapid process the uninjured, healthy adult brain. New myelin is continually generated along with new oligodendrocytes in active myelination, which perform myelin maintenance with subtle remodeling of specific areas (Bercury and Macklin 2015).

Demyelination is the pathological process where myelin sheaths are lost from around axons impairing nerve impulse conduction (Franklin and FfrenchConstant 2008). There are two major causes of primary demyelination in the CNS, the first is due to genetic abnormalities that affect glia, such as leukodystrophies, and the second is due to inflammatory damage to myelin and oligodendrocytes, which can be observed in neurological diseases such as 
MS and other neuroinflammatory disorders (Franklin and Ffrench-Constant 2008).

Remyelination is the process responsible of restoring entired myelin sheaths around demyelinated axons, reinstating saltatory conduction and ameliorating functional deficits (Franklin and Ffrench-Constant 2008). Extensive data indicate that, after demyelination, remyelinated internodes are thinner and shorter than, but after late time of recovery remyelinated fibers may have similar internode length and thickness to developmentally myelinated axons (Bercury and Macklin 2015).

\section{Oligodendrocytes}

Oligodendrocytes (OLs) are the CNS glial cells responsible for the production of the myelin sheath that surrounds axons isolating the electrical impulse in order to gain speed and efficiency (Nave 2010). OLs can have over 50 extensions reaching axons, and can myelinate them simultaneously (Copray et al. 2006, Liu et al. 2007, Nave 2010). OLs can interact with surrounding cells that influence OLs migration, differentiation and myelination (Kimelberg 2010, Li et al. 2016, Talbott et al. 2005). OL proliferation and differentiation is regulated by cytokines and growth factors (Nave 2010), such as BDNF (De Santi et al. 2009, Weishaupt et al. 2012) and CNTF (Stankoff et al. 2002). OLs express characteristic transcription factors that allow determination of their differentiation or maturation stage, such as Nkx.2, an early marker of OL precursor differentiation, and Olig1 and Olig2, expressed during early to late differentiation stages. Mature OLs express myelin basic protein (MBP), proteolipid protein (PLP), myelin oligodendrocyte glycoprotein (MOG), myelin associated glycoprotein (MAG) and 2',3'-cyclic nucleotide 3'-phosphodiesterase (CNPase) among others (Copray et al. 2006, Liu et al. 2007, Meffre et al. 2015, Miron et al. 2010, Nishiyama et al. 2009, Zhang H. et al. 2011). 


\section{Cyclic GMP}

Cyclic guanosine monophospate (cGMP) is a second messenger in signal transduction. It is generated by guanylyl cyclase enzymes (GC) that catalyze the conversion of GTP into cGMP. There are two main classes of GCs: nitric oxidesensitive guanylyl cyclase (NO-GC) that is mainly soluble, and particulate guanylyl cyclases (pGC) represented by the natriuretic peptide (NP)-receptor (NPR) group (Tsai and Kass 2009) (Fig 1).

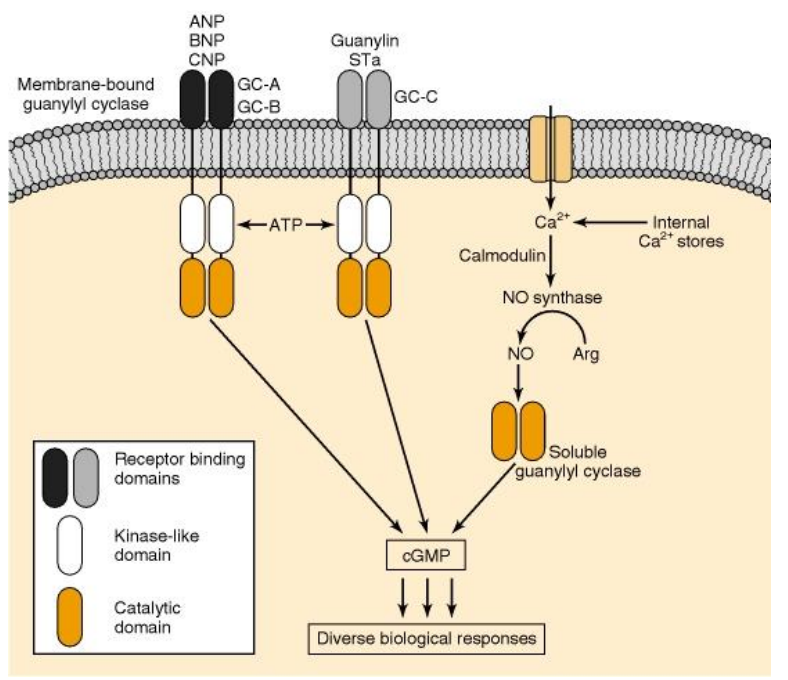

Figure 1: Schematic representation of cyclic GMP synthesizing pathways. GC activation mechanisms. GC-A, GC-B and GC are membrane bound GC and NO-GC is cytoplasmic. Scheme from Duman and Nestler, Guanylyl Ciclase, 1999 (Duman RS 1999).

\section{The NO - cGMP pathway}

Nitric oxide (NO) is a small, gaseous, highly diffusible, and reactive molecule with a short half-life, rapidly oxidized to the stable and inactive endproducts, nitrite and nitrate (Zhang J. and Snyder 1995). In the CNS, NO has been associated with the modulation of synaptic plasticity, brain development, visual and sensory processing, neuro-endocrine secretion and cerebral blood flow (Garthwaite J. 2000, Guix et al. 2005). It can act as a 
neurotransmitter/neuromodulator or as an inflammatory response mediator, low concentrations of NO mediate physiological signaling and can also be neuroprotective and it has shown to be essential for synaptic plasticity, control of cerebral blood flow, neurogenesis and synaptogenesis (Manucha 2016, Zhang J. and Snyder 1995). However, in high concentrations is a neuropathological agent responsible for excitotoxic cell death and neuroinflammatory cell damage in many neurological disorders (Duncan and Heales 2005, Manucha 2016, Murphy 2000) .

\subsection{Nitric oxide synthases}

Nitric oxide synthases (NOS) are a group of enzymes that produce NO by oxidation of one of the guanidine nitrogens of L-arginine, using $\mathrm{O}_{2}$ and NADPH as co-substrates and forming L-citrulline as product, a reaction that requires $\mathrm{O}_{2}$ and NADPH as co-substrates (Zhang J. and Snyder 1995). There are three isoforms of NOS, two of them NOS-1 and NOS-3 are expressed constitutively while NOS-2 is an inducible enzyme. NOS-1 is found in the nervous system (primarily in neurons and astrocytes) and NOS-3 is expressed in vascular endothelial cells. Both, NOS-1 and NOS-3, are calcium-calmodulin-dependent and produce nanomolar concentrations of $\mathrm{NO}$ in response to transient elevations in intracellular calcium. In neuronal populations this generally occurs by $\mathrm{N}$-methyl-D-aspartate (NMDA) type glutamate receptor stimulation that allows calcium entry (Maarsingh et al. 2009, Manucha 2016). NOS-2 is inducible at the transcriptional level and its activity is calcium-independent since it has tightly-bound calmodulin. NOS-2 produces higher and longer-lasting amounts of NO (micromolar concentrations) after induction by inflammatory compounds such as LPS, pro-inflammatory cytokines (IL-1 $\beta$, TNF- $\alpha$ and IFN- $\gamma$ ) or $A \beta$ peptides, that can cause neurotoxicity. In peripheral tissues this enzyme is mainly, but not exclusively, expressed in macrophages. In the CNS, NOS-2 is 
expressed in microglia and astroglia, and its generation of NO has been implicated in the pathogenesis of various insults as well as in neurological disorders (Brown and Neher 2010, Murphy 2000, Steinert et al. 2011). Upregulation of iNOS has been implicated in tissue damage in MS and EAE (Raivich and Banati 2004). However, iNOS-deficient mice develop more severe EAE (Willenborg et al. 2007), suggesting that NO may be neuroprotective.

\subsection{Guanylyl cyclises}

\section{NO-sensitive guanylyl cyclases}

NO-GC is recognized as the major receptor for NO, and mediates numerous of its physiological functions. NO-GC was initially thought to be entirely cytosolic and was thus named "soluble GC", however it has also been found associated to membranes (Zabel et al. 2002). NO-GC is composed of an $\alpha$ and a $\beta$ subunit and both subunits are required for catalytic activity (Koesling et al. 2004). Each subunit has a regulatory domain which contains a prosthetic heme group that is the NO-binding site, a catalytic domain that shares sequence homology with the corresponding domains in $\mathrm{PGC}$ and adenylyl cyclases and a central domain which allows subunit dimerization (Foster et al. 1999) (Fig. 4).

In contrast to the ubiquitous NO formation in CNS parenchymal cells, NO-dependent cGMP synthesis by activation of NO-GC appears to occur mainly in neurons and astrocytes. Not much is known about the regulation and function of cGMP formation in astrocytes during neuroinflammation, when an excess of NO production occurs (Baltrons et al. 2008). Inflammatory compounds known to induce astroglial reactivity and NOS-2 expression, such as LPS, A $\beta$ s or IL-1 $\beta$ have been shown to down-regulate NO-GC at the protein and mRNA level in rat brain astroglial cultures and after intracerebral 
administration in adult rat brain (Baltrons and Garcia 1999, Baltrons et al. 2002, Pedraza et al. 2003). In addition, decreased astroglial expression of the NO-GC $\beta$ subunit was observed in post-mortem brains of Alzheimer's disease (AD), MS and Creutzfeld-Jacob disease patients, suggesting that an impairment of the astroglial NO/cGMP system may bear some relation to neuronal dysfunction (Baltrons et al. 2004).

Si pones esta figura que musi

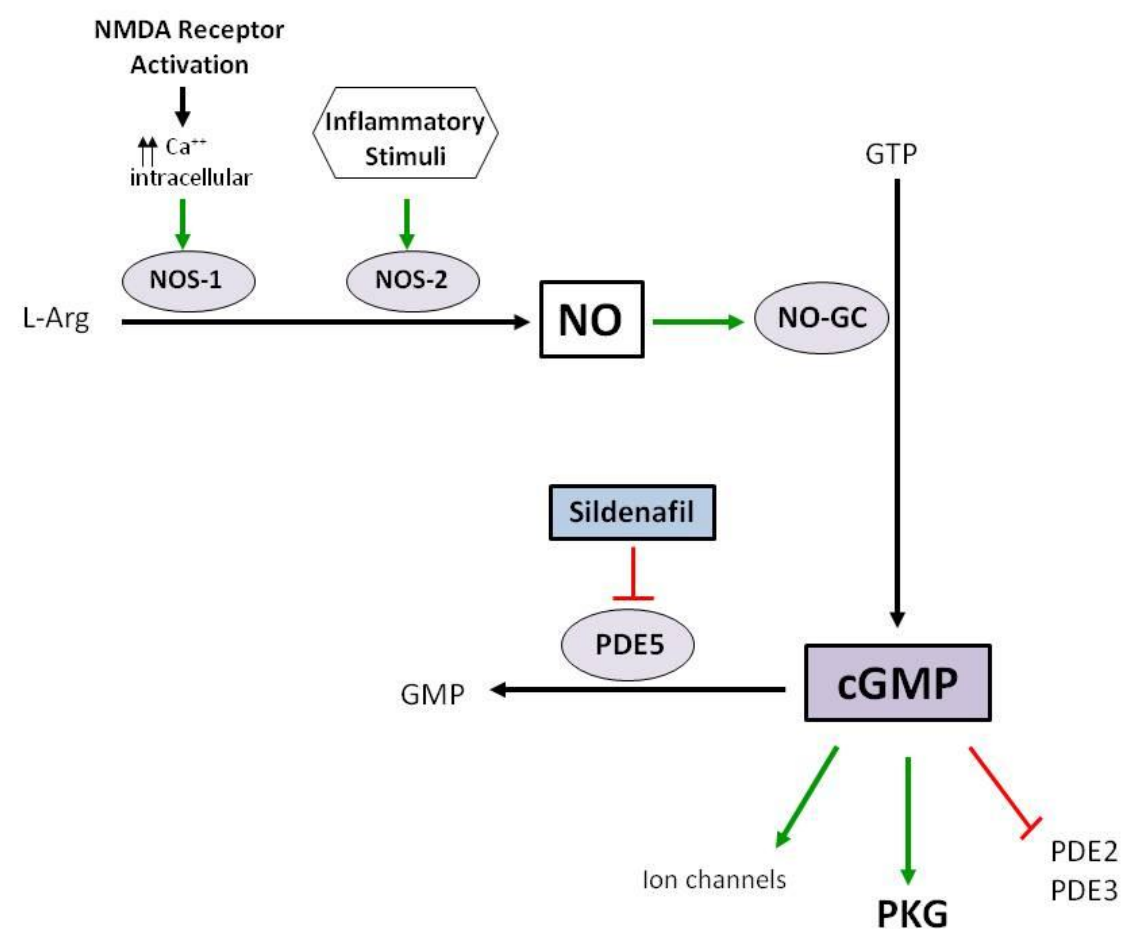

Figure 2: Schematic representation of NO-dependent cGMP formation, cGMP targets and site of action of sildenafil in the pathway 


\section{Natriuretic peptide receptor- guanylyl ciclases}

Particulate guanylyl cyclases (pGC) are membrane bound with extracellular receptors (Zabel et al. 2002). The pGC has three isoforms, two of them are membrane NPR that have GC activity: NPR-A or GC-A that binds atrial (ANP) and brain natriuretic peptide (BNP), NPR-B or GC-B binds C-type natriuretic peptide ( $\underline{\mathrm{CNP}})$ and is expressed in neuronal. The third isotype of GC is GC-C binds the endogenous peptide guanylin and can be activated by a bacterial enterotoxin and localized in the intestine (Fig 3) (Duman RS 1999). Functional natriuretic peptide receptors are mainly expressed un neuron; however they can also be expressed in astroglia and microglia regulating important physiological responses (Prado et al. 2010).

\section{3 cGMP targets}

Downstream targets of cGMP are cyclic nucleotide regulated ion channels, PKGs and cGMP-regulated PDEs (Fig 2).

\section{Cyclic nucleotide regulated ion channels.}

Cyclic nucleotide regulated ion channels are non-selective cation channels activated by cGMP and/or cAMP binding and have calcium permeability under physiological conditions (Bradley et al. 2005). Cyclic nucleotide regulated ion channels form heterotetrameric complexes consisting of two or three different types of subunits (Kaupp and Seifert 2002). In the CNS, this channels have been implicated in the regulation of synaptic plasticity, these channels are widely expressed in central and peripheral neurons, they control a variety of fundamental processes including signal transduction in retinal photoreceptors and in olfactory neurons (Biel et al. 1996, Bradley et al. 2005). 
PKGs are serine/threonine-kinases that are activated by cGMP binding. Two subtypes of PKG exists PKGI and PKGII, both homodimers that regulate multiple signaling pathways, phosphorylating ion channels, $G$ proteins and phosphorylating downstream signaling pathways. PKGI can be found as a soluble protein and has two isoforms PKGI $\alpha$ and PKGI $\beta$, both of them expressed predominantly in the CNS, especially in cerebellum and hippocampus. PKGII is membrane-bound and can also be found in CNS. PKGI/II mediates most of the cGMP effects, regulating multiple signaling pathways by phosphorylation of ion channels, G proteins and associated regulators and cytoskeleton-associated proteins, among others. (Hofmann et al. 2009, Tsai and Kass 2009). PKG is the main target of cGMP, its binding to PKG regulates transcription factors such as CREB, NF-KB and C-Fos (Vollmar 2005); more over PKG activation increases ErkI/II, Akt y GSK3 $\beta$ phosphorylation, among other molecules (Das et al. 2008). Erk and Akt pathways have been related with oligodendrocyte protection and differentiation (Guardiola-Diaz et al. 2012).

\section{cGMP-regulated PDEs.}

cGMP selectively regulates the activity of PDE2,PDE3 and PDE5 by binding to their regulatory domains. In PDE5, cGMP binding into its regulatory domain induces cGMP hydrolysis into GTP. In the case of PDE2 that has high affinity for CAMP and low affinity for CGMP, the binding of cGMP to the regulatory site provokes a conformational change which increases its enzymatic activity towards CAMP. PDE3 also has affinity for both, CAMP and CGMP, with a higher hydrolysis rate towards CAMP; however, cGMP binding to the catalytic site and inhibits CAMP breackdown, thereby regulating CAMP and CGMP signaling (Francis et al. 2011, Tsai and Kass 2009). 


\section{4. cGMP inactivation}

\section{Cyclic GMP PDES}

PDEs are the enzymes responsible for the hydrolysis of the phosphodiester bond of cyclic nucleotides such as CAMP and cGMP, controlling the duration and reach of the cyclic nucleotide signaling. Eleven different families of PDEs have been identified (PDE1 to PDE11), with different expression, substrate specificity, regulation or sensitivity to inhibitors. PDEs can be divided in three groups depending on the specificity for the nucleotide. PDEs specific for cGMP are:PDE5, PDE6 and PDE9. cGMP-specific PDE5 has 3 isoforms (PDE5A1-3) widely distributed and having no difference in activity between them (Tsai and Kass 2009).

PDE inhibitors were initially developed as potential therapeutic tools, recently PDE inhibitors are being used according to their specificity, to treat different disorders and potentiate the effect of the cyclic nucleotide signaling (Bell and Palmer 2011, Hertz and Beavo 2011). PDE5 inhibitors were initially developed because of the important role of this PDE in controlling cGMP levels in vascular smooth muscle and its effects on vascular tone. Three PDE5 inhibitors (vardenafil, tadalafil y sildenafil) are used worldwide for the treatment of different pathologies. Sildenafil (Viagra) is currently approved for the treatment of erectile dysfunction and pulmonary arterial hypertension (Bell and Palmer 2011, Tsai and Kass 2009).

Numerous studies in animal models have shown beneficial effects of PDE5 inhibition in the CNS. In focal brain injury, PDE5 inhibition promotes astrogliosis and angiogenesis, decreases microglia/macrophage activation and oxidative stress contributing with neuroprotection (Pifarre et al. 2010). Moreover, it has been described that sildenafil treatment ameliorates clinical symptoms of $E A E$, 
an in vivo model that mimics neuropathological and neuroinflammatory features of MS, inducing almost full recovery after 8 days of sildenafil treatment starting at peak of disease, effect associated with an increase in myelin staining and reduced axonal damage (Pifarre et al. 2011). In addition, sildenafil treatment after cuprizone induced demyelination in vivo, showed protective effects in cerebellum by preserving myelin and axons ultra-structure and reducing pro-inflammatory cytokines IFN- $\gamma$, TNF- $\alpha, \mathrm{IL}-1 \beta, \mathrm{IL}-2$ and COX-2 (Nunes et al. 2012). Furthermore, starting treatment with sildenafil at the onset on EAE prevents disease progression, showed oligodendrocyte protection against apoptotic death, reduced microglia/macrophage reactivity while increased the expression of $\mathrm{Ym}-1$ anti-inflammatory microglia/macrophage phenotype (M2) protein, increased in BDNF expression in splenocytes accompanied by an increase immune-reactivity of this neurotrophic factor in the SC of sildenafil treated mice; the augment of BDNF expression in SC of sildenafil treated mice was associated with increased expression in infiltrating leukocytes and axons and decreased pro-inflammatory cytokine expression in splenocytes, modulating adaptative immune response (Pifarre et al. 2014).

\section{5. cGMP and remyelination.}

\section{cGMP and oligodendrocytes}

Studies in immature rat brain slices have shown that increasing NO levels with a NO donor combined with a PDE inhibitor generated an increase in cGMP accumulation in oligodendrocytes (Tanaka et al. 1997). Furthermore, increasing cGMP levels by inhibiting PDE5 with sildenafil have been reported to increase neural stem cells and their neuronal and oligodendrocyte progeny in the mouse ischemic brain model (Bibollet-Bahena and Almazan 2009). Additionally, it has been reported that low NO concentrations or a cGMP analogue protect 
differentiated murine oligodendrocytes from caspase-mediated death via PKG (Benjamins and Nedelkoska 2007). Protection of mature and immature oligodendrocytes has been also reported in sildenafil-treated EAE mice (Pifarré et al. 2014) and very recent studies have shown that stimulation of the NOcGMP pathway promotes oligodendrocyte morphological development in vitro (Garthwaite G. et al. 2015).

As above mentioned, sildenafil treatment after cuprizone induced demyelination preserved myelin and axon integrity (Nunes et al. 2012, Raposo et al. 2014) and previous studies developed in the laboratory where this thesis was developed have shown in significant amelioration of EAE clinical symptoms after sildenafil treatment, suggesting a possible role of sildenafil in remyelination due to an increase in myelin stainings the protection exerted against apoptotic death of oligodendrocytes, the decrease of reactive gliosis and increase in neurotrophic factor BDNF (Pifarre et al. 2011, Pifarre et al. 2014). 
a

AIMS 
Studies conducted in the laboratory where this thesis was developed showed that in a model of multiple sclerosis (MS), MOG induced experimental autoimmune encephalomyelitis (EAE), that the administration of the PDE5 inhibitor sildenafil in the acute phase of the disease rapidly ameliorates clinical symptoms, prevents axonal, decreased CD3+-leukocyte infiltration and microglial/macrophage activation in the spinal cord and suggests to restore myelin content (Pifarre et al. 2011). Additionally, early administration of sildenafil have shown to delay EAE progression, preserves axons and myelin sheath integrity, prevents the death of oligodendrocytes and enhances expression of BDNF neurotrofic factor in chronic EAE, it was also observed reduced microglia/macrophage reactivity while increased the expression of Ym1 anti-inflammatory microglia/macrophage phenotype (M2) protein and modulating adaptative immune response (Pifarre et al. 2014).
\end{abstract}

\title{
1. General aim.
}

The general aim of this thesis was to study mechanisms involved in the remyelinating effect of sildenafil in CNS cells.

\section{Specific aims.}

1. To confirm the remyelinating potential of sildenafil in the spinal cord of $E A E$ mice and in demyelinated cerebellar organotypic cultures

2. To investigate the implication of the NO-cGMP-PKG pathway in the remyelinating effect of sildenafil

3. To investigate if sildenafil induces CNTF in CNS cells 
4. To investigate if sildenafil induces changes in inflammatory phenotype of microglia in demyelinated slice cultures and in bone marrow-derived macrophages (BMDM).

5. To investigate if sildenafil increases myelin phagocytosis in spinal cord of EAE mice and in BMDM 
a so 상

\section{MATERIALS AND METHODS}




\section{MATERIALS AND METHODS}

\section{MATERIALS}

\subsection{Reagents}

Table 1: Tissue Culture Material.

\begin{tabular}{|l|l|l|}
\hline Product & Abbreviation & Supplier \\
\hline Dubelco's Modified Eagle medium GlutaMax & DMEM & Gibco \\
\hline Fetal Bovine Serum & FBS & Gibco \\
\hline Basal medium containing Earle's salt & BME & Gibco, Invitrogen \\
\hline Hank's buffered salt solution & HBSS & Gibco, Invitrogen \\
\hline Heat Inactivated horse serum & HS & Gibco, Invitrogen \\
\hline Glucose & Glucose & Sigma-Aldrich \\
\hline L-Glutamine 200mM & L-Glutamine & Sigma-Aldrich \\
\hline Penicillin-Streptomycin & Pen/Strep & Sigma-Aldrich \\
\hline $\begin{array}{l}\text { Recombinant Macrophage Colony Stimulating } \\
\text { Factor }\end{array}$ & M-CSF & Immunotools \\
\hline Cell Culture Inserts & & Millipore \\
\hline
\end{tabular}

Table 2: Specific Reagents

\begin{tabular}{|c|c|c|c|}
\hline Product & Abbreviation & Use & Supplier \\
\hline \multicolumn{4}{|c|}{ cGMP analogues } \\
\hline $\begin{array}{l}\text { 8-Bromoguanosine } 3^{\prime}, 5^{\prime} \text {-cyclic } \\
\text { monophosphate sodium salt }\end{array}$ & 8BrcGMP & $\begin{array}{l}\text { Cell-permeable hydrolysis } \\
\text { resistant cGMP analog. } \\
\text { Activates PKG. }\end{array}$ & Sigma-Aldrich \\
\hline 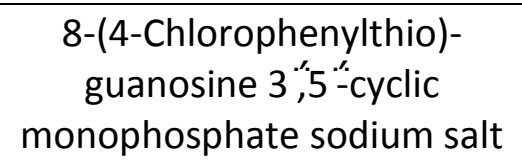 & 8pCPTcGMP & $\begin{array}{c}\text { Membrane-permeable } \\
\text { analog of cGMP, selective } \\
\text { activator of PKG. }\end{array}$ & Sigma-Aldrich \\
\hline \multicolumn{4}{|c|}{ cGMP increasing agents } \\
\hline N-methyl-D-Aspartate & NMDA & NMDA receptor agonist & Sigma-Aldrich \\
\hline BAY 41-2272 & BAY41 & NO-GC Activator & TOCRIS \\
\hline
\end{tabular}




\begin{tabular}{|c|c|c|c|}
\hline Sildenafil & Sil & PDE-5 Inhibtor & Sigma-Aldrich \\
\hline \multicolumn{4}{|c|}{ cGMP production inhibitors } \\
\hline $\begin{array}{l}\text { 1H-[1,2,4]Oxadiazolo[4,3- } \\
\text { a]quinoxalin-1-one }\end{array}$ & ODQ & Selective inhibitor of NO-GC & Sigma-Aldrich \\
\hline$N_{\omega}$-Nitro-L-arginine & L-NNA & Inhibitor of NOS & Sigma-Aldrich \\
\hline \multicolumn{4}{|c|}{ Signaling pathways inhibitors } \\
\hline $\begin{array}{l}\text { 8-[(4-Chlorophenyl)thio]- } \\
\text { guanosine-cyclic 3',5' } \\
\text { monophosphate }\end{array}$ & $\begin{array}{l}\text { Rp-8pCPT- } \\
\text { cGMP }\end{array}$ & PKG inhibitor & Biolog \\
\hline Rapamycin & & mTOR inhibitor & Calbiochem \\
\hline $\begin{array}{c}\text { 1,4-Diamino-2,3-dicyano-1,4- } \\
\text { bis[2- } \\
\text { aminophenylthio]butadiene }\end{array}$ & U0126 & $\begin{array}{c}\text { Selective non-competitive } \\
\text { inhibitor of the MAP kinase } \\
\text { kinase pathway. Inhibits } \\
\text { MEK } 1 / 2\end{array}$ & Calbiochem \\
\hline \multicolumn{4}{|c|}{ Inflammatory stimuli } \\
\hline $\begin{array}{l}\text { Recombinant Murine } \\
\text { Interleukin-4 }\end{array}$ & IL-4 & Induces M2 phenotype & Immunotools \\
\hline $\begin{array}{c}\text { Recombinant Mouse Interferon } \\
Y\end{array}$ & IFNy & Induces M1 phenotype & Millipore \\
\hline $\begin{array}{l}\text { Lipopolysaccharides from } \\
\text { Salmonella enterica }\end{array}$ & LPS & Induces M1 phenotype & Sigma-Aldrich \\
\hline \multicolumn{4}{|c|}{ Other specific reagents } \\
\hline $\begin{array}{l}\text { L- } \alpha \text {-Lysophosphatidylcholine } \\
\text { from egg yolk }\end{array}$ & LPC & Demyelinates axonal fibers & Sigma-Aldrich \\
\hline $\begin{array}{c}1,1^{\prime \prime} \text {-diotadecyl-3,3,3',3'- } \\
\text { tetramethyl-lindocarbocyanide } \\
\text { perchlorate }\end{array}$ & Dil & Lipophilic membrane stain & Sigma-Aldrich \\
\hline Oil Red-O & ORO & $\begin{array}{l}\text { Fat-soluble dye for lipid } \\
\text { staining }\end{array}$ & Sigma \\
\hline FluoPrep & & Mounting medium & $\begin{array}{l}\text { Biomeireux } \\
\text { S.A. }\end{array}$ \\
\hline RIPA Lysis Buffer & RIPA & $\begin{array}{l}\text { Lysis of cells to perform } \\
\text { analysis on proteins. }\end{array}$ & Millipore \\
\hline Anti phosphatases cocktail & & $\begin{array}{c}\text { Improves the yields of intact } \\
\text { proteins inhibiting enzymes } \\
\text { that modify proteins in cell } \\
\text { extracts }\end{array}$ & Sigma-Aldrich \\
\hline
\end{tabular}




\begin{tabular}{|c|c|c|c|}
\hline Anti proteases & & $\begin{array}{l}\text { Inhibits degradation of } \\
\text { proteins by endogenous } \\
\text { proteases }\end{array}$ & Roche \\
\hline $\begin{array}{l}\text { Ethylenediaminetetraacetic } \\
\text { acid }\end{array}$ & EDTA & \begin{tabular}{|l|} 
Ligand and chelating agent. \\
Preventing cells aggregates \\
and detaching adherent cells
\end{tabular} & Fluka \\
\hline TRIS buffer solution & Tris & $\begin{array}{c}\text { Buffer use in protein and } \\
\text { nucleic acid extraction and } \\
\text { purification. }\end{array}$ & Sigma \\
\hline Phosphate buffer saline & PBS & & Gibco \\
\hline Bovine serum albumin & BSA & $\begin{array}{c}\text { Blocking non-specific } \\
\text { antibody binding }\end{array}$ & Sigma \\
\hline Neonatal Goat serum & NGS & \begin{tabular}{|c|} 
Blocking non-specific \\
secondary antibody binding
\end{tabular} & Gibco \\
\hline $\begin{array}{c}\text { TruStain FcX anti-mouse } \\
\text { CD16/32 }\end{array}$ & & $\begin{array}{c}\text { Blocking Fc receptors in cell } \\
\text { membranes }\end{array}$ & Biolegend \\
\hline
\end{tabular}

\subsection{Antibodies.}

\section{Table 3: Primary Antibodies}

\begin{tabular}{|l|c|l|}
\hline Antibodies & Origin & Supplier and Reference \\
\hline anti-MBP & Rat & Abcam ab7349 \\
\hline anti- CNPase & Mouse & Abcam Ab6319 \\
\hline anti-Caspr & Rabbit & Abcam ab34151 \\
\hline anti-Olig2 & Rabbit & Millipore ab9610 \\
\hline anti-NF-200 & Mouse & Sigma-Aldrich N0142 \\
\hline anti- $\beta$ Actin & Mouse & Sigma-Aldrich A5316 \\
\hline anti-GAPDH Primary antibodies coupled to fluorescent dyes \\
\hline anti-NOS-2 & Mouse & Ambion AM4300 \\
\hline \multicolumn{2}{|c|}{ Rout } & Biolegend 141710 (Rat IgG2a,k) \\
\hline Alexa Fluor 488-anti-CD206 & Rat & Biolegend 400525 (Rat IgG2a,k) \\
\hline Alexa Fluor 488-Rat IgG2a,k Isotype & \multicolumn{2}{c|}{} \\
\hline
\end{tabular}




\section{Table 4: Secondary antibodies}

\begin{tabular}{|l|l|l|}
\hline Antibody & Made in & Supplier \\
\hline \multicolumn{3}{|c|}{ Alexa coupled to anti-lgG } \\
\hline Alexa Fluor anti Rat 488 & Goat & Invitrogen \\
\hline Alexa Fluor anti Mouse 568 & Goat & Invitrogen \\
\hline Alexa Fluor anti Rabbit 488 & Goat & Invitrogen \\
\hline Alexa Fluor anti Rabbit 568 & Goat & Invitrogen \\
\hline \multicolumn{2}{|c|}{ Horseradish peroxidase (HRP) conjugated anti-IgG } \\
\hline anti -Rat-HRP & Goat & Thermo Fisher \\
\hline anti -Mouse-HRP & Goat & Sigma \\
\hline
\end{tabular}

\section{2. $E A E$}

Two-month old female C57BL/6 mice (Charles River) were housed in the animal facility of Universitat Autonoma de Barcelona (UAB) under constant temperature and provided food and water ad libitum. Chronic Experimental Autoimmune Encephalomyelitis (EAE) was induced by immunization with MOG $35-55$ peptide (Scientific Technical Service, Universitat Pompeu Fabra Barcelona, Spain) as a model of MS. Mice were injected subcutaneously (sc) into the hind flanks with an emulsion of $100 \mu \mathrm{MOG}_{35-55}(3 \mathrm{mg} / \mathrm{ml})$ and $100 \mu \mathrm{l}$ Complete Freund's Adjuvant (CFA) supplemented with $4 \mathrm{mg} / \mathrm{ml}$ Mycobacterium tuberculosis H37RA (Difco). Additionally, animals received an intraperitoneal injection of $500 \mathrm{ng}$ pertussis toxin that was repeated 2 days after immunization. Control mice were immunized only with CFA supplemented with mycobacterium and compared with Naïve group (Pifarre et al. 2011). 


\subsection{EAE clinical score evaluation}

Mice were weighted daily and clinically evaluated for EAE-ch progression according to the following scores: 0 no disease sings, 0.5 partial loss of tail tonus, 1 loss of tail tonus, 2 moderate hind limb paraparesis, 2.5 severe hind limb paraparesis, 3 partial hind limb paralysis, 3.5 hind limb paralysis, 4 tetraplegy and 5 death.

\subsection{Treatments and Sacrifice}

\subsubsection{Acute phase treatment}

Immunized animals were randomly divided into two groups before being treated by injection (s.c) with vehicle (water) or sildenafil $(10 \mathrm{mg} / \mathrm{kg}$ ) once a day starting near peak of the disease (16 days post-immunization (dpi) score close to 2). Mice were sacrificed under pentobarbital anesthesia after 15 days of treatment (dot), spinal cords (SC) were collected (Pifarre et al. 2014).

\subsubsection{Chronic phase treatment}

Once immunized, the animals were randomly divided into two groups before starting treatments. Clinical symptoms peaked at $18 \mathrm{dpi}$ and stabilized thereafter at a mean score of 2 . Mice were treated by injection (s.c) with vehicle (water) or sildenafil $(10 \mathrm{mg} / \mathrm{kg}$ ) once a day starting at $41 \mathrm{dpi}$. After 17 days of treatment, mice were sacrificed $2 \mathrm{~h}$ after the last administration under pentobarbital anesthesia and SC were removed.

Experiments were approved by the UAB Animal and Human Experimentation Ethics Committee. 


\section{Culture procedures.}

\subsection{Cerebellar Organotypic Cultures}

Organotypic slice cultures were stablished from cerebellum of 7-day-old C57BL/6 mice (Harlan). Mice were killed by decapitation and cerebella were dissected. Sagital $300 \mu \mathrm{m}$ cerebellum slices were obtained by a Mcllwain Tissue Chopper (Mickle Laboratory). Three or four slices per well were seeded on Cell Culture Inserts in six-well plates and incubated at $37 \stackrel{\circ}{\circ} \mathrm{C}$ with $5 \% \mathrm{CO}_{2}$ in medium containing $50 \% \mathrm{BME}, 25 \% \mathrm{HBSS}, 25 \% \mathrm{HS}, 5 \mathrm{mg} / \mathrm{ml}$ glucose, $0.25 \mathrm{mM}$ L-glutamine and $25 \mathrm{ug} / \mathrm{ml}$ penicillin/streptomycin. Medium was changed every 2-3 days. After 7 days in vitro (DIV), the slices were demyelinated using L- $\alpha$ lysophosphatidylcholine (LPC) from egg yolk $(0.5 \mathrm{mg} / \mathrm{ml})$ for $14 \mathrm{~h}$. After that time medium was replaced with LPC-free medium (Birgbauer et al. 2004).

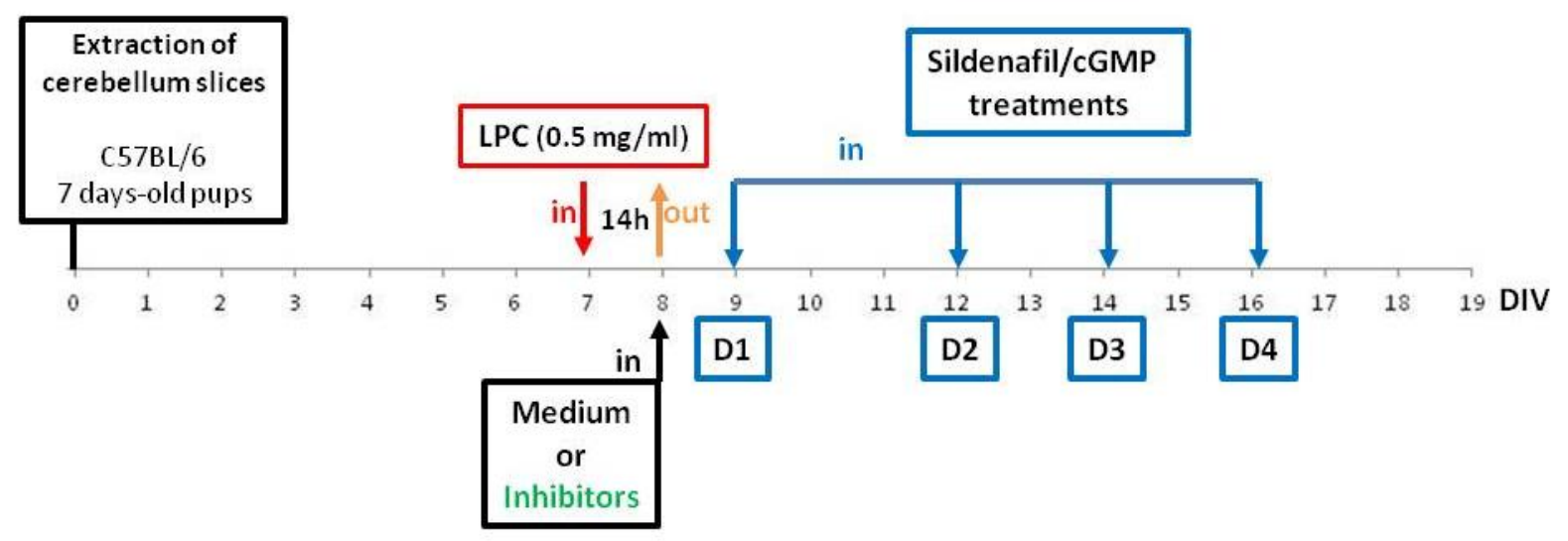

Figure 3: Scheme of mouse organotypic cerebellar culture. Treatment time points.

Treatments with specific activators or inhibitors of cGMP mediated pathways and kinases (Fig 2) were started at 9 DIV (Fig 1), and medium were replaced every 2-3 days until 19 DIV. Inhibitors of the NO-cGMP pathway were added $24 \mathrm{~h}$ before (8 DIV) (Fig 1 ). 


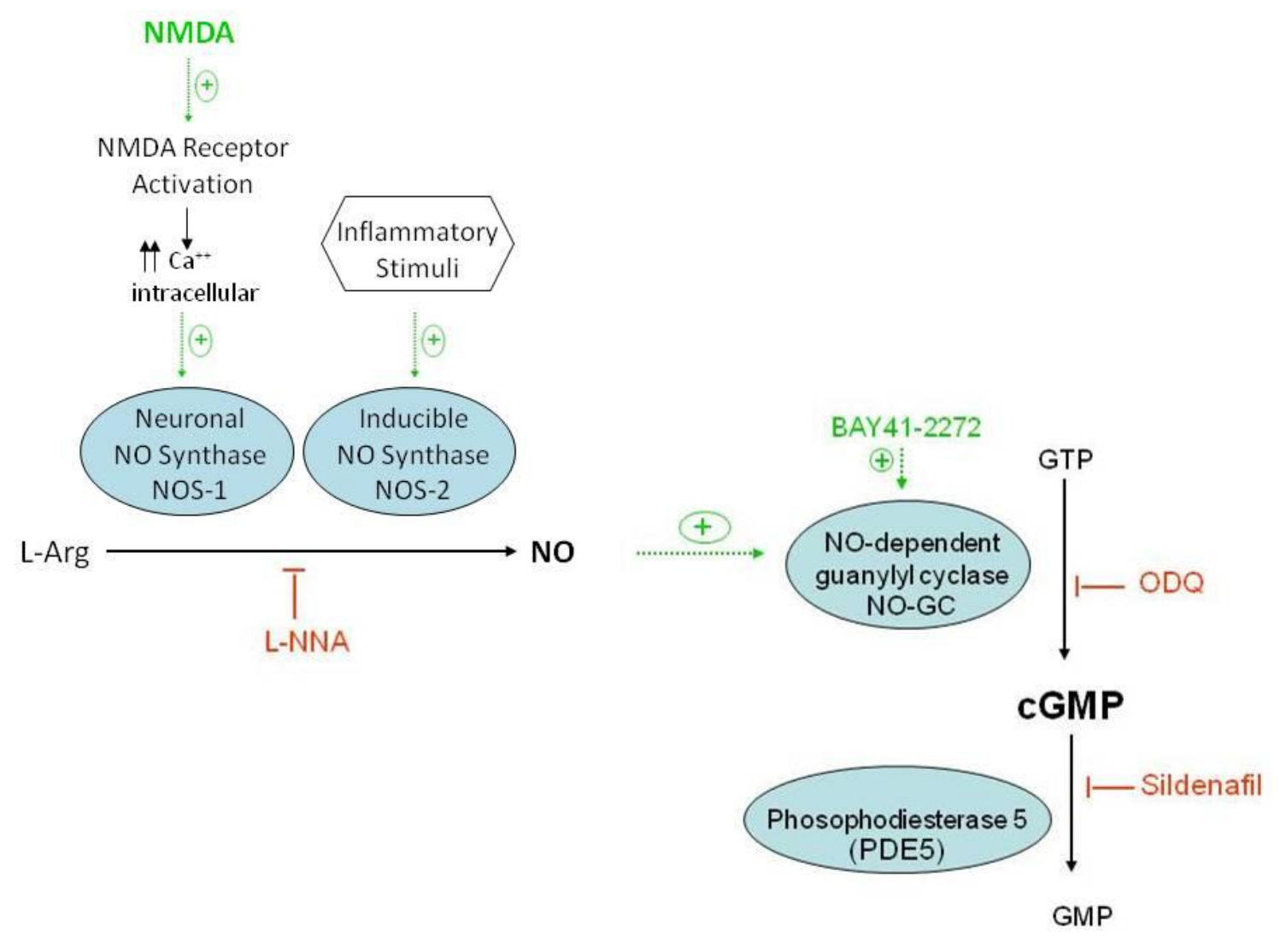

Figure 4: Treatments with specific activators or inhibitors of cGMP mediated pathways

\subsection{Bone Marrow derived Macrophage Culture}

Bone marrow derived macrophage cultures were obtained as previously describe by Classen, et al., 2009 (Classen et al. 2009) with some modifications. Briefly C57BL/6 naïve 8 to 12 week-old mice were used. Mice were euthanized by decapitation and hind legs were removed. Tibia and femur were exposed and epiphyses were cut and the medullary cavity of the bones was left visible. A $25 \mathrm{G}$ needle was introduced in the cavity, and the content was washed off with DMEM medium. Bone marrow was seeded in $140 \mathrm{~mm}$ plates in DMEM+20\%FBS+1\%peniciline/streptomycin containing $10 \mathrm{ng} / \mathrm{ml} \mathrm{M-CSF}$ and 
incubated at $37 \stackrel{\circ}{\circ} \mathrm{C}$ at $5 \% \mathrm{CO}_{2}$. After 4 days, a boost of $5 \mathrm{ng} / \mathrm{ml} \mathrm{M}$-CSF was added.

Cells were harvested at day 7 and isolated BMDM were seeded in DMEM+10\%FBS+1\%peniciline/streptomycin. For arginase activity and nitrite concentration 96-well plates were used, containing $2 \times 10^{5}$ cells/well. For contrast phase examination $35 \mathrm{~mm}$ plates were used, containing $1.5 \times 10^{6}$ cells/well. For mRNA and flow cytometry studies 6-well plates were used with a density of $1.5 \times 10^{6}$ cells/well. Myelin phagocytosis experiments were carried out in 24-well plates with $3 \times 10^{5}$ cells/well. After treatments, all culture media were collected and stored at $-80^{\circ} \mathrm{C}$ until use.

\section{Myelin phagocytosis.}

\subsection{Myelin Isolation and labelling.}

Myelin isolation was performed as previously describe by Larocca et al., 2007 with some modifications (Larocca and Norton 2007). Briefly, two C57BL/6 mice were euthanized by decapitation. Brains and SC were collected, weighted and homogenized in $0.3 \mathrm{M}$ sucrose containing anti-protease (1:25 dilution) to achieve to a final concentration of $5 \% \mathrm{w} / \mathrm{v}$, with a Potter-Elvehjem homogenizer mechanically driven at $800 \mathrm{rpm}$ (5 strokes). The homogenate was added into a tube containing sucrose $0.83 \mathrm{M}$ (carefully through the tube wall) to achieve an equal volume and generate a two-phase discontinuous sucrose gradient. The suspension was centrifuged at $75.000 \mathrm{xg}$ for $30 \mathrm{~min}$ at $4 \stackrel{\text { o }}{ }$. Myelin was isolated from the interface. Ten milliliters of Tris- $\mathrm{HCl} 1 \mathrm{M}$ was added to the myelin extract that was homogenized in Potter at $800 \mathrm{rpm}$. The suspension was brought to a final volume of $114 \mathrm{ml}$ with Tris- $\mathrm{HCl} 1 \mathrm{M}$. After centrifugation the pellet was resuspended in Tris- $\mathrm{HCl} 1 \mathrm{M}$. The procedure was repeated twice times with a first centrifugation at 75.000xg and a second at 
$12.000 x g$ for 15 min at $4 \stackrel{\circ}{ } \mathrm{C}$. The pellet was resuspended in MilliQ water and lyophilized in SPD Speed Vac (Thermo). Lyophilized myelin was weighted and stored at $-20 \stackrel{\circ}{ } \mathrm{C}$ until use (Larocca and Norton 2007).

For myelin labeling, lyophilized myelin was resuspended in MiliQ water to a final concentration of $1 \mathrm{mg} / \mathrm{ml}$ and one volume of 1,1'-Dioctadecyl3,3,3',3'-Tetramethylindocarbocyanine perchlorate (Dil) was added to reach a final concentration of $12 \mu \mathrm{g} / \mathrm{ml}$. After incubating at $37 \stackrel{\circ}{\circ} \mathrm{C}$ for $30 \mathrm{~min}$, the myelin-Dil suspension was centrifuged at $24.000 \times \mathrm{xg}$ for $20 \mathrm{~min}$ and $4 \stackrel{\mathrm{o} C}{ }$. Supernatant was discarded and labeled myelin was further resuspended in sterile PBS to a final concentration of $1 \mathrm{mg} / \mathrm{ml}$ and stored at $-20^{\circ} \mathrm{C}$ (Hendriks et al. 2008, van der Laan et al. 1996).

\subsection{Myelin phagocytosis assay.}

Myelin phagocytosis assay was performed as previously described (van der Laan et al. 1996). BMDM seeded in 24-well plates and stimulated for $24 \mathrm{~h}$, were incubated with Dil-labeled myelin $(25 \mu \mathrm{g} / \mathrm{ml})$ for $1.5 \mathrm{~h}$ at $37^{\circ} \mathrm{C}$. Cells were detached by adding PBS/5 mM EDTA for $15 \mathrm{~min}$ at $37{ }^{\circ} \mathrm{C}$ and cell fluorescence was determined by flow cytometry using a FACScalibur cytometer. Intensity and percentage of positive cells were used to quatify Dil-labeled myelin uptake after treatments (Hendriks et al. 2008).

\section{Nitrite concentration determination}

NO production was measured as nitrite using the Griess reagent (Classen et al. 2009) $24 \mathrm{~h}$ after BMDM stimulation. Briefly, the volume of $100 \mu \mathrm{l}$ culture supernatant was mixed with $100 \mu \mathrm{l} 1 \%$ sulfanilamide $0.1 \% \mathrm{~N}$-(1-naphthyl) ethylenediamine dihydrochloride and $2.5 \% \mathrm{H} 3 \mathrm{PO} 4$. Absorbance was measured at $540 \mathrm{~nm}$ in a multilabel plate reader VICTOR 3 (PerkinElmer). 


\section{Arginase activity assay.}

Arginase activity was measured in as previously described (Classen et al. 2009). Briefly, cells were lysed with $100 \mu \mathrm{l} 0.1 \%$ Triton X-100. After 15 min on a shaker, $100 \mu \mathrm{l} 50 \mathrm{mM}$ Tris- $\mathrm{HCl}$ and $10 \mu \mathrm{l} 100 \mathrm{mM} \mathrm{MnCl} 2$ were added. The enzyme activativation was performed by heating for $7 \mathrm{~min}$ at $56 \stackrel{\circ}{\circ}$. The lysate was incubated with $100 \mu \mathrm{l} 0.5 \mathrm{M} \mathrm{L}$-arginine $(\mathrm{pH} 9.7)$ at $37^{\circ} \mathrm{C}$ for $60 \mathrm{~min}$. Reaction was stopped with $900 \mu \mathrm{l} 96 \% \mathrm{H} 2 \mathrm{SO} / 85 \% \mathrm{H} 3 \mathrm{PO} 4 / \mathrm{H} 2 \mathrm{O} 2$ (1:3:7). Urea concentration was measured by adding $40 \mu \mathrm{l} \alpha$-isonitrosopropiophenone (dissolved in $100 \%$ ethanol) followed by heating at $95 \mathrm{C}$ for $30 \mathrm{~min}$ and read at $540 \mathrm{~nm}$ in a multilabel plate reader VICTOR 3 (PerkinElmer).

\section{Determination of mRNA levels by q-PCR.}

\subsection{RNA extraction}

RNA was extracted using Maxwell ${ }^{\circledR}$ RSC simply RNA Tissue Kit Promega following the manufacturer's instructions. In organotypic cerebellar cultures, RNA was extracted from 4 slices per condition, $24 \mathrm{~h}$ after treatments. In BMDM cultures, RNA extraction was performed $6 \mathrm{~h}$ after treatments.

\subsection{RNA Reverse Transcription}

RNA was reverse-transcribed using i-Script de Bio-Rad following the manufacturer's protocol. RNA was quantified using NanoDrop 1000 Thermo Scientific. Reverse transcription of 500 ng RNA from BMDM and 100 ng RNA from organotypic slices was performed. The reaction was done 5 min at $25 \stackrel{\circ}{\circ}$, $30 \mathrm{~min}$ at $42{ }^{\circ} \mathrm{C}$ and finally samples were heated at 95 으 for 5 min using $\mathrm{MJ}$ Research PTC-150 MiniCycler. 


\section{3. q-PCR}

The cDNA obtained was appropriately diluted to $100 \mathrm{ng} / \mathrm{ml}$ cDNA, and qPCR was performed using i-Taq de Bio-Rad. Master-mix for q-PCR contained 5 $\mu \mathrm{l}$ Syber green, $0.3 \mu \mathrm{l}$ of each forward and reverse primers and $1.9 \mu \mathrm{l}$ nucleasefree water, for a total of $7.5 \mu \mathrm{l}$ of master-mix per reaction well. The primers used can be found in table 5. For amplification Bio-Rad CFX96 Touch $^{\text {TM }}$ RealTime PCR Detection System was used. Further analysis was performed by BioRad CFX Manager ${ }^{\mathrm{TM}}$ 3.1 Software. HPRT was chosen as reference gene. Relative gene expression was assessed using the $\Delta \Delta C$ q Method (Livak and Schmittgen 2001).

\section{Table 5: Primer Sequences}

\begin{tabular}{|c|c|c|c|}
\hline Primers & Sequence $5^{\prime}-3^{\prime}$ & Size & NCBI Ref \\
\hline $\begin{array}{l}\text { HPRT-Fw } \\
\text { HPRT-Rv }\end{array}$ & $\begin{array}{l}\text { GATTAGCGATGATGAACCAGGTT } \\
\text { СCTCCCATCTCCTTCATGACA }\end{array}$ & $150 \mathrm{bp}$ & NM_013556.2 \\
\hline $\begin{array}{l}\text { MBP-Fw } \\
\text { MBP-Rv }\end{array}$ & $\begin{array}{l}\text { CACACACGAGAACTACCCA } \\
\text { GGTGTTCGAGGTGTCACAA }\end{array}$ & $115 b p$ & NM_001025258.2 \\
\hline $\begin{array}{l}\text { PLP-FW } \\
\text { PLP-Rv }\end{array}$ & $\begin{array}{l}\text { AGCAAAGTCAGCCGCAAAAC } \\
\text { CCAGGGAAGCAAAGGGGG }\end{array}$ & $121 b p$ & NM_001290562.1 \\
\hline $\begin{array}{l}\text { CNTF-Fw } \\
\text { CNTF-Rv }\end{array}$ & $\begin{array}{l}\text { TCGTTCAGACCTGACTGCTC } \\
\text { ACTCCAGCGATCAGTGCTTG }\end{array}$ & $115 b p$ & NM_170786.2 \\
\hline $\begin{array}{l}\text { BDNF-Fw } \\
\text { BDNF-Rv }\end{array}$ & $\begin{array}{l}\text { ATCCACTGAGCAAAGCCGAAC } \\
\text { GCCTTCATGCAACCGAAGTAT }\end{array}$ & $198 b p$ & NM_007540.4 \\
\hline $\begin{array}{l}\text { Arg 1-Fw } \\
\text { Arg 1-Rv }\end{array}$ & $\begin{array}{l}\text { TTGCGAGACGTAGACCCTGG } \\
\text { CAAAGCTCAGGTGAATCGGC }\end{array}$ & $160 \mathrm{bp}$ & NM_007482.3 \\
\hline CD206-Fw & CTTCGGGCCTTTGGAATAAT & $149 b p$ & NM_008625.2 \\
\hline
\end{tabular}




\begin{tabular}{|c|c|c|c|}
\hline CD206-Rv & TAGAAGAGCCCTTGGGTTGA & & \\
\hline $\begin{array}{l}\text { NOS-2-Fw } \\
\text { NOS-2-Rv }\end{array}$ & $\begin{array}{l}\text { CTGCATGGACCAGTAATAAGGCAAAC } \\
\text { CAGACAGCTTCTGGTCGATGTCATGA }\end{array}$ & $231 b p$ & NM_001313922.1 \\
\hline $\begin{array}{l}\text { COX-2-Fw } \\
\text { cox-2-Fw }\end{array}$ & $\begin{array}{l}\text { TCATTCACCAGACAGATTGCT } \\
\text { AAGCGTTTGCGGTACTCATT }\end{array}$ & $137 \mathrm{bp}$ & NM_011198.4 \\
\hline $\begin{array}{l}\text { IL-10-Fw } \\
\text { IL-10-Rv }\end{array}$ & $\begin{array}{l}\text { GCTCTTGCACTACCAAAGCC } \\
\text { CTGCTGATCCTCATGCCAGT }\end{array}$ & $112 b p$ & NM_010548.2 \\
\hline $\begin{array}{l}\text { IL-6-Fw } \\
\text { IL-6-Rv }\end{array}$ & $\begin{array}{l}\text { GCTTAATTACACATGTTCTCTGGGAAA } \\
\text { CAAGTGCATCATCGTTGTTCATAC }\end{array}$ & $93 b p$ & NM_031168.2 \\
\hline $\begin{array}{l}\text { IL-1 } \beta-F w \\
\text { IL-1 } \beta-R v\end{array}$ & $\begin{array}{l}\text { CCTGGGCTGTCCTGATGAGAG } \\
\text { TCCACGGGAAAGACACAGGTA }\end{array}$ & $131 b p$ & NM_008361.4 \\
\hline $\begin{array}{l}\text { TNF } \alpha-F w \\
\text { TNF } \alpha-R v\end{array}$ & $\begin{array}{l}\text { CTTCTCATTCCTGCTTGTG } \\
\text { ACTTGGTGGTTTGCTACG }\end{array}$ & $198 \mathrm{bp}$ & NM_013693.3 \\
\hline
\end{tabular}

\section{Analysis of BMDM phenotype by Flow Cytometry.}

After stimulation, BMDM were washed with medium and detached using cold PBS Ca ${ }^{++}$and $\mathrm{Mg}^{++}$free, scraping softly. Cells were centrifuged at 500xg for 5 min at $4 \stackrel{\circ}{ } \mathrm{C}$ and distributed in tubes at a concentration of $5 \times 10^{5}$ cells per tube.

For cellular membrane marker (CD206) staining, cells were centrifuged and pellets were resuspended in $100 \mu \mathrm{l}$ of TruStain FCX anti-mouse CD16/32 diluted 1:100 v/v in DMEM 1\% FBS and incubated for 15 min at $4 \stackrel{\circ}{\circ}$, in order to block non-specific binding to Fc receptors. Cells were washed in DMEM+1\%FBS and centrifuged at $500 \times \mathrm{xg}$ for $5 \mathrm{~min}$, at $4 \stackrel{\circ}{\mathrm{o}}$. Pellets were resuspended in fluorescence-labelled antibody (table 3 ) at the proper dilution and incubated for $1 \mathrm{~h}$ at $4 \stackrel{\circ}{ } \mathrm{C}$ in the darkness. After washing, pellets were fixed in $1 \%$ 
Paraformaldehyde (PFA) for $30 \mathrm{~min}$ at room temperature (RT). Cells were washed and pellets resuspended in PBS.

For intracellular marker (NOS-2) staining, cell pellets were fixed in $1 \%$ PFA 30min at RT prior to staining. Cells were washed in PBS and centrifuged at $500 \mathrm{~g}$ for $5 \mathrm{~min}$, at $4 \stackrel{\circ}{ } \mathrm{C}$. Fc blocking and permeabilization were performed the same time with TruStain FcX anti-mouse CD16/32 diluted 1:100 v/v in cytometry permeabilization buffer (CPB) prepared with PBS, 0.5\% Tween-20 and $10 \% \mathrm{NGS}, 100 \mu \mathrm{l}$ of blocking-permeabilization solution was added and incubated $1 \mathrm{~h}$ at RT. Cells were washed by adding CPB and centrifuged at 500xg for $5 \mathrm{~min}$, at $4 \stackrel{\circ}{ } \mathrm{C}$. Pellets were resuspended in $100 \mu$ primary antibody (table 3 ) proper diluted in CPB and incubated for $2 \mathrm{~h}$ at RT. As secondary antibody control, the primary antibody was replaced by CPB. Cells were washed and pellets were resuspended in $100 \mu \mathrm{l}$ of secondary Alexa-coupled antibody diluted 1:400 v/v in CPB (table 4) and incubated for $1 \mathrm{~h}$ at RT in the darkness. After washing, cells were resuspended in PBS and were analysed using a BD FACScanto (10,000 events per sample).

\section{Stainings}

\subsection{Immunofluorescence staining.}

Cervical-thoracic regions of the SC were fixed in 4\% PFA overnight at $4{ }^{\circ} \mathrm{C}$, cryopreserved by immersion in $30 \%$ sucrose in PBS and fresh-frozen cryostat-cut into $16 \mu \mathrm{m}$-thick sections (Microtome Cryostat Thermoshandon). Immunofluorescence staining (IF) was performed in all sections. After blocking with PBS, 3\% BSA, 10\% NGS, $0.2 \mathrm{M}$ Glycine for $2 \mathrm{~h}$, sections were incubated overnight (ON), at $4{ }^{\circ} \mathrm{C}$ with primary antibodies (table 3). Tissue was washed and incubated with the appropriated secondary Alexa-conjugated antibodies 
(table 4) diluted 1:1000 v/v. Nuclei were stained with DAPI $(0.25 \mu \mathrm{g} / \mathrm{ml})$. Control sections were incubated in the absence of primary antibodies.

Cerebellar organotypic slices were fixed with 4\% PFA for 60 min at RT. Slices were rinsed $10 \mathrm{~min}$ in PBS and further blocked with PBS, 10\% NGS, 0.5\% Triton X-100 for $2 \mathrm{~h}$. Afterwards slices were incubated with primary antibody (table 3) dilution overnight $(\mathrm{ON})$, at 4 으. Slices were washed twice prior to incubation with the appropriate secondary Alexa-conjugated antibody (table 4) diluted 1:1000 v/v in PBS+10\%NGS+0.3\%Triton X-100. Slices were washed twice with PBS for $10 \mathrm{~min}$, and incubated with Dapi for $10 \mathrm{~min}$, washed and mounted with FluoPrep.

\subsection{Oil-Red-O Staining.}

SC longitudinal sections were washed in PBS. ORO stainig was performed, slightly modified, as previously described (Koopman et al. 2001). Brieffly, $0.5 \mathrm{mg}$ ORO was dissolved in $100 \mathrm{ml}$ of $60 \%$ triethyl-phospate, creating a stock solution. To stain SC sections a working solution (6 stock solution : 4 deionized water) was used. Sections were rinsed in PBS and then incubated $1 \mathrm{~h}$ at RT in de ORO working solution. Afterwards sections were rinsed in deionized water three times and 10 min in tap water. Sections were flat embedded in $10 \%$ glycerol containing Dapi.

10. Determination of protein levels by Western Blot.

\subsection{Protein collection}

$\mathrm{SC}$ from EAE mice were homogenized in in $50 \mathrm{mM}$ Tris $-\mathrm{HCl}$ and $1 \mathrm{mM}$ EDTA, pH 7.4 containing RIPA with antiprotease and antiphosphatases cocktail at a $10 \% \mathrm{w} / \mathrm{v}$ proportion in a glass-teflon Potter-Elvehjeim homogenizer 
mechanically with 20 strokes at $800 \mathrm{rpm}$ as previously described (Pifarre et al. 2011).

Cerebellar slices, 4 per condition, were homogenized in $300 \mu \mathrm{l}$ of the previous mentioned homogenizing solution, by pipetting up and down 10 times. Homogenates were centrifuged at $700 \times x$ and supernatants were aliquot and frozen at -80 o $\mathrm{C}$ until use.

Protein levels in all samples were measured by Pierce BCA Protein Assay Kit (Thermo Scientific), following manufacturer's instructions.

\subsection{Western Blot assay}

Samples from SC or organotypic cultures homogenates, containing $20 \mu \mathrm{g}$ and $30 \mu \mathrm{g}$ of protein respectively, were subjected to Novex NuPAGE ${ }^{\circledR} 4-12 \%$ Bis-Tris Midi Gels Invitrogen electrophoresis carried out with the XCell SureLock ${ }^{\mathrm{TM}}$ Electrophoresis Cell. Transference was carried out using iBlot ${ }^{\mathrm{TM}} \mathrm{Gel}$ Transfer Device with the iBLot ${ }^{\circledast}$ Gel Transfer Stacks PVDF membrane, following manufacturer's instructions, during 7 minutes. The protein transference was confirmed by Ponceau staining. To avoid non-specific binding, membranes were blocked with $5 \% \mathrm{w} / \mathrm{v}$ powder milk in PBS ON at $4 \stackrel{\circ}{\circ}$. Membranes were incubated $\mathrm{ON}$ at 4 으 with the appropriated primary antibody (table 3). After washingwith PBS, 0,05\% Tween-20, membranes were incubated for 1 hour with secondary HRP-conjugated antibodies (table 4). Detection was performed with Millipore Luminata Forte Western HRP substrate. Results were analyzed with QuantityOne software. 


\section{Cytokine Detection}

Mouse TNF $\alpha$, IL-1 $\beta$ and IL-10 cytokines were detected using Luminex technology. Briefly, MILLIPLEX ${ }^{\circledR}$ MAP Mouse Cytokine/Chemokine Magnetic 96well plate Bead Panel Millipore (MCYTOMAG-70K) assay was used, following the manufacturer's instructions and with program Milliplex Analyte version 5.1.0.0. 
성 상 숭

RESULTS 


\section{RESULTS}

\section{Sildenafil administration to animals with EAE ameliorates symptoms and}

restores myelin protein levels.

Using MOG-induced EAE as a model of MS, the laboratory were this thesis was developed has previously shown that daily treatment with sildenafil at peak disease rapidly ameliorates clinical symptoms and neuropathology (Pifarre et al. 2011). An increase in LFB staining of myelin after 8 days of treatment suggested that sildenafil was promoting remyelination. Furthermore, administration of sildenafil from the onset of EAE symptoms when the immune response prevails, prevented disease progression (Pifarre et al. 2011, Pifarre et al. 2014). Ultrastructural analysis of spinal cord evidenced that sildenafil treatment was preserving axons and myelin and increasing the number of remyelinating axons. In order to confirm the remyelinating potential of sildenafil in EAE we have analyzed the effect of the drug on myelin proteins levels in the spinal cord of EAE animals treated from peak disease o and during the chronic phase of the disease. As shown in Fig 1A, C57BL/6 mice immunized with $\mathrm{MOG}_{35-55}$ developed clinical symptoms of $\mathrm{EAE}$ around 8 days postimmunization (dpi). Symptoms rapidly increased up to day 16 (clinical score around 2.5; moderate hind limb paraparesis) and slightly increased thereafter until the last day examined (30 dpi). Treatments with vehicle (water) or sildenafil $(10 \mathrm{mg} / \mathrm{kg})$ started at $16 \mathrm{dpi}$ (black arrow). A rapid amelioration was observed in the sildenafil-treated group $(n=17)$ compared with the vehicletreated group $(n=11)$. The clinical score stabilized close to 1 (loss of tail tonus) after 5 days of treatment and no further improvement was observed even when the treatment was extended for 10 more days (Fig 1A). Immune-staining for the major myelin protein MBP was performed in SC sections at the end of the treatment. As can be observed in the representative images shown in Fig 
1B, MBP staining was stronger in sildenafil-treated mice. Quantification of staining intensity showed than sildenafil treatment significantly increased MBP immune-reactivity respect to the vehicle-treated group.
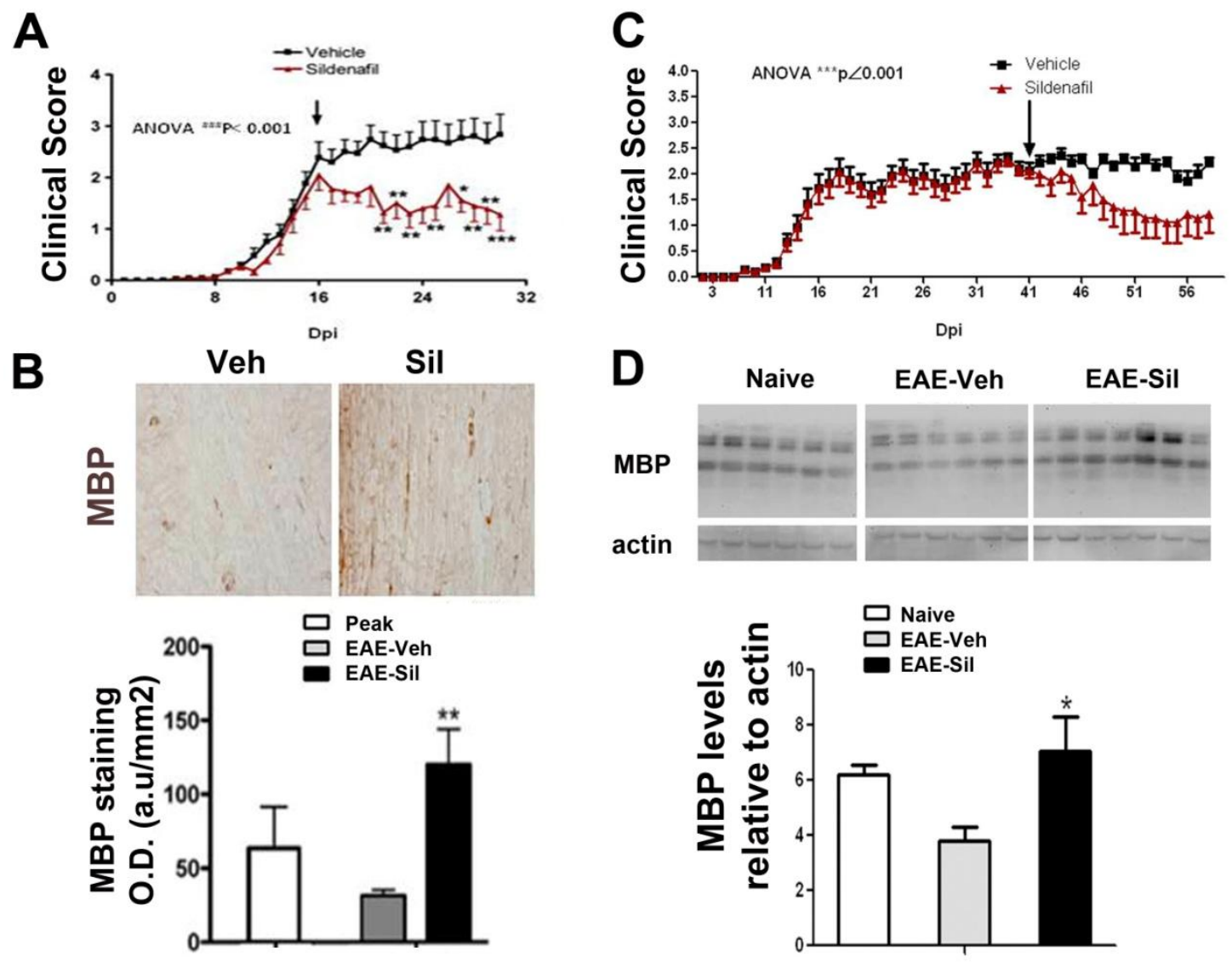

Figure 1: Sildenafil administration to animals with EAE ameliorates symptoms and restores myelin protein levels. Clinical evolution of MOG-induced EAE in mice treated with vehicle (VH; water) or sildenafil (Sil; $10 \mathrm{mg} / \mathrm{kg}$ ) daily starting at peak disease (16 dpi, arrow in A) or during the chronic phase (41 dpi, arrow in C). Sildenafil significantly ameliorates EAE severity with both treatments. Values are means \pm SEM $(n=11 \mathrm{Vh}$ and $17 \mathrm{Sil}$, acute phase; $8 \mathrm{Vh}-8 \mathrm{Sil}$, chronic phase). Two-way ANOVA reveals statistically significant differences between vehicleand sildenafil-treated animals with both treatments protocols $(* * * p<0.001)$; Bonferroni's post hoc analysis reveals significant differences after 5 days of treatment (dot) from peak disease ( $\left.{ }^{*} p<0.05 ;{ }^{* *} p<0.01 ;{ }^{* *} p<0.001\right)$. (B) MBP immune-staining in the SC of EAE mice treated with sildenafil from peak disease is significantly increased after 15 dot. Values are means \pm SEM ( $n=3-5$ mice per group). Student's t-Test ${ }^{* *} p<0.01$ vs vehicle-treated; (D) MBP protein levels analyzed by WB in SC of EAE mice treated during the chronic phase. In EAE vehicle-treated animals, MBP levels decrease respect to naïve group and recover after sildenafil treatment. Values are means $\pm \operatorname{SEM}(n=6)$, one-way ANOVA followed by Bonferroni's post-hoc $\left({ }^{*} p<0.05\right)$. 
In a parallel experiment (Fig $1 \mathrm{C}$ ), treatment was initiated during the chronic phase of the disease ( $41 \mathrm{dpi}$, arrow). Ten days after the initiation of sildenafil-treatment the clinical score was significantly decreased from values around 2 to values close to 1 , and stabilized at that level until the animals were sacrificed (58 dpi). WB analysis of MBP protein in SC homogenates (Fig 1D) showed that levels in EAE vehicle-treated animals were $40 \%$ lower than in naïve animals and that sildenafil treatment restored MBP levels. Taken together these results show that sildenafil stimulates myelin protein recovery when administered both in the acute phase of the disease and when the disease has become chronic.

\section{Sildenafil promotes remyelination in LPC-demyelinated mouse cerebellar} organotypic cultures.

To investigate if the remyelinating effect of sildenafil observed in EAE mice involved effects only in CNS cells or also required peripheral immuneregulatory actions, we used the in vitro model of mouse cerebellar organotypic cultures (ORG) demyelinated with LPC (Zhang H. et al. 2011). Cultures were established from cerebella of 7-day-old C57BL/6 mice as described in Methods (section 3.1). After 7 days in vitro (DIV), cerebellar slices were exposed to LPC $(0.5 \mathrm{mg} / \mathrm{ml})$ for $14-17 \mathrm{~h}$, a treatment that causes a dramatic demyelination without axonal or cell death (Birgbauer et al. 2004). Twenty-four hours after removing LPC, cultures were treated with four doses of sildenafil $(1 \mu \mathrm{M})$ alone or in combination with the cGMP-increasing agents BAY 41-2272 (BAY41; 3 $\mu \mathrm{M})$, a NO-GC activator, or the glutamate receptor agonist NMDA (30 $\mu \mathrm{M})$, as indicated in Methods (section 3.1). At 19 DIV, cerebellar slices were harvested and double immune fluorescence-stained for neurofilament (NF200, red) and myelin (MBP, green) and analyzed by confocal microscopy and Image-J 
software. Quantification of the area stained for MBP relative to the area stained for NF200 gave a remyelination index (RI). As shown in Fig 2A, LPCtreated slices show a significant reduction of MBP staining compared to control slices, whereas in slices exposed to cGMP-increasing compounds the amount of MBP surrounding neurofilaments notably increased. Quantification of the RI shows that the remyelination induced by sildenafil alone is similar to that attained in combination with BAY41 (BAY41+Sil) or NMDA (NMDA+Sil) (Fig 2B). Remyelination by BAY41 alone was $40 \%$ lower than that induced by BAY41+Sil (not shown). To confirm the remyelinating effect of cGMP-increasing treatments in cerebellar slices, we analyzed by WB the levels of MBP, a major myelin protein, and of 2',3'-cyclic-nucleotide 3'-phosphodiesterase (CNPase), a minor CNS myelin-protein that is only expressed in CNS oligodendrocytes. Results show that BAY41+Sil treatment significantly increased both MBP and CNPase (Fig 2C) in LPC-demyelinated cultures. We further analyzed mRNA expression of MBP by $\mathrm{qPCR}$ and showed that BAY41+Sil tendency to induced MBP gene expression (Fig 2D).

The presence of contactin-associated protein (Caspr) clusters in the paranodes delimiting myelin sheaths correlates with a proper remyelination of the axons (Fancy et al. 2011, Meffre et al. 2015). To investigate the remyelination status in sildenafil-treated cerebellar slices, double immunestaining for Caspr and NF200 was performed. As shown in Fig 2E, Caspr clusters associated with axons were drastically reduced in LPC-demyelinated cultures. Treatment with BAY41+Sil largely restored Caspr staining levels and distribution (Fig 2E,F). 


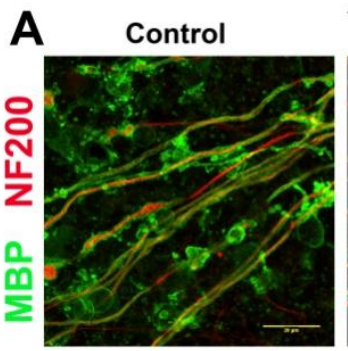

B

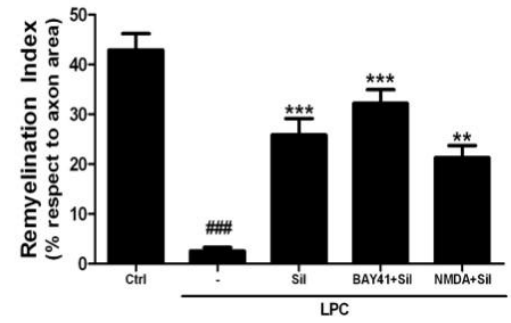

E

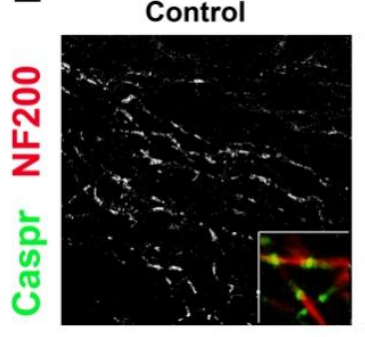

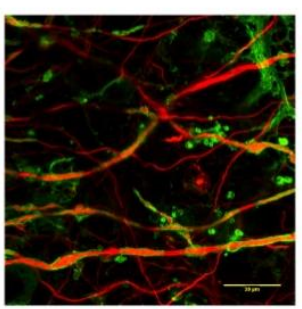

C
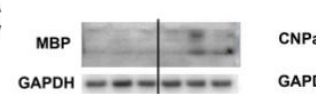

GAPDH ㅁPC - $L P C+B A Y 41+$ Sil

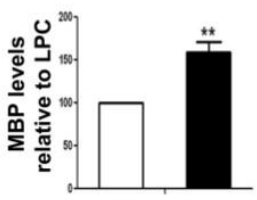

LPC
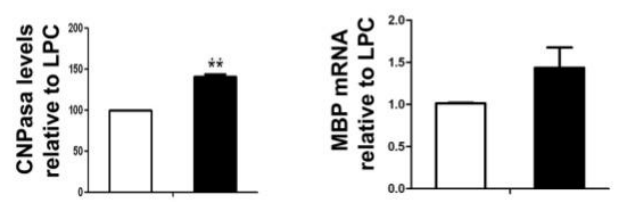

D

므 LPC

- LPC+BAY41+Sil

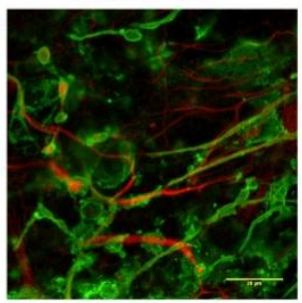

$\mathbf{F}$

BAY41+Sil
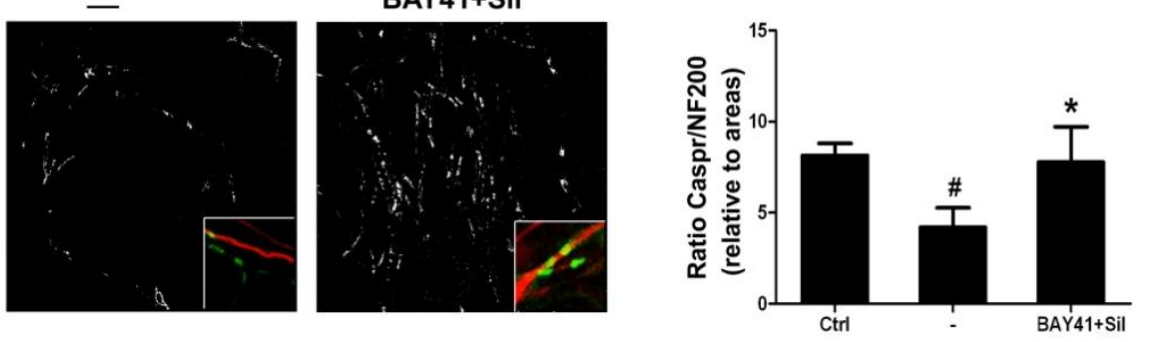

Figure 2: Treatments that increase cGMP promote remyelination in LPC-demyelinated organotypic cultures. (A) Representative images of MBP (green) and NF200 (red) staining in control or LPC $(0.5 \mathrm{mg} / \mathrm{ml})$-demyelinated mouse organotypic cerebellar cultures treated or not for 10 days with sildenafil $(1 \mu \mathrm{M})$ alone or in combination with BAY41 (3 $\mu \mathrm{M})$ or NMDA

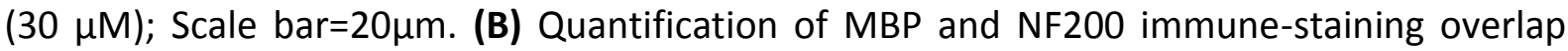
(remyelination index) reveals a drastic reduction in LPC-demyelinated cultures and recovery to almost control levels in cultures treated with sildenafil alone or in combination with cGMP synthesis stimuli. Values are means $\pm S E M$ of three independent experiments. One-way ANOVA followed by Bonferroni's post-hoc analysis reveals statistically significant differences between control and LPC-demyelinated slices $\left({ }^{\# \#} \mathrm{p}<0.001\right)$ and between LPC-demyelinated slices treated or not with cGMP-increasing compounds $\left(* * p<0.01,{ }^{* * *} p<0.001\right)$. (C) Representative WBs and quantification of $\operatorname{MBP}(n=3)$ and CNPase $(n=2)$ in LPC-demyelinated slices treated for 10 days with vehicle (LPC) or BAY41+Sil. Protein levels were normalized to GAPDH. The treatment significantly increased the amount of MBP and CNPase protein in LPC-demyelinated cultures; (D) MBP mRNA levels, analyzed by qPCR, showed a tendency to increase in LPC-demyelinated slices $24 \mathrm{~h}$ after the first dose (D1) of BAY41+Sil. Values are means $\pm S E M$ of three independent experiments. Data is presented relative to LPC. Student's t-test shows no significant differences in BAY41+Sil-treated LPC-demyelinated cultures respect to untreated. (E) Colocalization analysis of paranodal protein Caspr (green) and NF200 (red) immune-staining. Representative images of Caspr mascara (white); small panels show Caspr clusters over axons. (F) Quantification of area immune-stained for Caspr relative to area stained for NF-200 shows a decrease in LPC-demyelinated slices and restoration to control levels after BAY41+Sil treatment. Values are means $\pm S D(n=5-6$ images per condition) in a representative experiment that was replicated with similar results. One-way ANOVA 
followed by Bonferroni's post-hoc analysis reveals statistically significant differences between vehicle- and BAY41+sildenafil-treated slices ( ${ }^{*} p<0.05$ vs LPC; ${ }^{\#}<<0.05$ vs control).

\section{Mechanisms implicated in the remyelinating effect of sildenafil}

\subsection{Involvement of the NO-cGMP-PKG pathway in the remyelinating effect of sildenafil in LPC-demyelinated cerebellar cultures}

The observation that treatment of LPC-demyelinated cerebellar slices with sildenafil alone produced a similar remyelinating effect than its combination with BAY41 or NMDA, both of which increase cGMP production via NO-GC, suggested that activation of this enzyme was involved in the sildenafil effect. That this was in fact the case was demonstrated by the observation that sildenafil-induced remyelination was prevented in the presence of the NO-GC inhibitor ODQ (10 $\mu \mathrm{M}$; Fig 3A). Moreover, ODQ treatment decreased the amount of myelin associated with axons in control cultures, suggesting that NO-GC activity may be also implicated in the myelination process that occurs in the immature cerebellar slices during culture (Fig 3A). To investigate if induction of NOS-2 in LPC-demyelinated slices was responsible for the generation of the NO that stimulates NO-GC activity we first examined the effect of L-NNA, a predominant NOS-2 inhibitor, in sildenafilinduced remyelination. As shown in Fig 3B, L-NNA prevented the sildenafil effect. To further examine if NOS-2 was actually induced in the LPCdemyelinated slices we performed immune-fluorescence staining for NOS-2 (green) in cerebellar cultures exposed for $24 \mathrm{~h}$ to LPC, or to LPS $(1 \mu \mathrm{g} / \mathrm{ml})$ as a positive control. Fig 3 C shows that while only a few cells were stained for NOS2 in control cultures, numerous cells were NOS-2+ in cultures exposed to LPC or LPS. 
Cyclic GMP-dependent kinase (PKG) is the main target of cGMP. To examine if PKG was involved in sildenafil-induced remyelination we examined this effect in the presence or absence of the PKG inhibitor Rp-8pCPTcGMP (10 $\mu \mathrm{M}$ ). Results showed that the PKG inhibitor prevented the sildenafil effect (Fig 3D) implicating the kinase in the NO-cGMP signaling cascade.

A

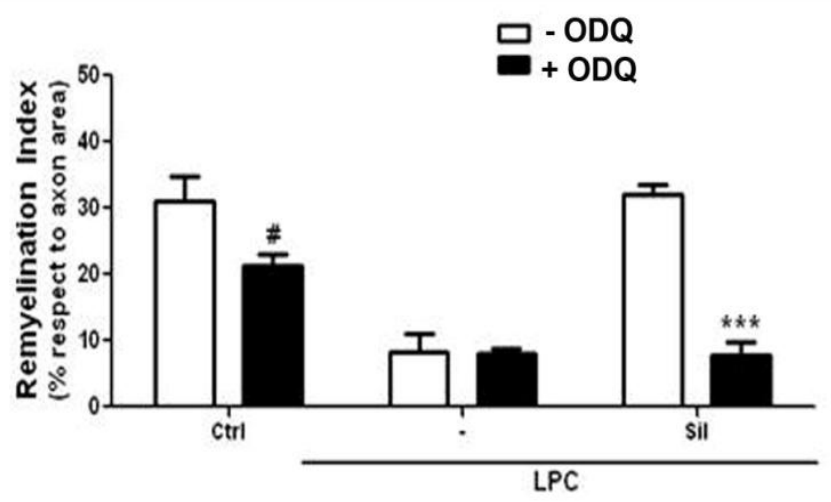

B

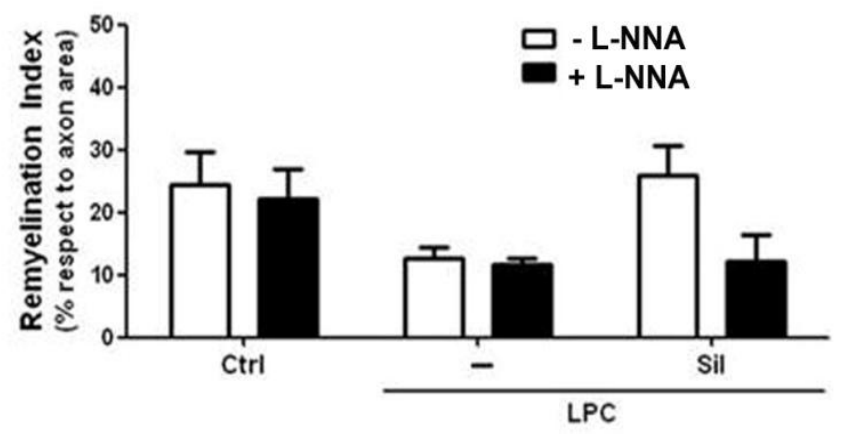

Ctrl

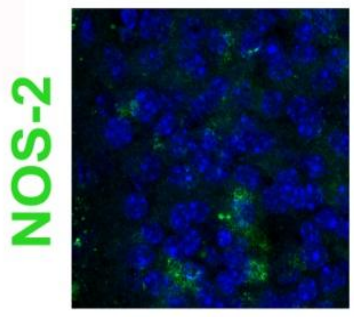

LPC
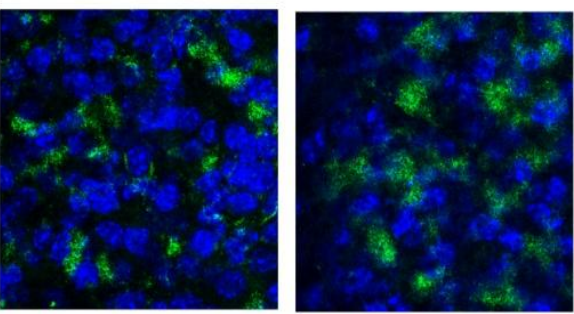

D

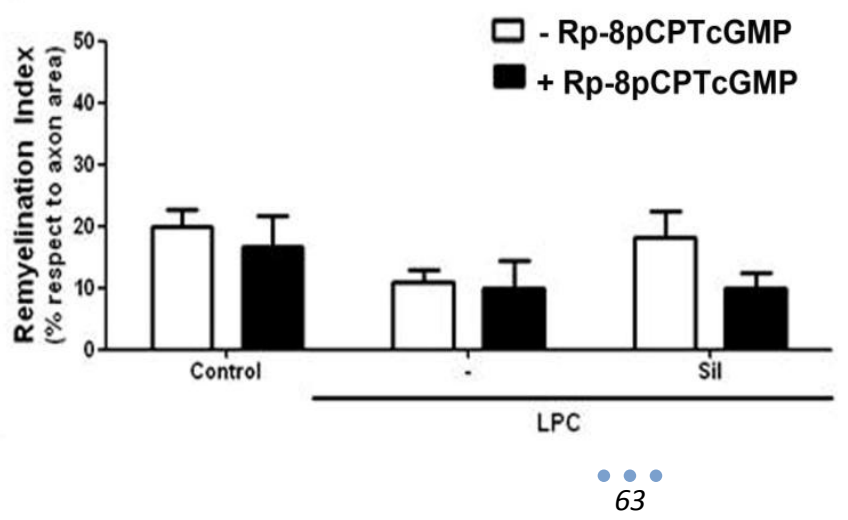

Figure 3: The remyelinating effect of sildenafil in LPCdemyelinated cultures is prevented by inhibitors of NOGC, NOS-2 and PKG activities. The remyelination index preand post-LPC was quantified in cerebellar slices treated 10 DIV post-LPC with sildenafil $(1 \mu \mathrm{M})$ in the presence of: (A) NO-GC inhibitor ODQ $(10 \mu \mathrm{M}), \mathrm{n}=2$; (B) NOS-2 inhibitor L-NNA (100 $\mu M), \quad n=3$. Values are means $\pm S E M$. Two-way ANOVA followed by Bonferroni's posthoc analysis reveals statistically significant differences in the absence or presence of ODQ in controls $\left({ }^{\#} p<0.05\right)$ and in sildenafiltreated $\left({ }^{* * *} \mathrm{P}<0.001\right)$ slices. (C) NOS-2 immune-staining (green) reveals similar levels of induction in LPC-demyelinated slices and in 24h LPS-treated slices. Cell nuclei stained with DAPI (blue). (D) PKG inhibitor Rp-8pCPT-cGMP (10 $\mu \mathrm{M})$. Representative figure replicated with similar results. Values are means $\pm S D(n=5-6$ images per condition). 


\subsection{Increasing CGMP promotes oligodendrocyte differentiation in the spinal}

cord of EAE mice and in LPC-demyelinated cerebellar cultures

Previous results have shown that treatment with sildenafil to MOGimmunized mice at the initiation of EAE symptoms prevents disease progression, preserves axons and myelin and protects immature and mature OLs (Pifarre et al. 2014). We have now examined if sildenafil affects OL maturation in the spinal cord of EAE animals treated with sildenafil for 15 days at peak disease by immune-staining for transcription factors involved in early (Nkx2.2) and late stages of OL differentiation (Olig2) and for the mature OL marker MBP. As shown in Fig 4A, staining intensity of Nkx2.2+-cells (green) is increased after sildenafil treatment. Quantification of bright Nkx2.2 cells (high expression) confirms a significant increase respect to vehicle-treated animals (Fig 4A). Double immune-staining for olig2 (red) and MBP (green) shows that after 15 days of treatment from peak disease olig2+/MBP+-cells (yellow arrows) and olig2-/MBP+-cells (green arrows) significantly increase in both vehicle-treated and sildenafil-treated animals (Fig 4B). In both cases the number of positive cells was higher in sildenafil-treated animal compared to vehicle-treated animals. The percentage of Olig2-/MBP+ cells respect to total $\mathrm{MBP}+$ cells was significantly increased in thoracic SC sections after 15 days of sildenafil treatment respect to vehicle (Fig 4B, right panel). A significant increase in the number olig2-/MBP+cells relative to total MBP+cells was also observed in LPC-demyelinated cerebellar cultures after 10 days of treatment with BAY41+Sil or NMDA+Sil (Fig 4C). Taken together these results indicate that stimulation of OL maturation may be an important mechanism contributing to the remyelinating effect of sildeanfil. 


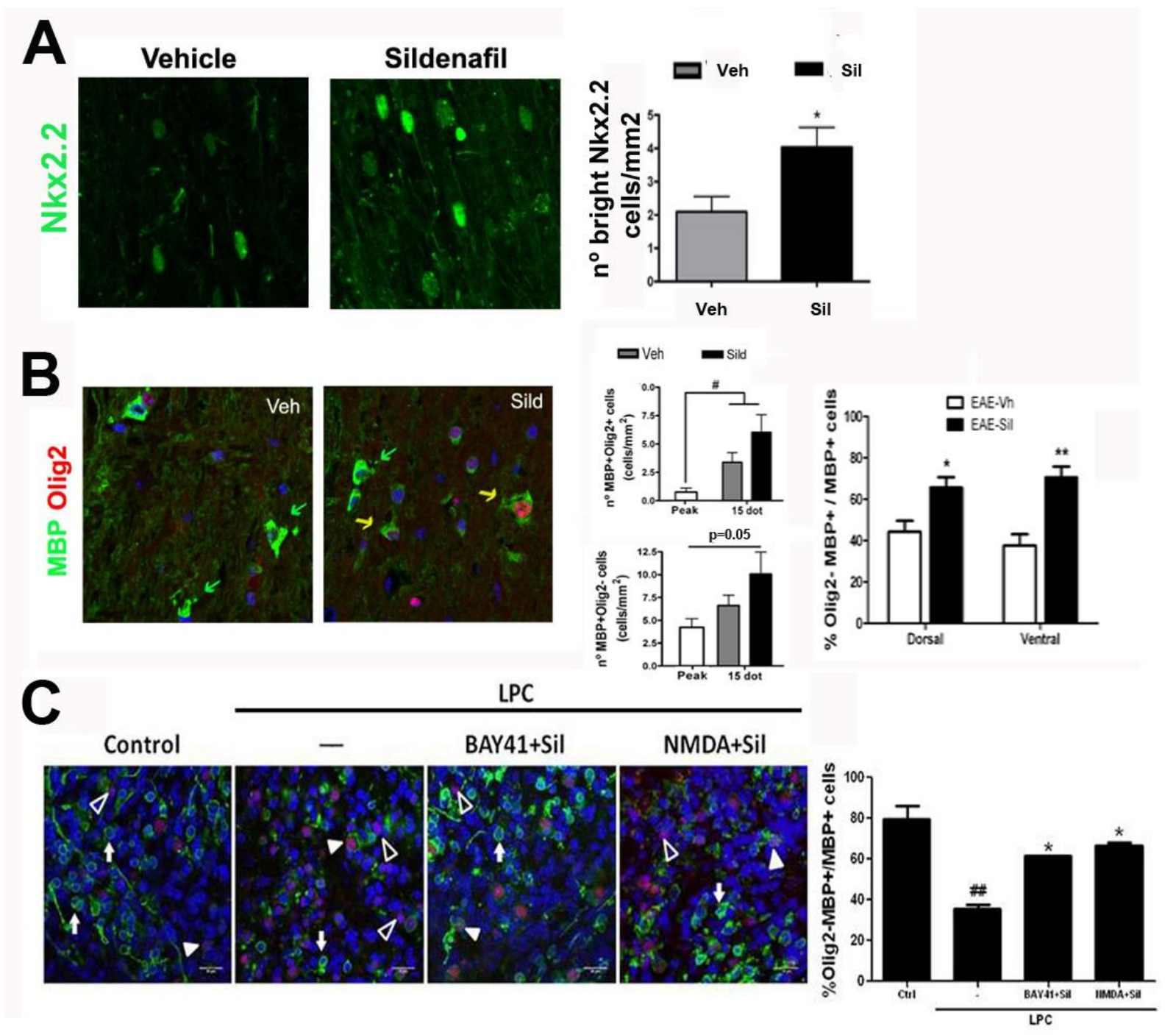

Figure 4: Increasing CGMP promotes oligodendrocyte differentiation in the spinal cord of EAE mice and in LPC-demyelinated cerebellar cultures. (A) Representative images of

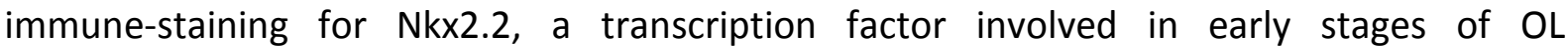
differentiation, in the SC of EAE mice treated with vehicle or sildenafil for 15 days starting at peak disease. Quantification of bright Nkx2.2 cells (high expression) shows a significant increase after sildenafil treatment. Values are mean \pm SEM ( $n=3-6$ mice per group) analyzed by Student's t-test $\left({ }^{*} \mathrm{p}<0.05\right)$; (B) Immune-staining for MBP (green) and Olig2 (red), a transcription factor expressed by differentiating oligodendrocyte lineage cells, images taken at 63X (left panel). Quantification of the number of MPB+/Olig2+ (yellow arrow) and $\mathrm{MPB}+/ O$ lig2- (green arrow) is shown in the center panel. The percentage of Olig2-/MBP+ cells respect to total $\mathrm{MBP}+$ cells in thoracic SC sections is shown in the right panel. Values are mean \pm SEM ( $n=3-5$ mice per group) and were analyzed by two-way ANOVA followed by Bonferroni's post-hoc test $\left({ }^{*} p<0.05,{ }^{* *} p<0.01\right)$. (C) MBP and Olig2 staining in LPCdemyelinated cerebellar cultures treated or not with Sil $(1 \mu \mathrm{M})+\mathrm{BAY} 41(3 \mu \mathrm{M})$ or NMDA (30 $\mu \mathrm{M})$. Open arrow heads: Olig2+/MBP- (immature OLs; open arrow heads); Olig2+/MBP+ (early mature OLs; arrow heads); Olig2-/MBP+ (mature myelinating OLs; arrow). Scale bar= 
$20 \mu \mathrm{m}$. The percentage of Olig2-/MBP+ respect to total MBP+ cells is significantly increased by cGMP-increasing treatments (right graph). Values are mean $\pm S E M$ of two independent experiments, analyzed by one-way ANOVA followed by Bonferroni's post hoc $\left({ }^{*} p<0.05\right.$ respect to $L P C ;{ }^{\#} \mathrm{p}<0.01$ respect to control).

\subsection{Sildenafil increases CNTF expression in spinal cord of EAE mice and in cerebellar organotypic cultures.}

Increased expression of trophic factors is associated with neuroprotective effects, oligodendrocyte support and proliferation and axon remyelination (De Santi et al. 2009, Weishaupt et al. 2012). CNTF has a recognized influence on OL differentation (Stankoff et al. 2002). Moreover, it has been shown that this growth factor acts as a quemoatractant controling $\mathrm{OL}$ progenitor migration during (Vernerey et al. 2013). Interestingly, recent in vitro studies demonstrated that the NO-cGMP-protein kinase G pathway upregulates CNTF expression in astrocytes and that astrocyte-derived CNTF enhances oligodendrocyte (OL) differentiation (Paintlia et al. 2013). In this work, using double immune-staining for CNTF and the astrocyte protein GFAP, we have observed a strong CNTF-staining in highly reactive astrocytes in the spinal cord of EAE mice (Fig 5A). We further show that treatment with sildenafil for 15 days at peak disease strongly enhances CNTF immune-staining compared to vehicle-treated animals (Fig 5B). In agreement with these results, we have also observed a significant increase in CNTF mRNA expression in LPCdemyelinated cerebellar slices $24 \mathrm{~h}$ after the first dose (D1) of Sil $(1 \mu \mathrm{M})+$ BAY41 $(3 \mu \mathrm{M})$, but not after the third dose, suggesting that CNTF induction may be is an early event contributing to the remyelinating effect of cGMP-increasing compounds (Fig 5C). 

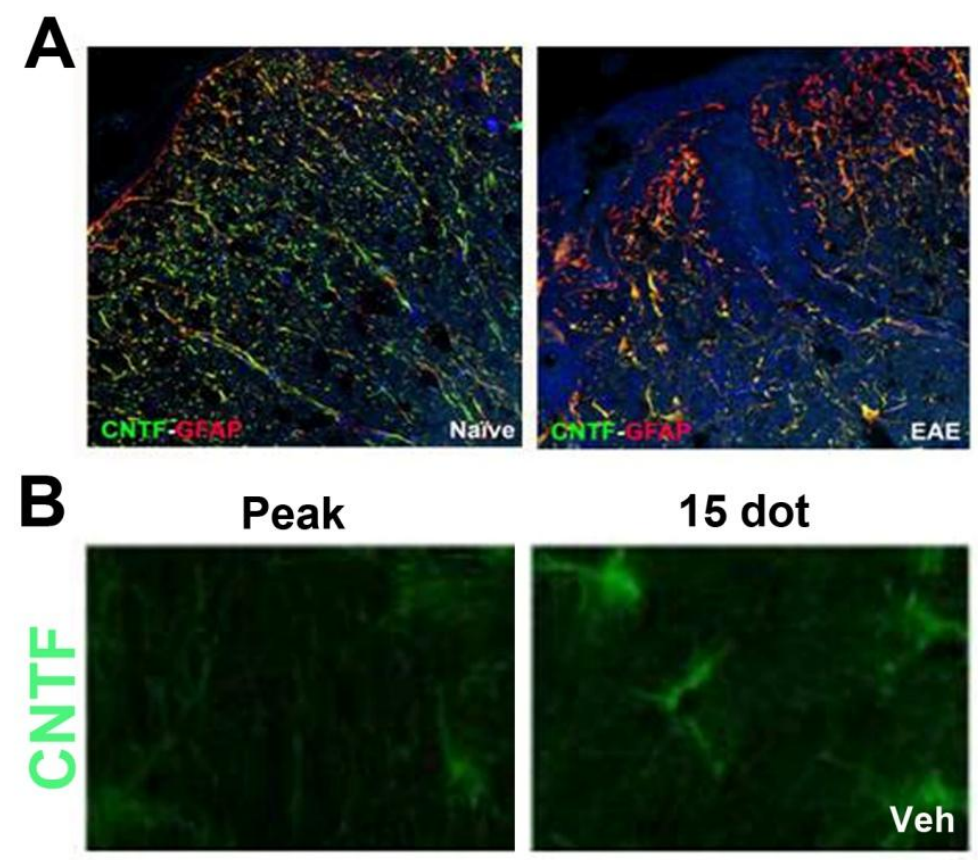

15 dot
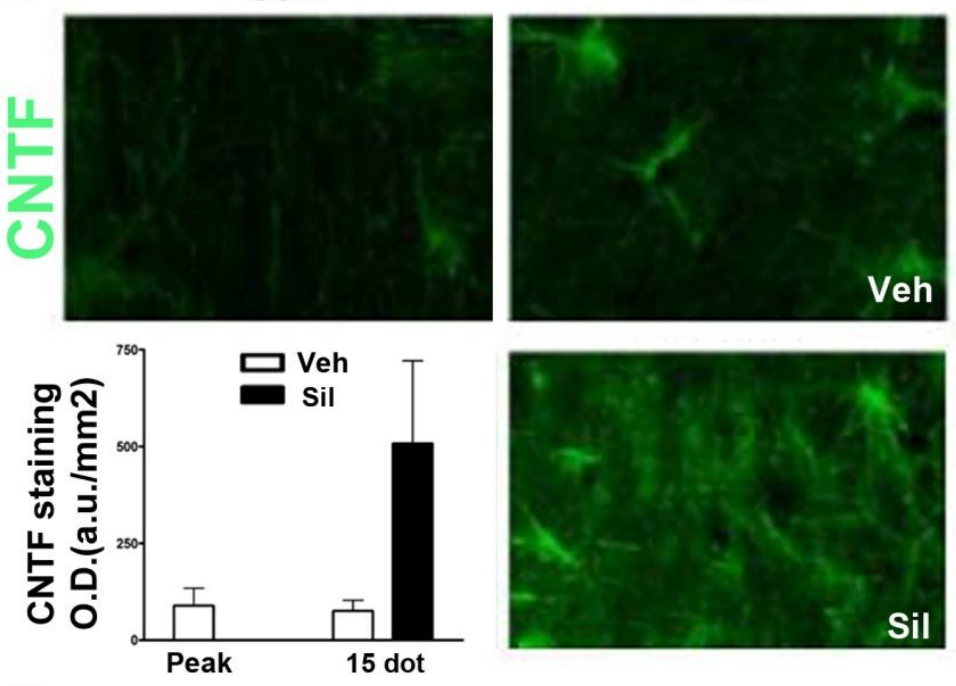

C

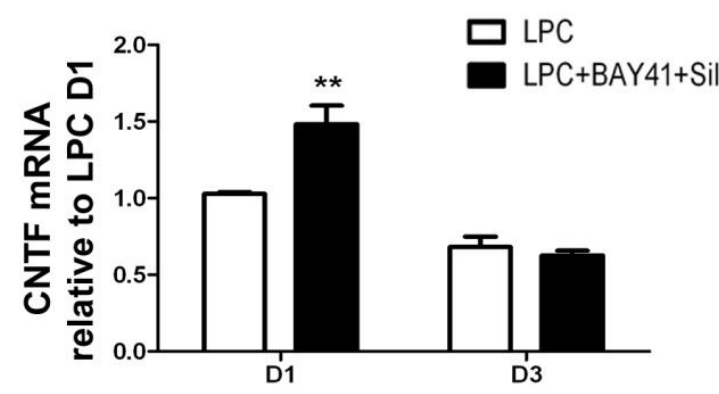

Figure 5: Sildenafil treatment increases CNTF expression in the spinal cord of EAE mice and in LPC-demyelinated cerebellar cultures. (A) Colocalization of GFAP (red) and CNTF (green) immune-staining in coronal sections of cervical spinal cord from naïve and EAE animals showing CNTF increased expression in reactive astrocytes; (B) Treatment with sildenafil for 15 days at peak EAE further increases CTNF levels when compared with vehicle-treated EAE animals Values are mean \pm SEM ( $n=5$ per group); $(C)$ CNTF mRNA levels assessed by qPCR in LPC-demyelinated cerebellar cultures $24 \mathrm{~h}$ after the first (D1) and third (D3) doses of BAY41 $(3 \mu \mathrm{M})+$ Sil $(1 \mu \mathrm{M})$, showing a significant increase of CNTF mRNA expression after the first dose. Values are mean $\pm S E M$ of three independent experiments. Data shown is relative to LPC. Two-way ANOVA followed by Bonferroni's post-hoc analysis reveals statistically significant differences respect to $\operatorname{LPC}(* * p<0.01)$. 


\subsection{Treatments that increase cGMP induce changes in the inflammatory}

microglial phenotype in LPC-demyelinated cerebellar cultures.

It has been reported that in the cuprizone-induced demyelinization mouse model that treatment with sildenafil reduces expression of the inflammatory cytokines IL-1 $\beta$ and TNF $\alpha$ and increases the expression of the anti-inflammatory cytokine IL-10 in cerebella (Nunes et al. 2015). Additionally it has been shown that treatment with sildenafil to EAE mice for 7 days starting at disease onset induced a decrease in the release of the pro-inflammatory cytokines IL-2, IFN $\gamma$ and TNF $\alpha$ in splenocytes. Furthermore, RNA microarray analysis of spinal cord and immune-staining revealed that sildenafil upregulates YM-1 (Pifarré et al. 2014), a marker of the alternative macrophage/microglial M2 phenotype that has neuroprotective and regenerative properties. To gain insight into the possible implication of a microglial phenotype change in the remyelinating effect of cGMP-increasing compounds, we have examined by qPCR mRNA expression of M1 (NOS-2 and COX-2) and M2 phenotype markers (Arg-1 and CD206) and of pro-inflammatory (IL-1 $\beta, T N F \alpha$, IL-6) and anti-inflammatory (IL-10) cytokines in LPS-demyelinated cerebellar slices $24 \mathrm{~h}$ after the first and third doses of Sil $(1 \mu \mathrm{M})+$ BAY41 $(3 \mu \mathrm{M})$. Results showed that mRNA expression of phenotype marker molecules in LPCdemyelinated slices do not significantly change between dose one (D1) and three (D3) of vehicle (Fig 6). In BAY41+Sil-treated slices there was a tendency to increase in Arg1 and COX-2 mRNA, but not in CD206 or NOS-2 mRNA after D1 and no change was observed after D3, except for a tendency to decrease in NOS-2 expression (Fig 6). 

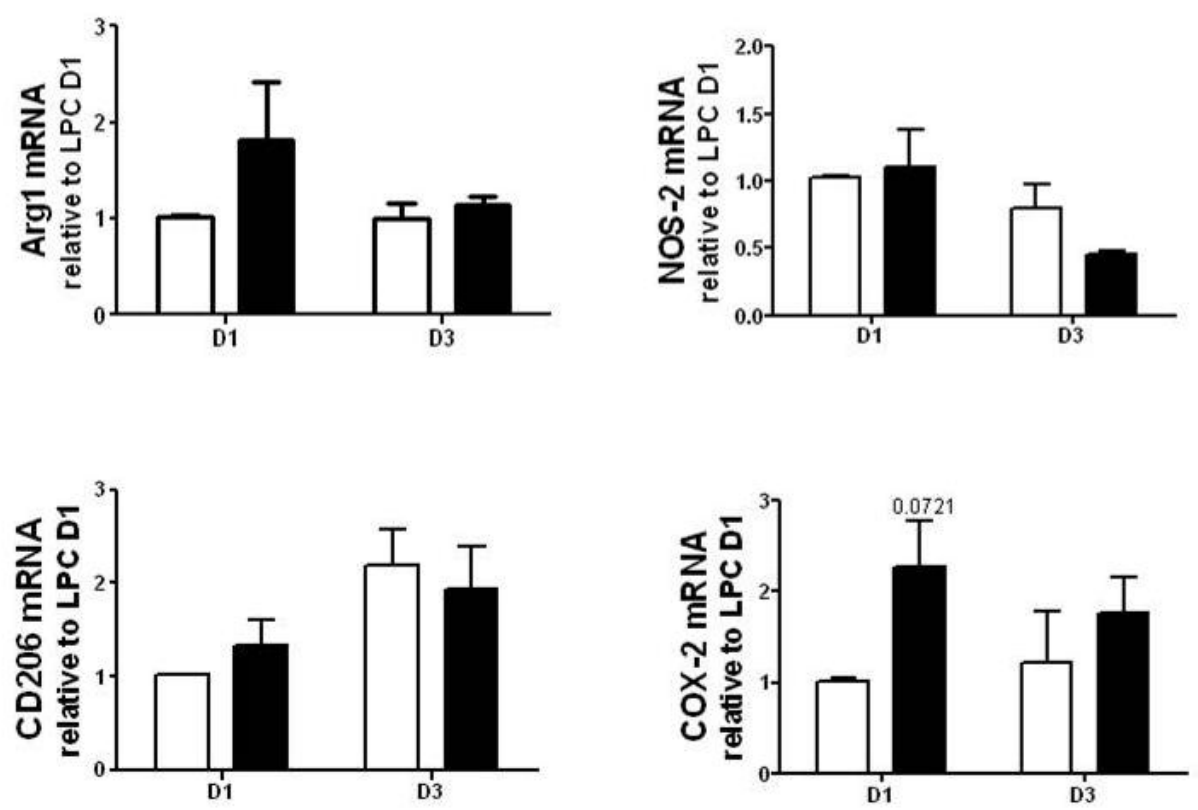

Figure 6: Effect of sildenafil treatment on microglia inflammatory phenotype markers in LPC-demyelinated cerebellar cultures. mRNA levels of M1 (NOS-2 and COX-2) and M2 (Arg-1 and CD206) phenotypic markers determined by qPCR in LPC-demyelinated slices treated or not with BAY41 $(3 \mu \mathrm{M})+\operatorname{Sil}(1 \mu \mathrm{M})$. mRNA was collected $24 \mathrm{~h}$ after first (D1) and third (D3) dose. Values are mean fold change \pm SEM of three independent experiments. Two-way ANOVA followed by Bonferroni's post-hoc analysis.

Regarding cytokines (Fig 7), again no change was observed in any of the cytokines from D1 to D3 in vehicle-treated slices. BAY41+Sil treatment induced a significant increase in IL-10 and IL-6 after D1, the larger increase corresponding to IL-6 (2-fold). After D3, no significant changes were observed in any of the cytokines, although a tendency to decrease was apparent in IL-1 $\beta$, TNF $\alpha$ and IL-10. Taken together these results suggest that a M2-like phenotype is induced after the first dose of cGMP stimuli (increases in Arg1 and IL-10) that also shows expression of IL-6 and COX-2. 


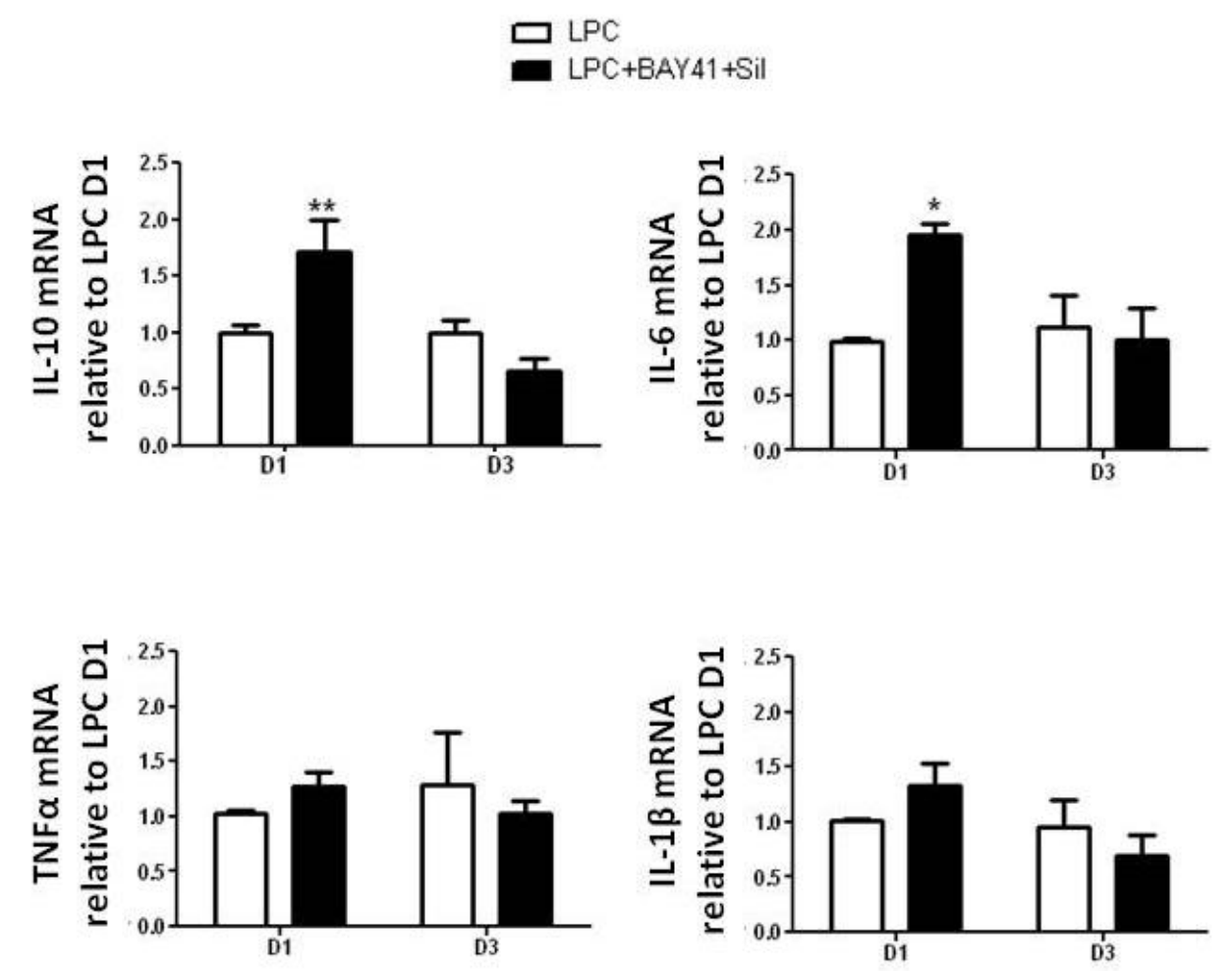

Figure 7: Sildenafil treatment induces changes in cytokine expression in LPC-demyelinated cerebellar cultures. mRNA levels of inflammatory cytokines assessed by qPCR in LPCdemyelinated cerebellar cultures $24 \mathrm{~h}$ after the first (D1) and third (D3) doses of BAY41 $(3 \mu \mathrm{M})+$ Sil $(1 \mu \mathrm{M})$, showing a significant increase in IL-6 and IL-10 cytokines after the first dose. IL-6, IL-1 $\beta$ and TNF $\alpha$ are values are mean fold change \pm SEM of three independent experiments. IL-10 is a representative figure replicated with similar results; values are mean fold change $\pm S D$ of triplicates. Two-way ANOVA followed by Bonferroni's post hoc analysis reveals statistically significant differences respect to LPC $\left({ }^{*} p<0.05, * * p<0.01\right)$.

\subsection{Treatments that increase cGMP induce phenotype changes in BMDM}

LPS-demyelinated cerebellar cultures are a complex system to study inflammatory phenotypic changes induced in microglia and the results presented above on the effect of treatment with cGMP-increasing stimuli are not easy to interpret. In order to directly examine the potential of cGMPincreasing compounds to modulate the inflammatory phenotype in monocytes, we used as model mice bone marrow derived macrophage (BMDM) primary cultures. These cells are readily polarized to a M1 phenotype by incubation 
with LPS (10-100 ng/ml)+IFN $(20 \mathrm{ng} / \mathrm{ml})$ and to a $\mathrm{M} 2$ phenotype by incubation with IL-4 (10-20 ng/ml) (Classen et al. 2009). These conditions were used as controls of phenotypic changes
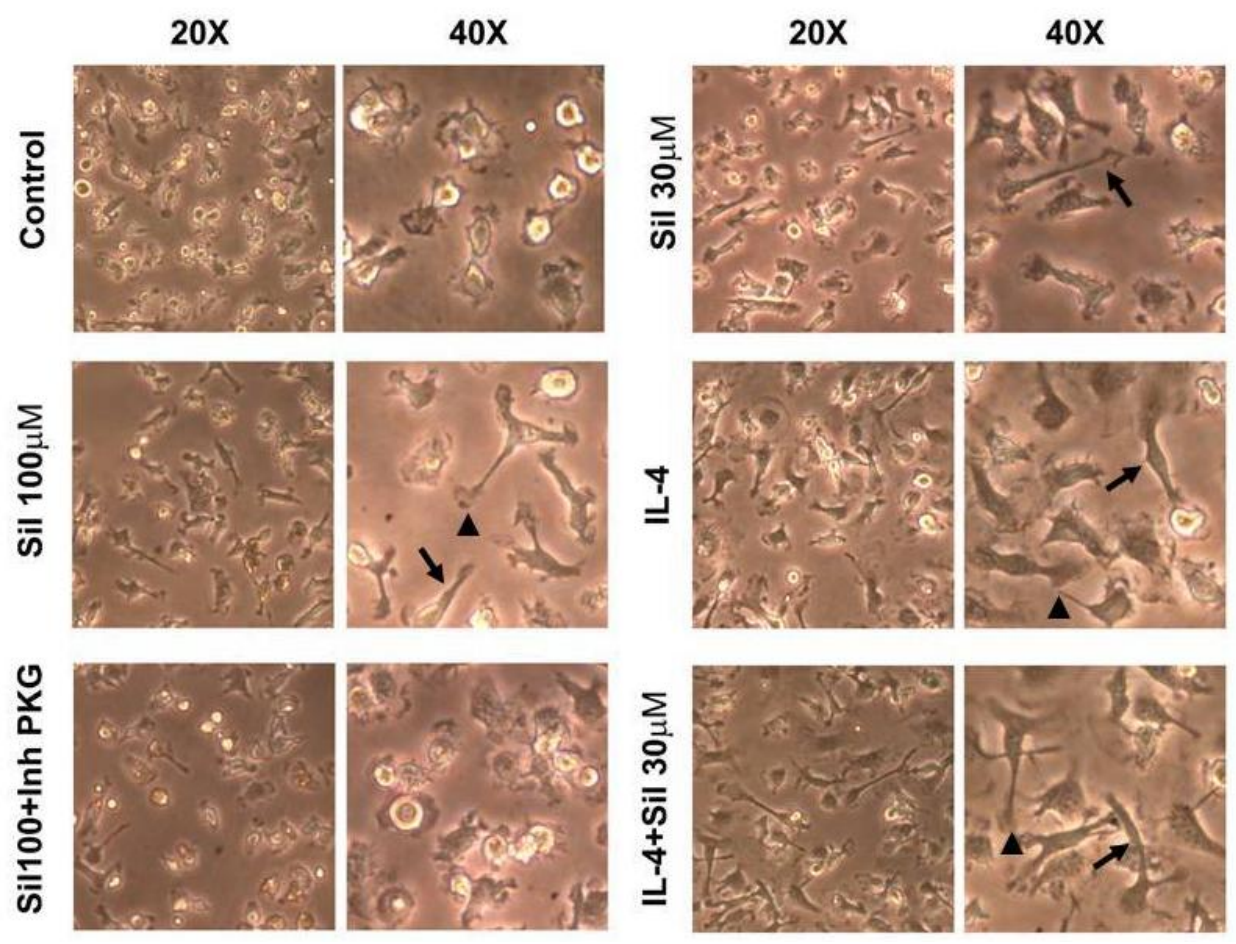

Fig 8: Sildenafil induces a morphological change in BMDM from C57BI/6 mice. Treatment of BMDM primary cultures with sildenafil for $24 \mathrm{~h}$ induced process elongation (arrow) and lamellipodia (arrow head) formation in a concentration-dependent manner (30-100 $\mu \mathrm{M})$. This effect was prevented by the specific protein kinase G (PKG) inhibitor Rp-8pCPTcGMP $(1 \mu \mathrm{M})$ added 30 min before (lower panel, left). The morphological change induced by sildenafil was similar but not identical to that produced by IL-4 $(20 \mathrm{ng} / \mathrm{ml})$, an inducer of the $\mathrm{M} 2$ phenotype (upper and middle panels). Moreover, sildenafil potentiated the IL-4 effect (lower panel, right).

As shown in Fig 8, when BMDM were treated with sildenafil (30-100 $\mu \mathrm{M})$ for $24 \mathrm{~h}$ the morphology of cells changed from a more rounded/amoeboid type to an elongated shape similar to that acquired when BMDM are treated with IL4 (Durafourt et al. 2012, McWhorter et al. 2013, Vereyken et al. 2011). Moreover, the combination of IL-4 $(20 \mathrm{ng} / \mathrm{ml})$ with sildenafil $(30 \mu \mathrm{M})$ produced 
an even more elongated shape (Fig 8). When sildenafil (100 $\mu \mathrm{M})$ was combined with the PKG inhibitor Rp-8pCPTcGMP $(1 \mu \mathrm{M})$ cell elongation was prevented.

Since sildenafil treatment induced a morphological change similar to that induced by IL-4 we further investigated if sildenafil could promote a shift from a $\mathrm{M} 1$ to a $\mathrm{M} 2$ phenotype in BMDM by analyzing nitrite concentration in the media as an index of NOS-2 induction (M1 effect) and arginase activity as an index of Arg1 gene expression that is increased by M2 stimuli (Classen et al. 2009). Cultures were treated with sildenafil alone (1-100 $\mu \mathrm{M})$ or in combination (added 60 min before) with to LPS+IFNY or IL-4. After 24h, nitrite concentration in the media and arginase activity in cell extracts were measured. No changes were observed in the concentration of nitrites in the media of cells treated with sildenafil or IL-4 alone or in combination (Fig 9A). As expected, LPS+IFNY induced a large increase in nitrite concentration that was not significantly affected by the presence of sildenafil, although at the highest concentration $(100 \mu \mathrm{M})$ used there was a tendency to decrease the LPS effect (Fig 9A). In contrast, arginase activity was increased not only by the M2 stimulus IL-4, but also by LPS+IFNy (Fig 9B). Sildenafil at the highest concentrations used (30-100 $\mu \mathrm{M})$ also induced a small non-significant increase in arginase activity in control cells and a small potentiation of the effect of LPS+IFN $\gamma$. However, when combined with IL-4 sildenafil produced a large potentiation of the cytokine effect (Fig 9B). 
A

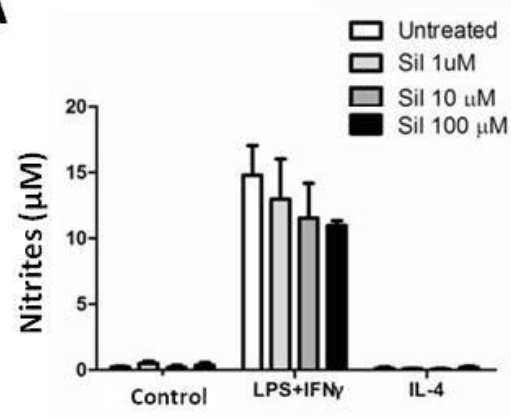

C

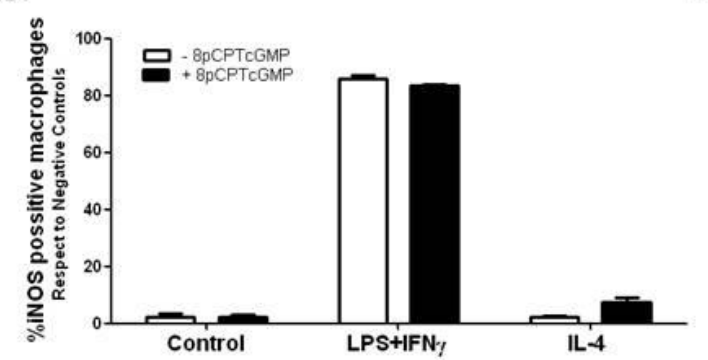

B

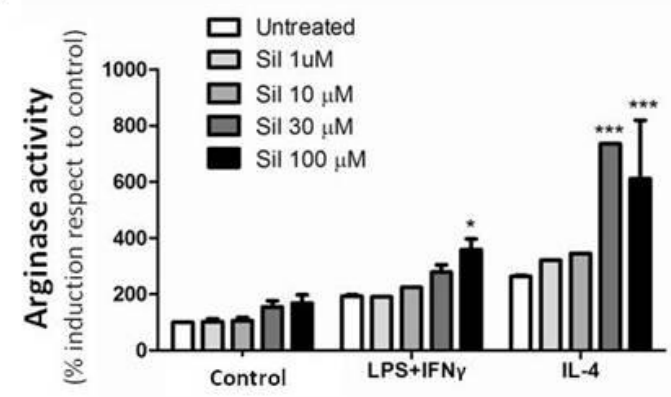

D

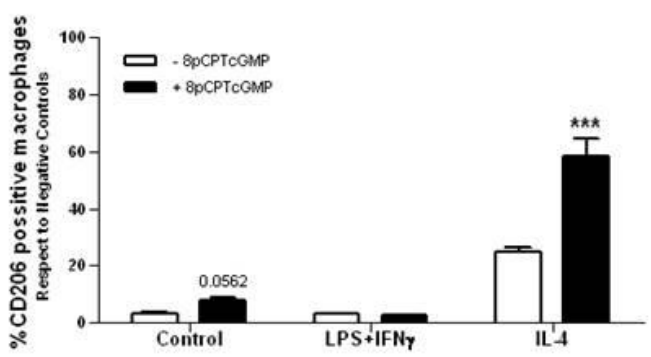

Figure 9: Sildenafil alters the inflammatory phenotype of mouse BMDM. (A-B) Primary cultures of BMDM were incubated for $24 \mathrm{~h}$ with LPS $(100 \mathrm{ng} / \mathrm{ml})+I N F \gamma(20 \mathrm{ng} / \mathrm{ml})$ to induce a M1 phenotype, with IL-4 $(20 \mathrm{ng} / \mathrm{ml})$ to induce a M2 phenotype, or with sildenafil $(1-100 \mu \mathrm{M})$ alone or in combination with the inflammatory stimuli (added 30 min before); (A) Nitrite accumulation in the media was only induced by LPS+INFY and was not significantly affected by combination with sildenafil; (B) Arginase activity was slightly increased in cells exposed to LPS+INFy and IL-4. Sildenafil (30-100 $\mu \mathrm{M})$ alone was little effective but potentiated the effect of the inflammatory stimuli, in particular that of IL-4. Values are mean \pm SEM of three independent experiments. Two-way ANOVA followed by Bonferroni's post-hoc analysis revealed statistically significant differences respect to untreated cells $\left({ }^{*} p<0.05 ;{ }^{* * *} p<0.001\right)$; (C-D) FACS analysis of the percentage of BMDM expressing the M1 phenotype marker NOS-2 $(n=2)$ or the M2 phenotype marker CD206 $(n=3)$. BMDM were left untreated (control) or treated for $48 \mathrm{~h}$ with LPS $(10 \mathrm{ng} / \mathrm{ml})+\mathrm{IFN} \gamma(20 \mathrm{ng} / \mathrm{ml})$, IL-4 $(10 \mathrm{ng} / \mathrm{ml})$ or the CGMP analogue 8 pCPTcGMP $(50 \mu \mathrm{M})$ alone or in combination with the inflammatory stimuli, added 30 min before; (C) The \% of cells expressing NOS-2 was notably increased in LPS+IFNY-treated cells and this was not affected by the cGMP analogue. (D) The \% of cells expressing CD206 was increased by IL-4. The CGMP analogue had a small effect and notably potentiated the effect of IL-4. Values are means \pm SEM analyzed by two-way ANOVA followed by Bonferroni's posthoc analysis revealed statistically significant differences $\left({ }^{* *} p<0.001\right)$ respect to cells not exposed to the cGMP analogue. 
These results indicate that sildenafil can promote a $\mathrm{M} 2$ phenotype but not properly induce a shift M1 to M2. In order to confirm these results we analyzed by flow cytometry the percentage of cells expressing NOS-2 or the M2 marker CD206 in BMDM treated with the cGMP analogue 8pCPTcGMP (50 $\mu \mathrm{M})$ alone or in combination (added $30 \mathrm{~min}$ before) with of LPS (10 ng/ml)+IFN $(20$ $\mathrm{ng} / \mathrm{ml})$ or IL-4 $(10 \mathrm{ng} / \mathrm{ml})$ for $48 \mathrm{~h}$. As shown in Fig $9 \mathrm{C}$, more than $80 \%$ percent of the cells expressed NOS-2 in LPS+IFNY-treated BMDM whereas the number of cells expressing this M1 marker was minimal in control cells or in cells treated with the cGMP analogue or IL-4, alone or in combination. In agreement with the nitrite data, 8pCPTcGMP did not affect the percentage of cells expressing NOS-2 expression in LPS+IFN $\gamma$-treated BMDM (Fig 9C). As expected, the number of cells expressing the M2 marker CD206 was increased in BMDM treated with IL-4. The CGMP analogue alone also increased the number of CD206-expressing cells to a small extend and significantly potentiated the effect of IL-4, doubling the number of CD206+ cells, in agreement with the sildenafil effect on arginase activity (Fig 9D). In contrast, no change in the number of CD206+ cells was observed in LPS+IFNץ-treated BMDM (Fig 9D). Furthermore, we analyzed the effect of the cGMP analogue on levels of the pro-inflammatory cytokine (IL-1 $\beta$ ) and the anti-inflammatory cytokine (IL-10) in the media of BMDM $18 \mathrm{~h}$ after treatment with the same stimuli using Luminex technology. Surprisingly, results showed a large increase in both cytokines in the media of LPS+IFNy-treated but not in IL-4-treated BMDM (Fig 10). The cGMP analogue alone induced a small increase in IL-10 release in control cells and a larger increase in IL-4-treated cells and significantly inhibited the increase in both cytokines induced by LPS+INFy but that of IL-1 $\beta$ to a much larger extend (Fig 10). These results support the contention that in BMDM cGMP promotes an anti-inflammatory phenotype. 

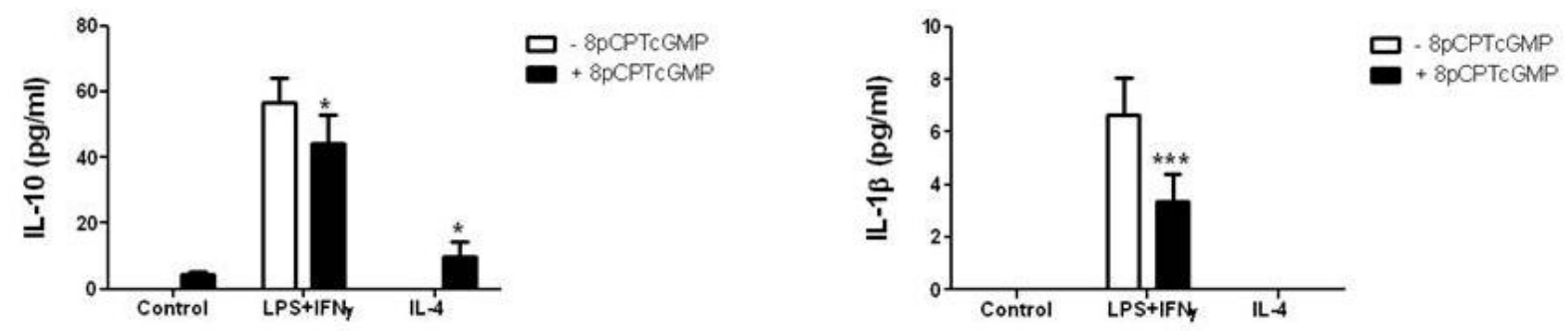

Figure 10: Increasing cGMP induces changes in pro-and anti-inflammatory cytokine release from BMDM. Cytokine was determined in BMDM media by Luminex technology. Cells were left untreated (control) or treated for $18 \mathrm{~h}$ with LPS $(10 \mathrm{ng} / \mathrm{ml})+\mathrm{IFN}$ ( $20 \mathrm{ng} / \mathrm{ml})$, IL-4 (10 $\mathrm{ng} / \mathrm{ml})$ or 8 PCPTcGMP $(50 \mu \mathrm{M})$ alone or in combination with the inflammatory stimuli, added $30 \mathrm{~min}$ before. Levels of both the anti-inflammatory cytokine IL-10 and the pro-inflammatory cytokine IL-1 $\beta$ were increased by LPS+INFy but were not affected by IL-4. The cGMP analogue induced a small but significant decrease in IL-10 levels and a larger decrease in IL$1 \beta$ in LPS+INFY-treated cells. However, in cells treated with IL-4 the analogue significantly increased IL-10 release. Results are representative of two independent experiments; values are means $\pm S D$, of two independent experiments. Two-way ANOVA followed by Bonferroni's post-hoc analysis revealed statistically significant differences $\left({ }^{*} p<0.05, * * * p<0.001\right)$ respect to cells not exposed to the cGMP analogue.

\subsection{Sildenafil increases myelin phagocytosis in microglia/macrophages in spinal cord of EAE animals and in BMDM}

It has been reported that in demyelinating disorders, such as MS, myelin debris interferes with the remyelination process (Kotter et al. 2006). Myelin clearance correlates with increased remyelination and differentiation of OPCs (Kotter et al. 2006, Miron and Franklin 2014). Furthermore, recent reports indicate that $\mathrm{M} 2$ cells have higher myelin phagocytic activity than M1 cells (Durafourt et al. 2012) and that M2 cell polarization is essential for efficient remyelination (Miron et al. 2013). To investigate if sildenafil treatment affects myelin debris phagocytosis in EAE mice we performed Oil-red O (ORO) staining in longitudinal SC sections. Results showed that 15 days of sildenafil $(10 \mathrm{mg} / \mathrm{kg})$ 
treatment starting after disease onset increased the amount of ORO-loaded vesicles in infiltrates (Fig 11 A-D). Quantification of the amount of ORO-loaded vesicles relative to infiltrated area in infiltrates of different sizes showed a significant increase in sildenafil-treated mice compared to vehicle-treated controls (Fig 11E). To investigate if this lipid-loaded vesicles stained by ORO were inside $\mathrm{M} 2$ cells, SC sections were double-stained for the M2-phenotype marker YM-1 and with ORO and were visualized by confocal microscopy. Confocal image analysis followed by 3D-reconstruction of images showed ORO in vesicles inside $\mathrm{Ym}-1$ possitive macrophage/microgial cells (Fig 11F).

To investigate if sildenafil has a direct effect on the myelin phagocytic capacity of macrophages, a myelin phagocytosis assay was performed on mouse BMDM. Cells were treated with the cGMP analogue 8Br-cGMP (500 $\mu \mathrm{M})$ or, sildenafil (30-100 $\mu \mathrm{M})$ alone or in combination with IL-4 $(20 \mathrm{ng} / \mathrm{ml})$. After $24 \mathrm{~h}$, cells were incubated with Dil-labelled myelin $(25 \mu \mathrm{g} / \mathrm{ml})$ for $90 \mathrm{~min}$ and myelin uptake was analyzed by flow cytometry. IL-4, the cGMP analogue and sildenafil significantly alone increased myelin phagocytosis (Fig 11G). The effect of cGMP-increasing stimuli alone was of higher magnitude than that induced by IL-4 and when added together their effects were a little less than additive. 

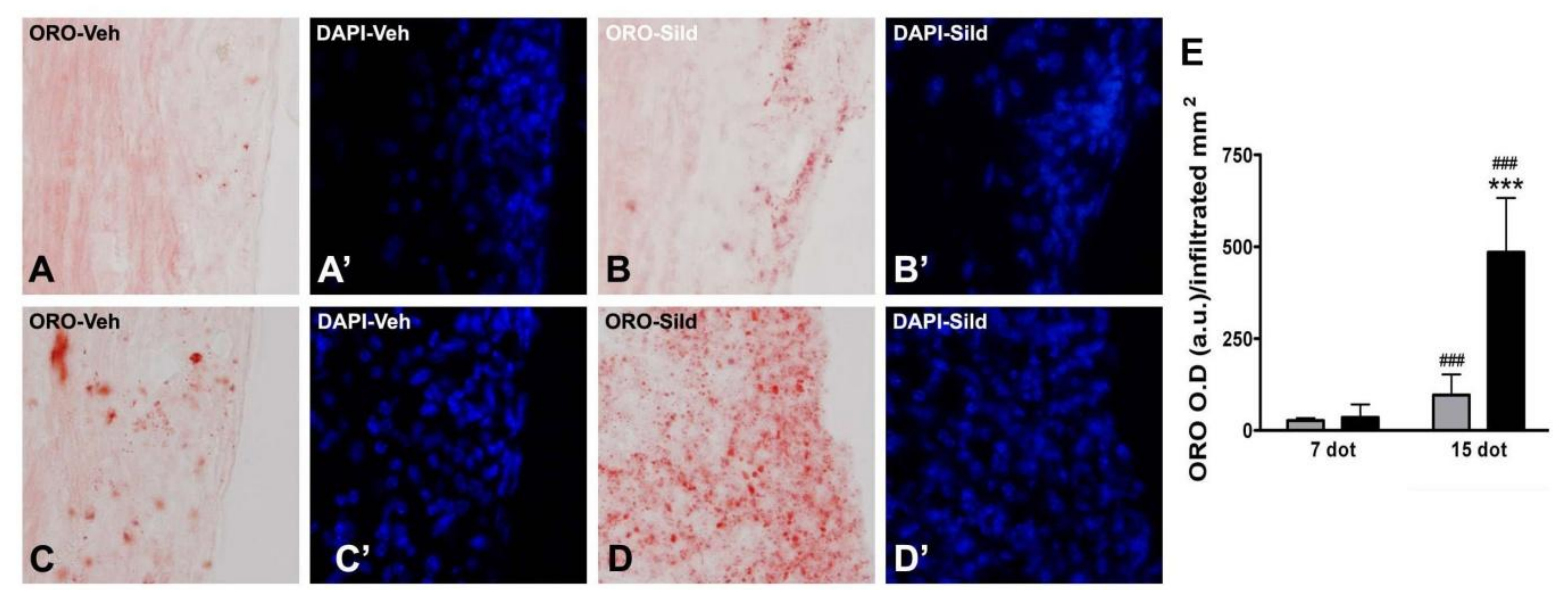

$\mathbf{F}$

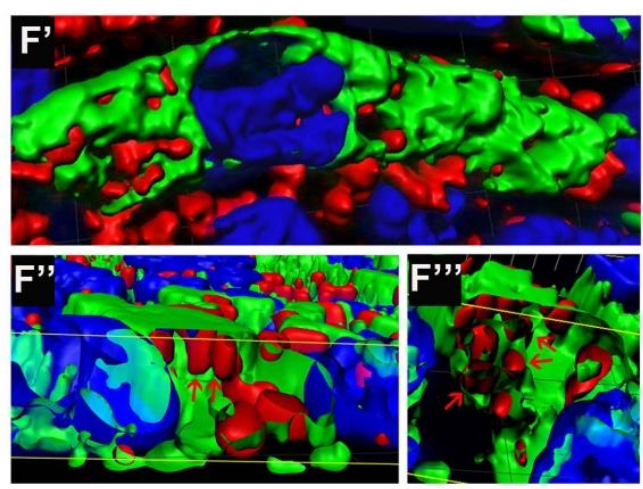

G

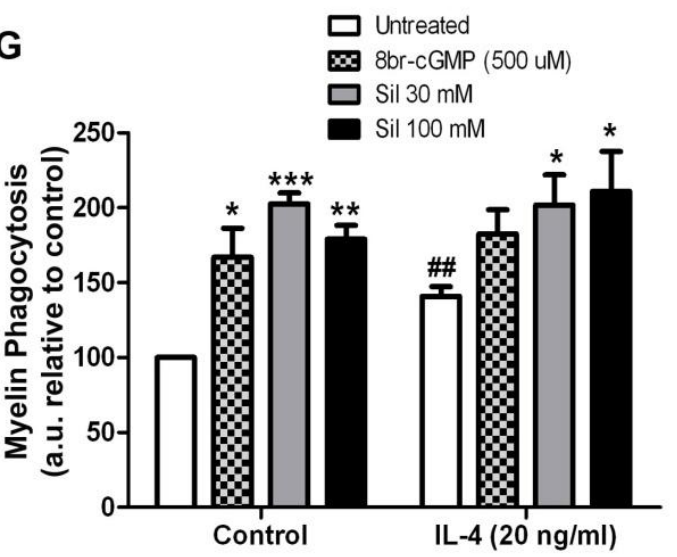

Fig 11. Sildenafil treatment enhances myelin phagocytosis in macrophages/microglia in the spinal cord of EAE animals and in mouse BMDM cultures. (A-D) Phagocytosis of myelin in the spinal cord of EAE animals evidenced by vesicular Oil-red $O$ (ORO) staining. Representative images of ORO staining in infiltrates (cell nuclei stained with DAPI) of different sizes in animals treated with vehicle $(A, C)$ or sildenafil $(B, D)$ for 7 or 15 days (dot) starting at onset of disease; (E) Quantification reveals that sildenafil significantly enhances ORO staining after 15 dot. Values are means \pm SEM ( $n=4-6)$. Two-way ANOVA followed by Bonferroni's post-hoc analysis reveals statistically significant differences respect to $E A E$ vehicle-treated animals after 15 dot $\left({ }^{*} p<0.05\right)$. (F) 3D rendering of macrophage/microgial cells positive for the M2-phenotype marker YM-1 (green) containing ORO in vesicles (red) in the spinal cord of sildenafil-treated EAE animals; Cell nuclei are shown in blue. (G) BMDM were treated for $24 \mathrm{~h}$ with the cGMP analogue $8 \mathrm{Br}-\mathrm{cGMP}(500 \mu \mathrm{M})$ or sildenafil $(30 \mu \mathrm{M}-100$ $\mu \mathrm{M})$ alone or in combination with IL-4 $(20 \mathrm{ng} / \mathrm{ml})$ and were exposed to Dil-labeled myelin for $90 \mathrm{~min}$. Myelin phagocytosis was analyzed by flow-cytometry. Values are means \pm SEM of three independent experiments. Two-way ANOVA followed by Bonferroni's post-hoc analysis reveals statistically significant differences respect to untreated $\left({ }^{*} p<0.05,{ }^{*} p<0.01\right.$, $* * * p<0.001)$ and respect to untreated control (\#\# $p<0.01)$. 
성 상 숭

\section{DISCUSSION}




\section{DISCUSSION}

In MS, inflammation, demyelination and axonal damage are important hallmarks of the pathology (Henderson et al. 2009, Lassmann 2014, Peterson and Fujinami 2007). This inflammatory and neurodegenerative nature of MS generates the necessity of the development of treatments that combine immune-modulatory and neuroprotective effects (Aharoni 2010).

In MS models, it has been observed that sildenafil improve clinical symptoms and disease progression. In EAE mice treated for 8 days with sildenafil starting at the acute phase (peak) of the disease, showed significantly amelioration of clinical symptoms associated with an increase in myelin staining and decreased of axonal loss, suggesting that sildenafil may be promoting remyelination and axonal protection; moreover, it was shown that 3 days after sildenafil treatment reduced the amount of infiltrating cells, increased the number of Foxp3+ lymphocyte $T$ regs and decreased microglia/macrophage activation (Pifarre et al. 2011). Sildenafil effects on remyelination were further studied by curpizone demyelination model, showing as well a significant amelioration of clinical symptoms associated with a protective effect on myelin structure, reduction of reactive gliosis (microglia and astrocytes) and decreased expression of pro-inflammatory cytokines (Nunes et al. 2012). Furthermore, treatment with sildenafil starting at the onset of EAE has shown to prevent the disease progression, to maintain myelin and axon structure, decrease microglial activation, down-regulate the innate and adaptative responses decreasing pro-inflammatory cytokine production and proliferation in splenocyte, and has shown to upregulate the alternative 
microglia/macrophage activation marker $\mathrm{Ym}-1$ associated with neuroregenerative effects (Pifarre et al. 2014).

The results obtained in this thesis showed that sildenafil treatment in de acute phase indeed ameliorates clinical symptoms decreasing clinical score close to 1 , and that extending the treatment from 8 to 15 days does not show further improvement. After 15 days of treatment increase MBP staining was observed, suggesting remyelination enhancement as seen previously (Pifarre et al. 2011). The results obtained also showed that when sildenafil treatment starts at the chronic phase of EAE stills promotes significant amelioration of the symptoms. Further analysis demonstrated that sildenafil promotes remyelination increasing MBP levels after 15 dot starting at chronic phase. This result has clinical significance since it shows that sildenafil exerts remyelinating and neuroprotective effects once EAE becomes chronic, when more infiltrating cells, more lesions and an increased grade of demyelination can be found (Berard et al. 2010).

Taking in account these results and with the aim to study mechanisms involved in sildenafil effects on CNS cells, mouse cerebellar organotypic cultures were established. EAE is induced by an auto-immune reaction against myelin peptide that promotes an acute attack by peripheral immune cells that infiltrate the CNS which is followed by demyelination (Constantinescu et al. 2011, McCarthy et al. 2012). On the other hand, cerebellar organotypic cultures demyelinated with lysophosphatidylcholine (LPC) have proven to be an excellent model to study demyelination-remyelination process without axonal death and excluding the influence of the immune system. This model is accessible to experimental perturbation, which allows testing the effect of different stimuli on the mechanisms that might be implied in the processes that 
wants to be studied (Birgbauer et al. 2004, Zhang H. et al. 2011). After LPC demyelination, microglia activation can be observed, myelin debris is generated as a consequence of demyelination and naked axons sometimes suffer damage which is evident by the presence of axonal bulbs, Caspr proteins are no longer visible, OPCs are present in the slices and after demyelination OPCs proliferation is induced (Zhang H. et al. 2011).

The results obtained in this work showed almost complete demyelination of axons after LPC treatment; however after 10 days of treatment with sildenafil myelin sheath reappeared increasing the remyelination index, along with Caspr clusters. Combination of sildenafil and BAY41, a direct activator of NO-GC, revealed a significant increase in myelin protein levels; however no significantly effects where observed in MBP mRNA expression; however, no further increase in remyelination index were observed compared with sildenafil alone. Similar effects on the remyelination index were observed after NMDA treatment in combination with sildenafil. NMDA is a glutamate analogue that activates this neurotransmitter receptors (NMDA-R), in cerebellum present primarily in granular neurons and can be also found in astrocytes and oligodendrocytes. Activation of NMDA-R allows calcium to entry into the cell and the activation of the constitutive form of NOS (NOS-1) and further NO production (Maarsingh et al. 2009, Manucha 2016, Verkhratsky and Kirchhoff 2007). This NO can diffuse across the plasmatic membrane generating cGMP not only in NMDA-R positive cells but also in neighbor cells.

One possible molecular-signaling pathway involved in the increase in remyelination by sildenafil is the NO-cGMP-PKG pathway. In the CNS, NO has been associated with the modulation of synaptic plasticity, brain development, visual and sensory processing, neuro-endocrine secretion and cerebral blood 
flow (Garthwaite J. 2000, Guix et al. 2005). Constitutive NOS (NOS-1 and NOS-3) produce small amounts of NO under physiological conditions (Maarsingh et al. 2009, Manucha 2016). On the other hand, NO has been also described as a molecule important in the inflammation modulation, considered as a neuropathological agent responsible for excitotoxic cell death and neuroinflammatory cell damage in many neurological disorders (Duncan and Heales 2005, Murphy 2000). Moreover, one of NO targets is the NO-GC, its binding induces NO-GC activation and further cGMP production. NO-cGMP pathway impairment may be implied in neurological dysfunctions, decreased astroglial expression of the NO-GC $\beta$ subunit was observed in astrocytes of post-mortem brains of different neurodegenerative diseases' patients (Baltrons et al. 2004). We have observed that effect of sildenafil on remyelination index was inhibited by NO-GC inhibitor (ODQ) and NOS inhibitor (L-NNA) treatments. Similar effects were found when PKG was inhibited with Rp-8pCPTcGMP. On the other hand, immune stainings revealed an increase in NOS-2 after $24 \mathrm{~h}$ of LPC treatment in organotypic cultures. As said before NOS-2 is induced under pro-inflammatory conditions, LPC demyelination in organotypic cultures leave axons exposed, myelin debris and microglia activation, characteristics of neuroinflammation (Zhang H. et al. 2011). NOS-2 produces higher and longerlasting amounts of NO after induction and can be expressed primarily in microglia and astrocytes cells (Brown and Neher 2010, García 2004, Maarsingh et al. 2009, Murphy 2000) suggesting that LPC treatment may be responsible of cGMP and NO increase, which can be in part promoting sildenafil effects. Furthermore, PKG targets important pathways involved in remyelination and neuroprotection, such as MEK/ERK and Akt/MTOR pathways (Dai et al. 2014, Guardiola-Diaz et al. 2012). Taking together, these results demonstrate that sildenafil treatment increases production of myelin by actions exerted directly 
on CNS cells, restoring myelin sheath and mature internodes which is associated with functional remyelination (Meffre et al. 2015, Zhang $\mathrm{H}$. et al. 2011) suggesting that NO-cGMP-PKG pathway activation is required to promote sildenafil effects.

In relapsing-remiting MS demyelinating episodes are characterized by the death of OLs followed by new OLs generation and migration, but with the recurrence of this episodes decreases their capacity of generation, which in consequence affects remyelination (Copray et al. 2006, Lassmann 2014); however, previous results have shown that sildenafil protects OLs from apoptotic death in EAE model (Pifarre et al. 2014). Taking previous and new results into account, in this work we study the effect of sildenafil in OLs maturation in organotypic cerebellar cultures. OLs express a series of specific molecules, which allows determining their differentiation or maturation stage. Neuron-Glial precursor cells (NG2+) are observed in cerebellar organotypic cultures (Zhang $H$. et al. 2011). OPCs can also be found in this model, expressing molecules such as: transcriptional factor Nkx2.2 and Platlet Derived Growth Factor $\alpha$ Receptor (PDGFaR) among others. Transcriptional factors Olig1 and Olig2 are express during early to late differentiation stages of immature OLs. More mature OLs express Myelin Basic Protein (MBP), Proteolipid Protein (PLP), Myelin Oligodendrocyte Glycoprotein (MOG), Myelin Associated Glycoprotein (MAG) and Cyclic Nucleotide Phosphodiesterase (CNPase) among others (Fig 12) (Copray et al. 2006, Liu et al. 2007, Meffre et al. 2015, Miron et al. 2010, Nishiyama et al. 2009, Zhang H. et al. 2011). 


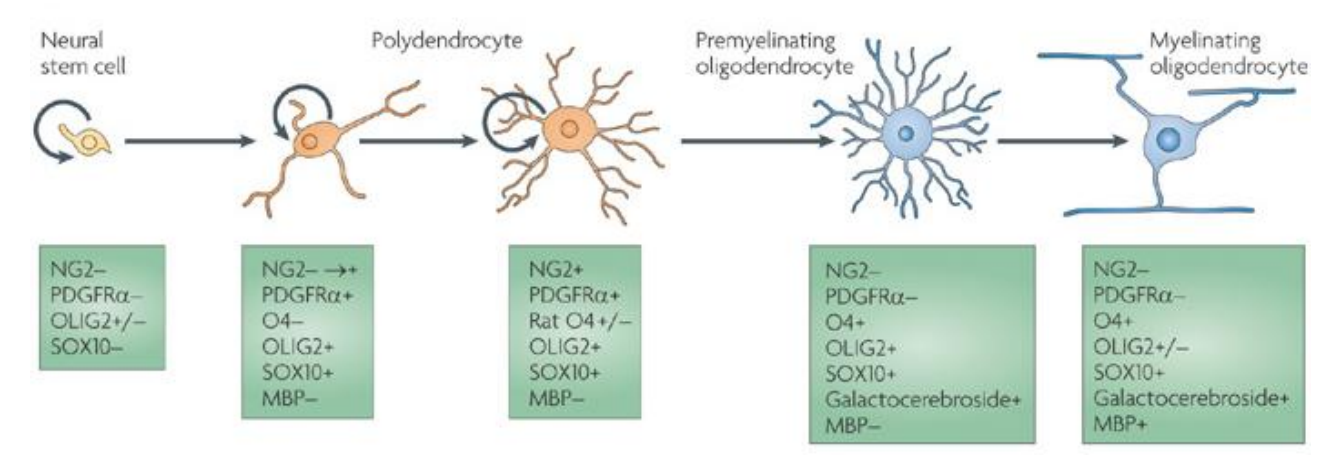

Figure 12: Olygodendrocyte maturation markers expression. Figure modified from Akiko Nishiyama, Mila Komitova, Ryusuke Suzuki \& Xiaoqin Zhu; Polydendrocytes (NG2 cells): multifunctional cells with lineage plasticity. Nature Reviews Neuroscience 10, 9-22 (January 2009). Molecules and protein expression of oligodendroglial cells throughout development (Nishiyama et al. 2009).

Our results showed that sildenafil treatment significantly increased the expression of OPCs transcription factor involved in early stage of $\mathrm{OL}$ differentiation (Nkx2.2+) and showed a tendency increased the number of mature OLs (Olig2+MBP+) as well as the number late stage mature OLs (Olig2$\mathrm{MBP}+$ ) in SC of EAE mice. Moreover, when ventral and dorsal thoracic sections of EAE mice $S C$ where analyzed, an increase number of late stage mature OLs (Olig2-MBP+) relative to the total $\mathrm{MBP}+$ mature OLs was found in sildenafil treated group. This result was further confirmed in organotypic cultures, where increased number of late stage mature oligodendrocytes relative to the total of mature oligodendrocytes was found with sildenafil treatment combined with BAY41 and with NMDA. Taking together this results demonstrate that cGMP increased by sildenafil is promoting maturation of OLs. In agreement with these results, other studies have demonstrated that an increase in intracellular cGMP derived from NO-GC in OLs promotes their maturation and arborization, extending the reach of each cell in cerebellar slices, the source of NO in this model was partially attributed to an increase production of NO in neighbor granular neurons via NMDA-R activation (Garthwaite G. et al. 2015); however 
recent studies have shown that OLs can also express NMDA receptors specially in their processes (Salter and Fern 2005); therefore cGMP levels in OLs could be increased by actions of NMDA-R agonists. Similar to these results, in an ischemic mouse model sildenafil has proven to increase nestin lineage OPCs and mature OLs (CNPAse+ and $\mathrm{CC} 1+$ ) in corpus callosum and striatum of treated mice (Zhang R. L. et al. 2012). Transduction signals of cGMP increase primarily occur via PKG, in OLs this kinase may be targeting different pathways implicated in OLs maturation and protection. Some of these pathways as above mention could be MEK/ERK and Aky/mTOR, different studies in vitro have involved them with growth and differentiation of oligodendrocytes (BibolletBahena and Almazan 2009, Kumar et al. 2013). Furthermore, recent in vitro studies have shown that ERK I/II activation is required for the progression of oligodendrocyte early progenitors to the development of immature oligodendrocytes, but does not affect the transition from immature to mature oligodendrocytes; however, mTOR activation is not required for the development of immature oligodendrocytes, but it shows to be essential in the transition from immature to mature myelinating oligodendrocytes (GuardiolaDiaz et al. 2012). Additionally, important cross-talk between Akt/mTOR and MEK/ERK pathway has been studied, demonstrating that both pathways regulate MBP mRNA and protein expression and that Akt/mTOR inhibition increase ERK I/II phosphorylation in vitro (Dai et al. 2014) 


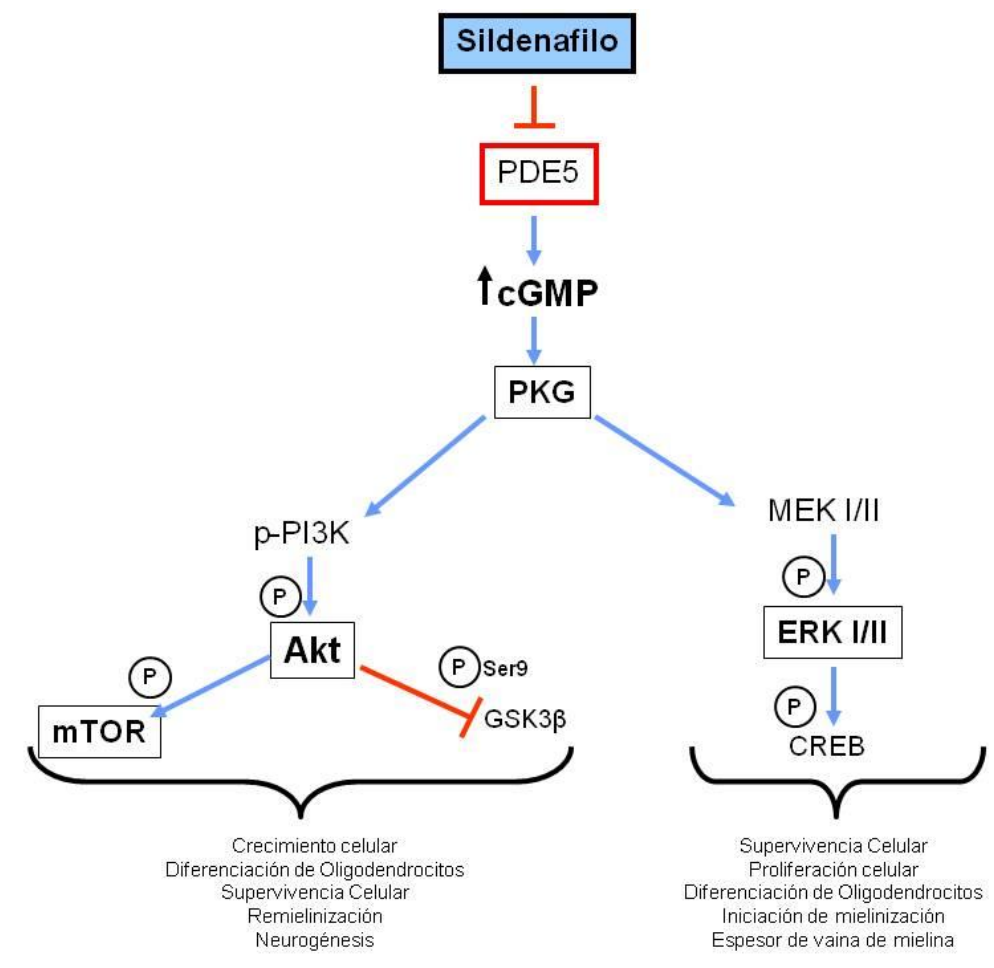

Figure 13: Sildenafil possible mechanism pathway

Therefore, sildenafil not only protects OLs from apoptotic death, but this work shows that it promotes OLs maturation into mature myelinating OLs.

Other mechanism possibly implicated in sildenafil ameliorating and remyelinating effects was the generation of trophic factors. Previous studies have demonstrated that sildenafil increases BDNF expression in splenocytes of EAE mice after sildenafil treatment and in SC sections, denoting that the increased BDNF expression in SC was mainly generated by infiltrating leukocytes and in axons (Pifarre et al. 2014). Another important neurotrophic factor associated with remyelination and regeneration process is CNTF. The results of this work showed that sildenafil treatment to EAE-mice increased CNTF expression in the SC, and was observed primarily by astrocytes. Furthermore cGMP increase also induced CNTF gene expression in cerebellar organotypic cultures. The CNTF produced in our model could be enhancing sildenafil effects on OLs, it has been recognized influence of CTNF on OL 
differentiation (Stankoff et al. 2002) and it has been recently shown that this growth factor acts as a quemoatractant controlling OL progenitor migration during remyelination (Vernerey et al. 2013). In agreement with the results shown in this work, it has been recently demonstrated in vitro that the NOcGMP-protein kinase G pathway up-regulates CNTF expression in astrocytes and that astrocyte-derived CNTF enhances OLs differentiation (Paintlia et al. 2013).. Moreover, studies have demonstrated that CNTF plays an important role in myelin protein expression and in oligodendrocyte protection against apoptotic death (Modi et al. 2013); therefore sildenafil effect on oligodendrocyte protection against apoptotic death observed in previously the EAE model (Pifarre et al. 2014) may be partially exerted through sildenafil increase expression of CNTF. Moreover, treatment with exogenous CNTF injection (s.c.) in the cuprizone-demyelinating mouse model, increased the myelin protein MOG expression after demyelination, thus suggesting that CNTF may be potentiating remyelination (Salehi et al. 2013). Treating EAE mice with mesenchymal cells overexpressing CNTF induced functional recovery of the disease, reduced demyelination, increased NG2+ cells (OLs precursors), decreased pro-inflammatory cytokines (TNF $\alpha$ and IFN $Y$ ) and increased antiinflammatory cytokine IL-10 (Lu et al. 2009). This evidence suggests that sildenafil enhances the production not only of BDNF but also CNTF, and this increased expression of neurotrophic factors may develop important mechanisms and actions in the CNS after demyelinating and inflammatory lesions, promoting oligodedroglial protection and differentiation.

In EAE model it was previously described that sildenafil treatment significantly decreased microglial/macrophage activation and showed down regulation of adaptative immune response by decreasing pro-inflammatory cytokines (IL-2, INFY and TNF $\alpha$ ) release by splenocytes re-stimulated with MOG, 
it was also described that sildenafil increased alternative activation microglia/macrophage marker Ym-1 (Pifarre et al. 2014); these results suggest that sildenafil besides having remyelinating and neuroprotective effects, it can also be promoting anti-inflammatory effects in the IS and CNS and may be promoting M2 microglia/macrophage phenotype. In order to study sildenafil effects on CNS inflammatory microglial phenotype, cytokines and microglia/macrophage phenotypic markers were determined.

The M1 phenotype has been related to release of pro-inflammatory cytokines, cytotoxicity, radical oxygen species (ROS) release, auto antigen presentation to $T$ cells and therefore contributing with disease progression as has been observed Alzehimer's disease, MS and stroke studies (Chhor et al. 2013, Rawji et al. 2016). The M2 anti-inflammatory phenotype has been related with the production of anti-inflammatory cytokines and is associated with regeneration properties and wound healing (Gensel and Zhang 2015, Ransohoff and Perry 2009). Furthermore, the $M 2$ phenotype resolution and regenerative properties have been related with inducing OPCs differentiation, remyelination and promoting myelin clearance (Durafourt et al. 2012, Kotter et al. 2006, Miron et al. 2013, Wang et al. 2015, Yu et al. 2015).

Our results showed that BAY41+Sil treatment in LPC demyelinated cerebellar cultures induced tendency to an early increased in Arg-1 (M2 phenotype marker) and COX-2 (M1 phenotype marker), no changes were found in CD206 (M2 phenotype marker) expression and a late decrease tendency in NOS-2 (M1 phenotype marker) expression was observed.

Increased arginase activity has been associated with alternatively activated microglia/macrophages (M2) (Gensel and Zhang 2015, Ransohoff and Perry 2009) which converts L-arginine into ornithine, a precursor of proline and 
polyamines. Polyamines have been related with oxidative stress amelioration and cellular proliferation (Guasco Herrera et al. 2014). Curiously, in our results the treatment induced a tendency to increase M1 marker, COX-2 simultaneously with the increase Arg-1; COX-2 increase has usually been associated to pro-inflammatory process (Deininger and Schluesener 1999, Minghetti 2004). However recent studies propose anti-inflammatory properties of COX-2, demonstrating the presence of a group of lipids in postmortem brain samples of Alzehimer's disease patients, with pro-resolving and antiinflammatory properties called pro-resolving lipid mediators (SPMs) synthesized by 5-lipoxygenase (LOX) and COX; this SPMs have shown to improve neuronal survival and $A \beta_{2}$ phagocitosys in vitro (Zhu et al. 2016). Therefore, the early increase in COX-2 observed in the cerebellar organotypic cultures after sildenafil treatment could be promoting the production of SPMs. Moreover, COX-2 increase has been associated with M2b/c (immuneregulatory/immune-suppressor) phenotype associated with the production of anti-inflammatory prostaglandins (Chhor et al. 2013, Ransohoff and Perry 2009, Wu et al. 2013), and wound healing after spinal cord injury (Gensel and Zhang 2015). On the other hand, within sildenafil treatment doses tendency to decrease M1 phenotype was observed, suggesting that PDE5 inhibitor may be promoting healing and regeneration of tissue by enhancing a M2-like phenotype and diminishing the pro-inflammatory phenotype.

In order to confirm the inflammatory effect of sildenafil in CNS, cytokine expression was determined in organotypic cerebellar cultures. Results showed that BAY41+Sil treatment significantly increase IL-10 and IL-6 24h after first dose, no changes were found in IL-1 $\beta$ and TNF $\alpha$, pro-inflammatory cytokines, expression. 
IL-10 is a known anti-inglammatory cytokine, its functions are exerted primarly on dendirtic cells and macrophages, IL-10 inhibits major histocompatibility complex class II expression and inhibits the production of proinflammatory cytokines and mediators (IL-1, IL-6, IL-12, TNF $\alpha$ ) (Mosser and Zhang 2008). In agreement with previous results in EAE model (Pifarre et al. 2014), recent studies have shown that the increased expression of IL-10 and promotion of $\mathrm{M} 2$ microglia phenopype after estrogen treatment promotes neuroprotection preventing EAE progression (Benedek et al. 2016). Moreover, it has been shown that IL-10 increase expression resulted in attenuated inflammatory response, decreased microglia activation and less neurodegeneration in EAE model (Mayo et al. 2016). On the other hand, IL-6 was classically conceived as a pro-inflammatory cytokine; recently, more studies come to light showing its anti-inflammatory properties. In agreement with our results, studies performed by using interleukin-6 (IL-6) fused to its soluble receptor (sIL-6R) protein have shown that IL-6 increase in vivo has effects on myelination, inducing OPCs to differentiate into mature oligodendrocytes and promoting their survival (Haggiag et al. 2001, Valerio et al. 2002). Moreover, increase immune-regulatory response, by increasing IL-6 and IL-10 expression, has been associated with myelin repair in chronic phase of EAE in IL-4Ra ${ }^{-/-}$mice (Gaupp et al. 2008). Even though previous studies have shown that sildenafil treatment reduced pro-inflammatory cytokines expression in mouse cerebella of cuprizone-demyelinated model (Nunes et al. 2012) and in splenocytes of EAE mice (Pifarre et al. 2014), in our results BAY41+Sil treatment in cerebellar slices did not show significant changes in pro-inflammatory cytokines expression. In the case of TNF $\alpha$ excessive generation in brain has been involved in the pathogenesis of stroke, traumatic brain injury and Alzehimer's disease (Clark and Vissel 2016) and IL-1 is a 
known pro-inflammatory cytokine, the release of this cytokine has been associated with cytotoxicity (Rawji et al. 2016).

Taking these results together suggests that sildenafil is promoting a mixed microglia phenotype, since an early increase in the expression of Arg-1, COX-2 was observed accompanied by an increase expression of IL-10 and IL-6; these features are recently being associated with $\mathrm{M} 2 \mathrm{~b} / \mathrm{c}$ microglia/macrophage phenotype which shows immune-regulatory and immune-suppressor properties by promoting inflammatory resolution, tissue repair, production of anti-inflammatory and prostaglandins (Colton 2009, Chhor et al. 2013, Gensel and Zhang 2015, Ransohoff and Perry 2009, Wu et al. 2013) and even more, this phenotype has been associated with OPCs differentiation (Miron et al. 2013). Recent studies have indentified another mixed microglia/macrophage phenotype not classically M1 nor alternatively activated M2 cells; they were called "resolution-phase" macrophages (rM), since this particular phenotype has been observed in macrophages isolated from the resolving phase of acute inflammation. rM showed to increase M2 marker CD206 and anti-inflammatory molecules (IL-10 and $\mathrm{PGD}_{2}$ ) expression, along with M1 markers including NOS2, COX-2 (Bystrom et al. 2008). Moreover, new evidence has emerge showing that after spinal cord injury, exogenous IL-4 treatment increase the population of $\mathrm{M} 2$ phenotype, but it also appeared another population of cells suggesting to be infiltrating macrophages with a mixed phenotype co-expressing M1 markers (NOS-2, COX-2, LOX, CD16/32) and M2 markers (Arg-1, CD206) as well as anti-inflammatory cytokines IL-10 and TGF $\beta 1$ and were associated with $\mathrm{rM}$, known to be important in the resolving of inflammation (Francos-Quijorna et al. 2016). Even though the phenotype markers and cytokines expressed after BAY41+Sil treatment in our cerebellar slices is very similar to those observed in the $\mathrm{rM}$, our treatment in this model despite increasing Arg-1 failed in 
promoting CD206; moreover no expression of NOS-2 or any other proinflammatory molecule besides COX-2 was observed. Therefore it is not clear yet if sildenafil is promoting $\mathrm{rM}$ unique phenotype in CNS.

Mouse cerebellar organotypic cultures are complex models to study inflammatory phenotype changes; this can result as a consequence of the presence of the other cells that are part of the CNS, such as astrocytes that could also be contributing in the production of cytokines and other inflammatory molecules (like NOS-2). In order to study more specifically sildenafil effects on microglia/macrophage phenotype BMDM cultures were established. The study of these cells grants clinical significance since EAE model as well as in MS peripheral immune cell infiltrates can be found (Berard et al. 2010, Henderson et al. 2009).

BMDM cultures were established as previously described (Classen et al. 2009) and were polarized into M1 phenotype with LPS+INFy or into M2 phenotype with IL-4; a un-polarized BMDM population was used as control. Results showed nitrite accumulation only in M1 BMDM and that sildenafil treatment showed a tendency to decrease this accumulation. Additionally NOS2 positive cell number significantly increased in LPS+INFY treated BMDM; however treatment with CGMP analogue did not decreased the number NOS-2 positive cell population. On the other hand, the three populations of BMDM showed arginase activity; nevertheless, sildenafil treatment showed a tendency to increase arginase activity in control BMDM, being significant in M1 BMDM at the highest concentration of sildenafil and significantly doubled arginase activity in M2 BMDM. Moreover, CD206 positive cell number increased after IL4 treatment; cGMP analogue induced an increase in CD206 positive population 
in control BMDM and further potentiated the number of CD206 positive cells in IL-4 treated BMDM.

In order confirm the effect of CGMP increase on inflammatory phenotypes; IL-10 and IL-1 $\beta$ release were determined in the culture media of BMDM 18h after treatments. Results showed that LPS+INFY treatment significantly increased IL-10 release in BMDM, these results agree with those of Howes, et al. that demonstrated that C57BL/6 BMDM produce higher levels of IL-10 in response to bacterial products such as LPS (Howes et al. 2016), similar IL-10 increase has been observed in primary microglia after LPS treatment (Chhor et al. 2013); nevertheless, cGMP analogue treatment significantly reduced IL-10 production in LPS+INFy treated BMDM. Interestingly, IL-10 production was not observed in control or IL-4 stimulated BMDM; however, CGMP analogue increased IL-10 production in both populations, being significant in IL-4 BMDM. On the other hand, there was only IL-1 $\beta$ release on behave of LPS+INFY BMDM and treatment with CGMP analogue significantly decreased the production of IL-1 $\beta$ in this M1 population. In agreement with this results, inhibiting PDE activity in human monocytes decreased the release of IL$1 \beta$ and this effect was mimic by cGMP analogues and NO donor suggesting NOGC activation is implied in the effect (von Bulow et al. 2005). Taking these results together suggest that increase cGMP levels promoted by sildenafil affect inflammatory outcomes, do not significantly reverse M1 phenotype but it does promote $\mathrm{M} 2$ phenotype and anti-inflammatory mediators.

One of the important actions of microglia/macrophage in neurodegenerative diseases is their phagocytic activity of cellular and myelin debris produced in the lesions (Ransohoff and Perry 2009). In neurodegenerative diseases, such as MS, olygodendrocyte differentiation is not 
observed in demyelinated lesions, and it has been proved that the presence of myelin debris can impair remyelination by inhibition of OPCs differentiation (Kotter et al. 2006). For this reason myelin clearance by phagocytic cells has gained relevance. Studies have shown that M2 macrophages phagocyte greater amount of myelin than M1 (Durafourt et al. 2012). Myelin phagocytosis was assessed in EAE model through ORO staining, making evident that the lipid vesicles around infiltrates increase in EAE mice treated with sildenafil at the onset of the disease; furthermore, it was observed that most of the vesicles where inside $\mathrm{Ym}-1$ stained M2 microglia/macrophages. To confirm that sildenafil was promoting myelin phagocytosis in $\mathrm{M} 2$ cells, control and $\mathrm{M} 2$ BMDM where treated with sildenafil and a cGMP analogue for $24 \mathrm{~h}$ before being exposed to purified myelin. Flow cytometry analysis revealed that sildenafil treatment increased myelin phagocytosis in IL-4 stimulated BMDM compared with controls and LPS treated BMDM (data not shown); moreover sildenafil significantly increases myelin pahocytosis in control and M2 BMDM, this effect was mimicked by cGMP analogue. This increase in myelin clearance is another mechanism promoted by sildenafil essential for remyelination to take place.

The results observed in organotypic cerebellar and BMDM cultures did not showed a clear pro or anti-inflammatory phenotype induction. These results showed that sildenafil can promote inflammatory changes through cytokine expression and could be generating a mixed microglia/macrophage phenotype. Nowadays increasing evidence of mixed or overlapping microglia/macrophage phenotype can be found, and has been associated with the recovery after damage. IL-4 treatment of macrophages in vitro produced IL6 and co-expressed CD206 (M2 marker) without affecting immunosuppressive properties of M2 phenotype macrophages (Casella et al. 2016). Moreover, the 
expression of Arg-1 as well as IL-1 $\beta$ was associated with neurite growth promotion and spinal cord injury recovery (Fenn et al. 2014). IL-4 gene therapy to EAE mice decreased demyelination and axonal loss showing an increase in the expression of CD206 in microglia/macrophages, but also an increase IL-6 (Casella et al. 2016). Even more, it has comes to light evidence that a proinflammatory environment at the beginning of the lesion followed by antiinflammatory environment with increase of pro-resolving and tissue regenerating molecules is required for an effective resolution and repair after CNS injury (Rawji et al. 2016) and that the whole spectrum of microglia/macrophage phenotypes are required in the resolution of CNS injury (Gensel and Zhang 2015, Rawji et al. 2016).

Indeed classifying microglia/macrophages as classically (M1) or alternatively-activated (M2) in ex-vivo (such as organotypic cerebellar cultures) or in vivo models is a complex matter. Some authors are starting to consider as either of both phenotypes, since this nomenclature was generated from monocyte-derived macrophages treated in vitro using defined cytokine stimuli and controlled environment, but after inflammatory stimuli in vivo microglia/macrophage plasticity promotes the generation of a broad spectrum of slightly different phenotypes that can be required for the resolution and healing process to take place (Gensel and Zhang 2015, Stables et al. 2011). Therefore, it cannot be said that sildenafil treatment is inducing a shift into M1 or M2 phenotype, but it is affecting immune response in CNS and in IS, generating anti-inflammatory mediators that promotes resolution of inflammatory process. More importantly sildenafil treatment increased myelin phagocytosis in non-polarized BMDM suggesting that this restoring and essential process can be promoted despite microglia/macrophage phenotype. 


\section{잉 CONCLUSIONS}




\section{CONCLUSIONS}

1. Sildenafil treatment ameliorates clinical symptoms in mouse chronic EAE model when administrated in the acute and in chronic phase.

2. Sindenafil treatment promotes remyelination of axons and maturefunctional internodes increasing myelin protein levels.

3. The NO-cGMP-PKG pathway is required in sildenafil-induced remyelination.

4. Some of the mechanisms underliying sildenafil-induced remyelination and neuroprotection are associated with:

- Maturation of oligodendocytes

- Increased CNTF expression in CNS

- Modulation of inflammatory process

- Increased myelin phagocytic capacity 
a do 숭 REFERENCES 


\section{REFERENCES}

Abbott NJ, Patabendige AA, Dolman DE, Yusof SR, Begley DJ. 2010. Structure and function of the blood-brain barrier. Neurobiol Dis 37: 13-25.

Aharoni R. 2010. Immunomodulatory drug treatment in multiple sclerosis. Expert Rev Neurother 10: 1423-1436.

Aloisi F. 2001. Immune function of microglia. Glia 36: 165-179.

Baltrons MA, Garcia A. 1999. Nitric oxide-independent down-regulation of soluble guanylyl cyclase by bacterial endotoxin in astroglial cells. J Neurochem 73: 2149-2157.

Baltrons MA, Pedraza CE, Heneka MT, Garcia A. 2002. Beta-amyloid peptides decrease soluble guanylyl cyclase expression in astroglial cells. Neurobiol Dis 10: 139-149.

Baltrons MA, Pifarre P, Ferrer I, Carot JM, Garcia A. 2004. Reduced expression of NO-sensitive guanylyl cyclase in reactive astrocytes of Alzheimer disease, Creutzfeldt-Jakob disease, and multiple sclerosis brains. Neurobiol Dis 17: 462-472.

Baltrons MA, Pifarre P, Berciano MT, Lafarga M, Garcia A. 2008. LPS-induced down-regulation of NO-sensitive guanylyl cyclase in astrocytes occurs by proteasomal degradation in clastosomes. Mol Cell Neurosci 37: 494-506.

Bell AS, Palmer MJ. 2011. Novel phosphodiesterase type 5 modulators: a patent survey (2008 2010). Expert Opin Ther Pat 21: 1631-1641.

Benedek G, Zhang J, Bodhankar S, Nguyen H, Kent G, Jordan K, Manning D, Vandenbark AA, Offner $H$. 2016. Estrogen induces multiple regulatory $B$ cell subtypes and promotes $M 2$ microglia and neuroprotection during experimental autoimmune encephalomyelitis. J Neuroimmunol 293: 45-53.

Benjamins JA, Nedelkoska L. 2007. Cyclic GMP-dependent pathways protect differentiated oligodendrocytes from multiple types of injury. Neurochem Res 32: 321-329.

Berard JL, Wolak K, Fournier S, David S. 2010. Characterization of relapsing-remitting and chronic forms of experimental autoimmune encephalomyelitis in C57BL/6 mice. Glia 58: 434-445.

Bercury KK, Macklin WB. 2015. Dynamics and mechanisms of CNS myelination. Dev Cell 32: 447458.

Bibollet-Bahena O, Almazan G. 2009. IGF-1-stimulated protein synthesis in oligodendrocyte progenitors requires PI3K/mTOR/Akt and MEK/ERK pathways. J Neurochem 109: 1440-1451.

Biel M, Zong X, Hofmann F. 1996. Cyclic nucleotide-gated cation channels molecular diversity, structure, and cellular functions. Trends Cardiovasc Med 6: 274-280.

Birgbauer E, Rao TS, Webb M. 2004. Lysolecithin induces demyelination in vitro in a cerebellar slice culture system. J Neurosci Res 78: 157-166.

Bradley J, Reisert J, Frings S. 2005. Regulation of cyclic nucleotide-gated channels. Curr Opin Neurobiol 15: 343-349.

Brown GC, Neher JJ. 2010. Inflammatory neurodegeneration and mechanisms of microglial killing of neurons. Mol Neurobiol 41: 242-247.

Bynoe MS, Bonorino P, Viret C. 2007. Control of experimental autoimmune encephalomyelitis by CD4+ suppressor T cells: peripheral versus in situ immunoregulation. J Neuroimmunol 191: 61-69.

Bystrom J, Evans I, Newson J, Stables M, Toor I, van Rooijen N, Crawford M, Colville-Nash P, Farrow S, Gilroy DW. 2008. Resolution-phase macrophages possess a unique inflammatory phenotype that is controlled by cAMP. Blood 112: 4117-4127.

Casella G, Garzetti L, Gatta AT, Finardi A, Maiorino C, Ruffini F, Martino G, Muzio L, Furlan R. 2016. IL4 induces IL6-producing M2 macrophages associated to inhibition of neuroinflammation in vitro and in vivo. J Neuroinflammation 13: 139.

Clark IA, Vissel B. 2016. Excess cerebral TNF causing glutamate excitotoxicity rationalizes treatment of neurodegenerative diseases and neurogenic pain by anti-TNF agents. J

Neuroinflammation 13: 236. 
Classen A, Lloberas J, Celada A. 2009. Macrophage activation: classical versus alternative. Methods Mol Biol 531: 29-43.

Colton CA. 2009. Heterogeneity of microglial activation in the innate immune response in the brain. J Neuroimmune Pharmacol 4: 399-418.

Constantinescu CS, Farooqi N, O'Brien K, Gran B. 2011. Experimental autoimmune encephalomyelitis (EAE) as a model for multiple sclerosis (MS). Br J Pharmacol 164: 10791106.

Copray S, Balasubramaniyan V, Levenga J, de Bruijn J, Liem R, Boddeke E. 2006. Olig2 overexpression induces the in vitro differentiation of neural stem cells into mature oligodendrocytes. Stem Cells 24: 1001-1010.

Chhor V, et al. 2013. Characterization of phenotype markers and neuronotoxic potential of polarised primary microglia in vitro. Brain Behav Immun 32: 70-85.

Dai J, Bercury KK, Macklin WB. 2014. Interaction of mTOR and Erk1/2 signaling to regulate oligodendrocyte differentiation. Glia 62: 2096-2109.

Das A, Xi L, Kukreja RC. 2008. Protein kinase G-dependent cardioprotective mechanism of phosphodiesterase- 5 inhibition involves phosphorylation of ERK and GSK3beta. J Biol Chem 283: 29572-29585.

De Santi L, Annunziata P, Sessa E, Bramanti P. 2009. Brain-derived neurotrophic factor and TrkB receptor in experimental autoimmune encephalomyelitis and multiple sclerosis. J Neurol Sci 287: 17-26.

Deininger MH, Schluesener HJ. 1999. Cyclooxygenases-1 and -2 are differentially localized to microglia and endothelium in rat EAE and glioma. J Neuroimmunol 95: 202-208.

Dong Y, Benveniste EN. 2001. Immune function of astrocytes. Glia 36: 180-190.

Duman RS NE. 1999. Guanylyl Cyclase in Siegel GJ AB, Albers RW, et al, ed. Basic Neurochemistry: Molecular, Cellular and Medical Aspects. Philadelphia: Lippincott-Raven.

Duncan AJ, Heales SJ. 2005. Nitric oxide and neurological disorders. Mol Aspects Med 26: 67-96.

Durafourt BA, Moore CS, Zammit DA, Johnson TA, Zaguia F, Guiot MC, Bar-Or A, Antel JP. 2012. Comparison of polarization properties of human adult microglia and blood-derived macrophages. Glia 60: 717-727.

Fancy SP, et al. 2011. Axin2 as regulatory and therapeutic target in newborn brain injury and remyelination. Nat Neurosci 14: 1009-1016.

Fedoroff S, Hao C. 1991. Origin of microglia and their regulation by astroglia. Adv Exp Med Biol 296: 135-142.

Fenn AM, Hall JC, Gensel JC, Popovich PG, Godbout JP. 2014. IL-4 signaling drives a unique arginase+/IL-1beta+ microglia phenotype and recruits macrophages to the inflammatory CNS: consequences of age-related deficits in IL-4Ralpha after traumatic spinal cord injury. J Neurosci 34: 8904-8917.

Fernando MR, Reyes JL, lannuzzi J, Leung G, McKay DM. 2014. The pro-inflammatory cytokine, interleukin-6, enhances the polarization of alternatively activated macrophages. PLoS One 9: e94188.

Foster DC, Wedel BJ, Robinson SW, Garbers DL. 1999. Mechanisms of regulation and functions of guanylyl cyclases. Rev Physiol Biochem Pharmacol 135: 1-39.

Francis SH, Blount MA, Corbin JD. 2011. Mammalian cyclic nucleotide phosphodiesterases: molecular mechanisms and physiological functions. Physiol Rev 91: 651-690.

Francos-Quijorna I, Amo-Aparicio J, Martinez-Muriana A, Lopez-Vales R. 2016. IL-4 drives microglia and macrophages toward a phenotype conducive for tissue repair and functional recovery after spinal cord injury. Glia.

Franklin RJ, Ffrench-Constant C. 2008. Remyelination in the CNS: from biology to therapy. Nat Rev Neurosci 9: 839-855.

Friese MA, Montalban X, Willcox N, Bell JI, Martin R, Fugger L. 2006. The value of animal models for drug development in multiple sclerosis. Brain 129: 1940-1952. 
García A, Baltrons, M.A. 2004. The nitric oxide/cyclic GMP pathway in CNS glial cells. Advances in Molecular and Cell Biology 31: 575-593.

Garg N, Smith TW. 2015. An update on immunopathogenesis, diagnosis, and treatment of multiple sclerosis. Brain Behav 5: e00362.

Garthwaite G, Hampden-Smith K, Wilson GW, Goodwin DA, Garthwaite J. 2015. Nitric oxide targets oligodendrocytes and promotes their morphological differentiation. Glia 63: 383-399.

Garthwaite J. 2000. The phisiologycal roles of nitric oxide in the central nervous system. Nitric Oxide: 259-275.

Gaupp S, Cannella B, Raine CS. 2008. Amelioration of experimental autoimmune encephalomyelitis in IL-4Ralpha-/- mice implicates compensatory up-regulation of Th2-type cytokines. Am J Pathol 173: 119-129.

Gensel JC, Zhang B. 2015. Macrophage activation and its role in repair and pathology after spinal cord injury. Brain Res 1619: 1-11.

Ghafouri M, Amini S, Khalili K, Sawaya BE. 2006. HIV-1 associated dementia: symptoms and causes. Retrovirology 3: 28.

Griffiths MR, Gasque P, Neal JW. 2009. The multiple roles of the innate immune system in the regulation of apoptosis and inflammation in the brain. J Neuropathol Exp Neurol 68: 217226.

Guardiola-Diaz HM, Ishii A, Bansal R. 2012. Erk1/2 MAPK and mTOR signaling sequentially regulates progression through distinct stages of oligodendrocyte differentiation. Glia 60: 476-486.

Guasco Herrera C, Chávez Servín JL, Ferriz Martínez RA, de la Torre Carbot K, Elton Puente E, García Gasca T. 2014. Poliaminas: pequeños gigantes de la regulación metabólica. REB. Revista de educación bioquímica 33: 51-57.

Guix FX, Uribesalgo I, Coma M, Munoz FJ. 2005. The physiology and pathophysiology of nitric oxide in the brain. Prog Neurobiol 76: 126-152.

Haggiag S, Zhang PL, Slutzky G, Shinder V, Kumar A, Chebath J, Revel M. 2001. Stimulation of myelin gene expression in vitro and of sciatic nerve remyelination by interleukin- 6 receptorinterleukin-6 chimera. J Neurosci Res 64: 564-574.

Hailer NP. 2008. Immunosuppression after traumatic or ischemic CNS damage: it is neuroprotective and illuminates the role of microglial cells. Prog Neurobiol 84: 211-233.

Hauser SL, Oksenberg JR. 2006. The neurobiology of multiple sclerosis: genes, inflammation, and neurodegeneration. Neuron 52: 61-76.

Henderson AP, Barnett MH, Parratt JD, Prineas JW. 2009. Multiple sclerosis: distribution of inflammatory cells in newly forming lesions. Ann Neurol 66: 739-753.

Hendriks JJ, Slaets H, Carmans S, de Vries HE, Dijkstra CD, Stinissen P, Hellings N. 2008. Leukemia inhibitory factor modulates production of inflammatory mediators and myelin phagocytosis by macrophages. J Neuroimmunol 204: 52-57.

Hertz AL, Beavo JA. 2011. Cyclic nucleotides and phosphodiesterases in monocytic differentiation. Handb Exp Pharmacol: 365-390.

Herz J, Zipp F, Siffrin V. 2010. Neurodegeneration in autoimmune CNS inflammation. Exp Neurol 225: 9-17.

Hofmann F, Bernhard D, Lukowski R, Weinmeister P. 2009. cGMP regulated protein kinases (cGK). Handb Exp Pharmacol: 137-162.

Howes A, et al. 2016. Differential Production of Type I IFN Determines the Reciprocal Levels of IL10 and Proinflammatory Cytokines Produced by C57BL/6 and BALB/C Macrophages. J Immunol 197: 2838-2853.

Kaupp UB, Seifert R. 2002. Cyclic nucleotide-gated ion channels. Physiol Rev 82: 769-824.

Kim SU, de Vellis J. 2005. Microglia in health and disease. J Neurosci Res 81: 302-313.

Kim YS, Joh TH. 2006. Microglia, major player in the brain inflammation: their roles in the pathogenesis of Parkinson's disease. Exp Mol Med 38: 333-347. 
Kimelberg HK. 2010. Functions of mature mammalian astrocytes: a current view. Neuroscientist 16: 79-106.

Koesling D, Russwurm M, Mergia E, Mullershausen F, Friebe A. 2004. Nitric oxide-sensitive guanylyl cyclase: structure and regulation. Neurochem Int 45: 813-819.

Koopman R, Schaart G, Hesselink MK. 2001. Optimisation of oil red O staining permits combination with immunofluorescence and automated quantification of lipids. Histochem Cell Biol 116: 63-68.

Kotter MR, Li WW, Zhao C, Franklin RJ. 2006. Myelin impairs CNS remyelination by inhibiting oligodendrocyte precursor cell differentiation. J Neurosci 26: 328-332.

Kumar S, Patel R, Moore S, Crawford DK, Suwanna N, Mangiardi M, Tiwari-Woodruff SK. 2013. Estrogen receptor beta ligand therapy activates PI3K/Akt/mTOR signaling in oligodendrocytes and promotes remyelination in a mouse model of multiple sclerosis. Neurobiol Dis 56: 131-144.

Larocca JN, Norton WT. 2007. Isolation of myelin. Curr Protoc Cell Biol Chapter 3: Unit3 25.

Lassmann H. 2014. Mechanisms of white matter damage in multiple sclerosis. Glia 62: 1816-1830.

Lee HH, Park SC, Choe IS, Kim Y, Ha YS. 2015. Time Course and Characteristics of Astrocyte Activation in the Rat Brain after Injury. Korean J Neurotrauma 11: 44-51.

Li J, Zhang L, Chu Y, Namaka M, Deng B, Kong J, Bi X. 2016. Astrocytes in Oligodendrocyte Lineage Development and White Matter Pathology. Front Cell Neurosci 10: 119.

Liu Z, Hu X, Cai J, Liu B, Peng X, Wegner M, Qiu M. 2007. Induction of oligodendrocyte differentiation by Olig2 and Sox10: evidence for reciprocal interactions and dosagedependent mechanisms. Dev Biol 302: 683-693.

Livak KJ, Schmittgen TD. 2001. Analysis of relative gene expression data using real-time quantitative PCR and the 2(-Delta Delta C(T)) Method. Methods 25: 402-408.

Lu Z, Hu X, Zhu C, Wang D, Zheng X, Liu Q. 2009. Overexpression of CNTF in Mesenchymal Stem Cells reduces demyelination and induces clinical recovery in experimental autoimmune encephalomyelitis mice. J Neuroimmunol 206: 58-69.

Ludwin SK, Rao VT, Moore CS, Antel JP. 2016. Astrocytes in multiple sclerosis. Mult Scler.

Maarsingh H, Zaagsma J, Meurs H. 2009. Arginase: a key enzyme in the pathophysiology of allergic asthma opening novel therapeutic perspectives. Br J Pharmacol 158: 652-664.

Manucha W. 2016. Mitochondrial dysfunction associated with nitric oxide pathways in glutamate neurotoxicity. Clin Investig Arterioscler.

Mayo L, et al. 2016. IL-10-dependent Tr1 cells attenuate astrocyte activation and ameliorate chronic central nervous system inflammation. Brain 139: 1939-1957.

McCarthy DP, Richards MH, Miller SD. 2012. Mouse models of multiple sclerosis: experimental autoimmune encephalomyelitis and Theiler's virus-induced demyelinating disease. Methods Mol Biol 900: 381-401.

McWhorter FY, Wang T, Nguyen P, Chung T, Liu WF. 2013. Modulation of macrophage phenotype by cell shape. Proc Natl Acad Sci U S A 110: 17253-17258.

Meffre $D$, et al. 2015. Liver $X$ receptors alpha and beta promote myelination and remyelination in the cerebellum. Proc Natl Acad Sci U S A 112: 7587-7592.

Minghetti L. 2004. Cyclooxygenase-2 (COX-2) in inflammatory and degenerative brain diseases. J Neuropathol Exp Neurol 63: 901-910.

Miron VE, Franklin RJ. 2014. Macrophages and CNS remyelination. J Neurochem.

Miron VE, Ludwin SK, Darlington PJ, Jarjour AA, Soliven B, Kennedy TE, Antel JP. 2010. Fingolimod (FTY720) enhances remyelination following demyelination of organotypic cerebellar slices. Am J Pathol 176: 2682-2694.

Miron VE, et al. 2013. M2 microglia and macrophages drive oligodendrocyte differentiation during CNS remyelination. Nat Neurosci 16: 1211-1218.

Modi KK, Sendtner M, Pahan K. 2013. Up-regulation of ciliary neurotrophic factor in astrocytes by aspirin: implications for remyelination in multiple sclerosis. J Biol Chem 288: 18533-18545. 
Mosser DM, Edwards JP. 2008. Exploring the full spectrum of macrophage activation. Nat Rev Immunol 8: 958-969.

Mosser DM, Zhang X. 2008. Interleukin-10: new perspectives on an old cytokine. Immunol Rev 226: 205-218.

Murphy S. 2000. Production of nitric oxide by glial cells: regulation and potential roles in the CNS. Glia 29: 1-13.

Nakamizo T, et al. 2003. Phosphodiesterase inhibitors are neuroprotective to cultured spinal motor neurons. J Neurosci Res 71: 485-495.

Nave KA. 2010. Myelination and support of axonal integrity by glia. Nature 468: 244-252.

Nimmerjahn A, Kirchhoff F, Helmchen F. 2005. Resting microglial cells are highly dynamic surveillants of brain parenchyma in vivo. Science 308: 1314-1318.

Nishiyama A, Komitova M, Suzuki R, Zhu X. 2009. Polydendrocytes (NG2 cells): multifunctional cells with lineage plasticity. Nat Rev Neurosci 10: 9-22.

Nunes AK, Raposo C, Luna RL, Cruz-Hofling MA, Peixoto CA. 2012. Sildenafil (Viagra(R)) down regulates cytokines and prevents demyelination in a cuprizone-induced MS mouse model. Cytokine 60: 540-551.

Nunes AK, Raposo C, Rocha SW, Barbosa KP, Luna RL, da Cruz-Hofling MA, Peixoto CA. 2015. Involvement of AMPK, IKbetaalpha-NFkappaB and eNOS in the sildenafil anti-inflammatory mechanism in a demyelination model. Brain Res 1627: 119-133.

Paintlia MK, Paintlia AS, Singh AK, Singh I. 2013. S-nitrosoglutathione induces ciliary neurotrophic factor expression in astrocytes, which has implications to protect the central nervous system under pathological conditions. J Biol Chem 288: 3831-3843.

Pedraza CE, Baltrons MA, Heneka MT, Garcia A. 2003. Interleukin-1 beta and lipopolysaccharide decrease soluble guanylyl cyclase in brain cells: NO-independent destabilization of protein and NO-dependent decrease of mRNA. J Neuroimmunol 144: 80-90.

Peterson LK, Fujinami RS. 2007. Inflammation, demyelination, neurodegeneration and neuroprotection in the pathogenesis of multiple sclerosis. J Neuroimmunol 184: 37-44.

Pifarre P, Prado J, Giralt M, Molinero A, Hidalgo J, Garcia A. 2010. Cyclic GMP phosphodiesterase inhibition alters the glial inflammatory response, reduces oxidative stress and cell death and increases angiogenesis following focal brain injury. J Neurochem 112: 807-817.

Pifarre P, Prado J, Baltrons MA, Giralt M, Gabarro P, Feinstein DL, Hidalgo J, Garcia A. 2011. Sildenafil (Viagra) ameliorates clinical symptoms and neuropathology in a mouse model of multiple sclerosis. Acta Neuropathol 121: 499-508.

Pifarre P, Gutierrez-Mecinas M, Prado J, Usero L, Roura-Mir C, Giralt M, Hidalgo J, Garcia A. 2014. Phosphodiesterase 5 inhibition at disease onset prevents experimental autoimmune encephalomyelitis progression through immunoregulatory and neuroprotective actions. Exp Neurol 251: 58-71.

Prado J, Baltrons MA, Pifarre P, Garcia A. 2010. Glial cells as sources and targets of natriuretic peptides. Neurochem Int 57: 367-374.

Raivich G, Banati R. 2004. Brain microglia and blood-derived macrophages: molecular profiles and functional roles in multiple sclerosis and animal models of autoimmune demyelinating disease. Brain Res Brain Res Rev 46: 261-281.

Raivich G, Jones LL, Werner A, Bluthmann H, Doetschmann T, Kreutzberg GW. 1999. Molecular signals for glial activation: pro- and anti-inflammatory cytokines in the injured brain. Acta Neurochir Suppl 73: 21-30.

Ransohoff RM, Perry VH. 2009. Microglial physiology: unique stimuli, specialized responses. Annu Rev Immunol 27: 119-145.

Raposo C, Luna RL, Nunes AK, Thome R, Peixoto CA. 2014. Role of iNOS-NO-cGMP signaling in modulation of inflammatory and myelination processes. Brain Res Bull 104: 60-73.

Rawji KS, Mishra MK, Yong VW. 2016. Regenerative Capacity of Macrophages for Remyelination. Front Cell Dev Biol 4: 47. 
Salehi Z, Hadiyan SP, Navidi R. 2013. Ciliary neurotrophic factor role in myelin oligodendrocyte glycoprotein expression in Cuprizone-induced multiple sclerosis mice. Cell Mol Neurobiol 33: 531-535.

Salter MG, Fern R. 2005. NMDA receptors are expressed in developing oligodendrocyte processes and mediate injury. Nature 438: 1167-1171.

Sharma R, Fischer MT, Bauer J, Felts PA, Smith KJ, Misu T, Fujihara K, Bradl M, Lassmann H. 2010. Inflammation induced by innate immunity in the central nervous system leads to primary astrocyte dysfunction followed by demyelination. Acta Neuropathol 120: 223-236.

Sofroniew MV, Vinters HV. 2010. Astrocytes: biology and pathology. Acta Neuropathol 119: 7-35.

Stables MJ, Shah S, Camon EB, Lovering RC, Newson J, Bystrom J, Farrow S, Gilroy DW. 2011. Transcriptomic analyses of murine resolution-phase macrophages. Blood 118: e192-208.

Stankoff B, Aigrot MS, Noel F, Wattilliaux A, Zalc B, Lubetzki C. 2002. Ciliary neurotrophic factor (CNTF) enhances myelin formation: a novel role for CNTF and CNTF-related molecules. J Neurosci 22: 9221-9227.

Steinert JR, Robinson SW, Tong H, Haustein MD, Kopp-Scheinpflug C, Forsythe ID. 2011. Nitric oxide is an activity-dependent regulator of target neuron intrinsic excitability. Neuron 71: 291-305.

Streit WJ, Conde JR, Fendrick SE, Flanary BE, Mariani CL. 2005. Role of microglia in the central nervous system's immune response. Neurol Res 27: 685-691.

Talbott JF, Loy DN, Liu Y, Qiu MS, Bunge MB, Rao MS, Whittemore SR. 2005. Endogenous Nkx2.2+/Olig2+ oligodendrocyte precursor cells fail to remyelinate the demyelinated adult rat spinal cord in the absence of astrocytes. Exp Neurol 192: 11-24.

Tanaka J, Markerink-van Ittersum M, Steinbusch HW, De Vente J. 1997. Nitric oxide-mediated cGMP synthesis in oligodendrocytes in the developing rat brain. Glia 19: 286-297.

Town T, Nikolic V, Tan J. 2005. The microglial "activation" continuum: from innate to adaptive responses. J Neuroinflammation 2: 24.

Tsai EJ, Kass DA. 2009. Cyclic GMP signaling in cardiovascular pathophysiology and therapeutics. Pharmacol Ther 122: 216-238.

Valerio A, Ferrario M, Dreano M, Garotta G, Spano P, Pizzi M. 2002. Soluble interleukin-6 (IL-6) receptor/IL- 6 fusion protein enhances in vitro differentiation of purified rat oligodendroglial lineage cells. Mol Cell Neurosci 21: 602-615.

van der Laan LJ, Ruuls SR, Weber KS, Lodder IJ, Dopp EA, Dijkstra CD. 1996. Macrophage phagocytosis of myelin in vitro determined by flow cytometry: phagocytosis is mediated by CR3 and induces production of tumor necrosis factor-alpha and nitric oxide. J Neuroimmunol 70: 145-152.

Veerhuis R, Nielsen HM, Tenner AJ. 2011. Complement in the brain. Mol Immunol 48: 1592-1603. Vereyken EJ, Heijnen PD, Baron W, de Vries EH, Dijkstra CD, Teunissen CE. 2011. Classically and alternatively activated bone marrow derived macrophages differ in cytoskeletal functions and migration towards specific CNS cell types. J Neuroinflammation 8: 58.

Verkhratsky A, Kirchhoff F. 2007. NMDA Receptors in glia. Neuroscientist 13: 28-37.

Vernerey J, Macchi M, Magalon K, Cayre M, Durbec P. 2013. Ciliary neurotrophic factor controls progenitor migration during remyelination in the adult rodent brain. J Neurosci 33: 32403250.

Vollmar AM. 2005. The role of atrial natriuretic peptide in the immune system. Peptides 26: 10861094.

von Bulow V, Rink L, Haase H. 2005. Zinc-mediated inhibition of cyclic nucleotide phosphodiesterase activity and expression suppresses TNF-alpha and IL-1 beta production in monocytes by elevation of guanosine 3',5'-cyclic monophosphate. J Immunol 175: 46974705.

Voskuhl RR, Peterson RS, Song B, Ao Y, Morales LB, Tiwari-Woodruff S, Sofroniew MV. 2009. Reactive astrocytes form scar-like perivascular barriers to leukocytes during adaptive immune inflammation of the CNS. J Neurosci 29: 11511-11522. 
Wang G, et al. 2015. HDAC inhibition prevents white matter injury by modulating microglia/macrophage polarization through the GSK3beta/PTEN/Akt axis. Proc Natl Acad Sci U S A 112: 2853-2858.

Weishaupt N, Blesch A, Fouad K. 2012. BDNF: the career of a multifaceted neurotrophin in spinal cord injury. Exp Neurol 238: 254-264.

Weller RO, Galea I, Carare RO, Minagar A. 2010. Pathophysiology of the lymphatic drainage of the central nervous system: Implications for pathogenesis and therapy of multiple sclerosis. Pathophysiology 17: 295-306.

Willenborg DO, Staykova M, Fordham S, O'Brien N, Linares D. 2007. The contribution of nitric oxide and interferon gamma to the regulation of the neuro-inflammation in experimental autoimmune encephalomyelitis. J Neuroimmunol 191: 16-25.

Wu D, Zheng S, Li W, Yang L, Liu Y, Zheng X, Yang Y, Wang Q, Smith FG, Jin S. 2013. Novel biphasic role of resolvin D1 on expression of cyclooxygenase-2 in lipopolysaccharide-stimulated lung fibroblasts is partly through PI3K/AKT and ERK2 pathways. Mediators Inflamm 2013: 964012.

Wyss-Coray T. 2006. Inflammation in Alzheimer disease: driving force, bystander or beneficial response? Nat Med 12: 1005-1015.

Yu Z, et al. 2015. MSX3 Switches Microglia Polarization and Protects from Inflammation-Induced Demyelination. J Neurosci 35: 6350-6365.

Zabel U, et al. 2002. Calcium-dependent membrane association sensitizes soluble guanylyl cyclase to nitric oxide. Nat Cell Biol 4: 307-311.

Zhang $H$, Jarjour AA, Boyd A, Williams A. 2011. Central nervous system remyelination in culture--a tool for multiple sclerosis research. Exp Neurol 230: 138-148.

Zhang J, Snyder SH. 1995. Nitric oxide in the nervous system. Annu Rev Pharmacol Toxicol 35: 213233.

Zhang RL, Chopp M, Roberts C, Wei M, Wang X, Liu X, Lu M, Zhang ZG. 2012. Sildenafil enhances neurogenesis and oligodendrogenesis in ischemic brain of middle-aged mouse. PLoS One 7: e48141.

Zhu M, Wang X, Hjorth E, Colas RA, Schroeder L, Granholm AC, Serhan CN, Schultzberg M. 2016. Pro-Resolving Lipid Mediators Improve Neuronal Survival and Increase Abeta42 Phagocytosis. Mol Neurobiol 53: 2733-2749. 